\title{
Thrombin generation at macroscopic surfaces : a study in a tubular flow reactor
}

Citation for published version (APA):

Billy, D. R. H. M. (1996). Thrombin generation at macroscopic surfaces : a study in a tubular flow reactor. [Doctoral Thesis, Maastricht University]. Rijksuniversiteit Limburg.

https://doi.org/10.26481/dis.19960628db

Document status and date:

Published: 01/01/1996

DOI:

$10.26481 /$ dis. $19960628 \mathrm{db}$

Document Version:

Publisher's PDF, also known as Version of record

\section{Please check the document version of this publication:}

- A submitted manuscript is the version of the article upon submission and before peer-review. There can be important differences between the submitted version and the official published version of record.

People interested in the research are advised to contact the author for the final version of the publication, or visit the DOI to the publisher's website.

- The final author version and the galley proof are versions of the publication after peer review.

- The final published version features the final layout of the paper including the volume, issue and page numbers.

Link to publication

\footnotetext{
General rights rights.

- You may freely distribute the URL identifying the publication in the public portal. please follow below link for the End User Agreement:

www.umlib.nl/taverne-license

Take down policy

If you believe that this document breaches copyright please contact us at:

repository@maastrichtuniversity.nl

providing details and we will investigate your claim.
}

Copyright and moral rights for the publications made accessible in the public portal are retained by the authors and/or other copyright owners and it is a condition of accessing publications that users recognise and abide by the legal requirements associated with these

- Users may download and print one copy of any publication from the public portal for the purpose of private study or research.

- You may not further distribute the material or use it for any profit-making activity or commercial gain

If the publication is distributed under the terms of Article $25 \mathrm{fa}$ of the Dutch Copyright Act, indicated by the "Taverne" license above, 


\section{THROMBIN GENERATION AT MACROSCOPIC SURFACES}

A study in a tubular flow reactor 
Billy, Didier Roger Henri Marie

Thrombin generation at macroscopic surfaces: a study in a tubular flow reactor Didier Billy

Thesis Maastricht - With ref. - With summary in french and in dutch ISBN 90-5681-009-X

Subject headings: prothrombinase / flow conditions / phospholipid membrane

Omslag en druk, Unigraphic 


\title{
THROMBIN GENERATION AT MACROSCOPIC SURFACES
}

A study in a tubular flow reactor

\author{
PROEFSCHRIFT
}

Ter verkrijging van de graad van doctor aan de Rijksuniversiteit Limburg te Maastricht, op gezag van de Rector Magnificus, Prof. Mr. M.J. Cohen, volgens het besluit van het College van Dekanen, in het openbaar te verdedigen op vrijdag 28 juni om 12.00 uur

door

\section{Didier Billy}


Promotor

Co-promotor

Beoordelingscommissie
Prof. Dr. H.C. Hemker

Dr. Th. Lindhout

Prof. Dr. Y. Nemerson, (vooritter)

Dr. W.Th. Hermens

Prof. Dr. P.J.E.H.M. Kitslaar

Prof. Dr. R.S. Reneman

Prof. Dr. H.A.J. Struijker Boulier 
A ma mère, ma grand mère ma soeur et Laurent

Pour Liesbeth 
Financial support by the Netherlands Heart Foundation and by the Foundation Dr. Ir. J.H.J. v.d. Laar for the publication of this thesis is gratefully acknowledged. 


\section{Contents}

\section{Chapter 1}

General Introduction.

\section{Chapter 2}

Introduction

\section{Chapter 3}

Prothrombin Activation by Prothrombinase in a Tubular Flow Reactor.

\section{Chapter 4}

Inhibition of Prothrombinase by Antithrombin-Heparin at a Macroscopic Surface.

\section{Chapter 5}

Inhibition of Prothrombinase at Macroscopic Lipid Membranes:

Competition between Antithrombin and Prothrombin.

\section{Chapter 6}

Prothrombin Contributes to the Assembly of the Factor Va-Factor Xa

Complex at Phosphatidylserine-containing Phospholipid Membranes.

\section{Chapter 7}

Prothrombin Conversion under Flow Conditions by Prothrombinase

Assembled on Adherent Platelets.

\section{Chapter 8}

General Discussion

Résumé

Samenvatting 
Merci à Suzette Béguin, Bonnie-Britt Razé-Gersjes, Han Speijer, Vincent Franssen, Theo Lindhout, George Willems, Coen Hemker, Johan Heemskerk. Sans votre aide précieuse, cette thèse ne serait pas. 


\section{Chapter 1}

\section{General Introduction}

The mechanism by which the blood is maintained fluid within the vessels and which also prevents excessive blood loss, is known as haemostasis. The complexity of the haemostasis system is an important subject of investigation. Two basic processes have been identified: the activation and aggregation of blood platelets, which constitute the cellular component of the haemostatic plug, and the coagulation system which leads to the formation of the fibrin network that stabilizes the haemostatic plug (1).

Flowing blood makes of haemostasis a dynamic event that influences the interaction between the vascular wall, blood platelets and components of the coagulation system (2). Studies with platelets have demonstrated that local flow conditions influence the deposition and growth of platelet aggregates on the vascular surface. Nevertheless, as far as the blood coagulation process, most investigations have been conducted in static systems. Although these studies have revealed important findings on the reaction mechanisms of blood coagulation, they neglected the physiological transport processes induced by flow. That is, in static systems, where clotting factors are bound to phospholipid vesicles, product formation is mostly a function of the reactant concentrations, but not a function of the dynamic aspects of flow, such as transport phenomena and shear forces (3).

\section{Aim of this study}

The objective of our investigations was to obtain a quantitative description of thrombin formation and its regulation at a macroscopic surface under well-defined flow conditions. For that purpose we used the tubular flow reactor developed by Gemmell et al (4) and a previously described method (5) for the assembly of the prothrombin converting complex, prothrombinase, consisting of the serine protease factor $\mathrm{Xa}$ and the non-enzymatic cofactor factor $\mathrm{Va}$, at the phospholipid coated inner wall of a glass capillary.

\section{Survey of this thesis}

A general overview on the haemostatic processes is presented in chapter 2-Part 1. Chapter 2-Part 2 gives a short description of the principles of mass transport from a perfusion solution towards the wall of the capillary that contains an immobilized enzyme and the transport of reaction products from the catalytic surface to the bulk solution. 
In chapter 3 we describe flow experiments that resulted in either a kinetically controlled regime of thrombin production or a diffusion controlled regime. Under the former conditions, the rate of thrombin production reflects the amount of prothrombinase present in the capillary, whereas in the diffusion controlled situation the rate of transport of prothrombin to the catalytic surface limits the rate of thrombin production. Under the conditions of the well-defined kinetically controlled regime, we were able to analyze the rate of thrombin production as a function of the substrate concentration near the catalytic surface. These experiments revealed a catalytic efficiency of the prothrombinase complex at a macroscopic surface that was much higher than found for small unilamellar phospholipid vesicles in static suspension. We also demonstrated that the true $\mathrm{K}_{\mathrm{m}}$ and $\mathrm{k}_{\text {cat }}$ were not influenced by the wall shear rate.

In chapters 4 and 5 we present the results of a study on the kinetics of inhibition of prothrombinase by antithrombin and antithrombin-heparin in the tubular flow reactor. Chapter 4 reports on the inhibition under kinetic and diffusion-controlled situations using heparins with different chain length: unfractionated heparin, low molecular weight heparin and the synthetic pentasaccharide heparin. In this study we observed that prothrombin protects prothrombinase from inhibition by antithrombin. More detailed experiments (chapter 5) showed that prothrombin simply competes with antithrombin for prothrombinase. Half-maximal protection was found with 5 $\mathrm{nM}$ of prothrombin, which in fact is the true $\mathrm{K}_{\mathrm{m}}$ of prothrombin activation at the catalytic surface (chapter 3).

Chapter 6 describes hitherto unrecognized phenomenon: prothrombin contributes to the assembly of the prothrombinase complex. This study demonstrated unequivocally that, at phospholipid membranes with low phosphatidylserine content, the presence of prothrombin is required to form a stable prothrombinase complex. Consumption of prothrombin resulted in the dissociation and thus loss of prothrombin converting activity of the prothrombinase complex.

In view of the subtle changes in the membrane that may influence the assembly of prothrombinase and thus the procoagulant properties, we initiated a study on prothrombin activation at the surface of adherent platelets under flow conditions. Chapter 7 reports the data of a study in which platelets were adhered to a fibrinogencoated coverslip mounted in a parallel plate chamber. Perfusion of these adherent. platelets with solutions of factor $\mathrm{Xa}$, factor $\mathrm{Va}$ and prothrombin revealed that stable prothrombinase complexes could be assembled. But the aspect of the binding of fluorescent labeled annexin V as well as enzyme kinetic consideration indicated that when platelets adhere to immobilized fibrinogen they provide a surface with procoagulant patches (hot spots) on which prothrombin converting complex assembles. 


\section{Chapter I}

\section{References}

1. Ratnoff O.D. 1994: The development of knowledge about haemostasis and thrombosis. Bloom AL. Thomas DP (eds.): Haemostasis and Thrombosis, $2^{\text {nd }}$ ed. Churchill Livingstone, p. 3-28.

2. Leonard EF. 1987: Rheology of thrombosis. Hemostasis and Thrombosis, Basic Principles and Clinical Practice. Colman R.W.. Hirsh J., Marder V J., Salzman E.W., $2 \approx$ edition. JB Lippincot Company, Philadelphia. Chapter 70: $1111-1122$

3. Slack S.M. Cui Y.. Turitto V.T. 1993: The effect of flow on blood coagulation and thrombosis. Thromb. Haemostas. 70: 129-134.

4. Gemmell C.H., Turitto V.T., Nemerson Y. 1988: Flow as regulator of the activation of factor X by tissue factor. Blood 72: 1404-1406.

5. Schoen P., Lindhout T., Willems G., Hemker H.C. 1990: Continuous flow and the prothrombinase-catalyzed activation of prothrombin. Thromb. Hacmostas. 64: 542-547. 



\section{Chapter 2}

\section{Introduction}

\section{Part 1: Haemostasis}

The primary function of haemostasis is to confine blood in the vascular system by assuring the arrest of bleeding. The haemostatic process is confronted to a difficult dilemma: on the one hand it should respond to lesions appearing in the vascular system with the formation of a haemostatic plug and on the other hand the growth of this haemostatic plug must be limited to the site of injury. Furthermore, procoagulant activity that escapes into the circulation away from the haemostatic plug must be managed.

Haemostatis can be described as the close cooperation between the following systems:

- Formation of the primary haemostatic plug following the interaction between damaged blood vessel and circulating platelets: adherence, shape change and aggregation of platelets.

- Blood coagulation: stabilization of the primary haemostatic plug by a fibrin network.

- Regulation of blood coagulation:localisation of the enzymatic reactions at the site of injury and inhibition of thrombus growth.

\section{The primary haemostatic plug}

Resting platelets are discoid cells with a diameter varying between 2 and 4 microns and a thickness of about 0.5 micron. They are anucleate and produced by cytoplasmic fragmentation of megakaryocytes. The site of platelet formation is still a subject of investigation. However, the bone marrow is thought to be the principal site of platelet production $(1,2)$.

These smallest cells present in the circulation are under normal condition not able to adhere on vascular endothelium or to each other (3). Upon vessel injury, a part of the endothelium lining is damaged and subendothelial structures are exposed. Among them are different types of collagen, basement membrane and microfibrils. Of the various plasma proteins that are necessary for platelet adhesion, von Willebrand factor (VWF) appears to be the most important. Mediated by VWF, platelets adhere to the exposed microfibrillar structures of the subendothelium. The VWF binds to a specific receptor, glycoprotein Ib (GP Ib) on the plasma membrane of resting platelets (4). Under the combined action of collagen, traces of thrombin 
(formed earlier in the coagulation) and adenosine-5'-diphosphate (ADP), the adhered platelets become activated. This activation is characterized by a morphological change of the platelet from a discoid to an irregular spherical form followed by the development of pseudopodia. Then, platelets rapidly spread out over the damaged surface. At the same time, these activated platelets secrete the content of their storage granules. Two types of granules are secreted: $\alpha$-granules which contain a number of proteins involved in haemostasis, like fibrinogen, VWF, factor V etc., and dense bodies rich in low molecular weight compounds like calcium ions and ADP.

This release of potent agonists results in the stimulation, activation and aggregation of other platelets present in the neighborhood of the injury. The interaction of platelet agonist with a primary receptor induces conformational changes in GPIIb-IIIa (5), leading to the exposure of high affinity binding sites for fibrinogen (inside-out signaling) (6). Together, receptor and adhesive proteins are involved in the bridging of platelets to each other. A large platelet aggregate is formed which covers the injured surface and consequently stops the loss of blood. However, at this stage haemostasis is not yet complete: the primary haemostatic plug has to be stabilized. At the same time as the platelets adhere to the site of injury, the blood coagulation system is initiated, resulting in the formation of thrombin which converts the soluble plasma protein fibrinogen into fibrin. The polymerized fibrin strands are crosslinked by factor XIIIa and form the insoluble fibrin network that stabilizes the platelet plug.

\section{Blood coagulation}

The different clotting factors present in the blood are designated by Roman numbers from I to XIII. These proteins that circulate as precursors (zymogen), i.e. in an inactive form. are converted to serine proteases or co-factors by limited proteolysis. Activated coagulation factors are symbolized by addition of " $\mathrm{a}$ ".

Overview of the mechanisms. The first event is the simultanous activation of factor $\mathrm{X}$ and factor IX (Fig.1). These reactions are catalyzed by the tissue factor-factor VIla complex. After vascular injury. the plasma protein factor VII or its activated form factor VIla binds to a transmembrane glycoprotein, tissue factor (TF), present on cell surfaces $(7,8)$. This association results in the tissue factor-factor VIH(a) complex. Then tissue factor is able to exen two cofactor effects: firstly, it increases the sensibility of factor VII to potent activators like factor Xa, factor IXa and factor VIIa $(9,10)$ and secondly. it enhances the efficiency of factor Vila in activating its substrates, factor $\mathrm{X}$ and factor IX (11-13). Factor Xa generated by the tissue factorfactor VIIa complex converts a low but sufficient amount of prothrombin to thrombin. Thrombin then converts the factors V and VIII to factors Va and VIIIa to 
essential cofactors for prothrombin and factor X activation, respectively $(14,15)$. These activations require the presence of a suitable membrane to which the enzymecofactor complexes can bind (16-18). Such a procoagulant surface is generated by thrombin when it induces in platelets adhered to collagen the exposition of procoagulant phospholipids at their outer surface by the so-called flip-flop mechanism $(19,20)$.

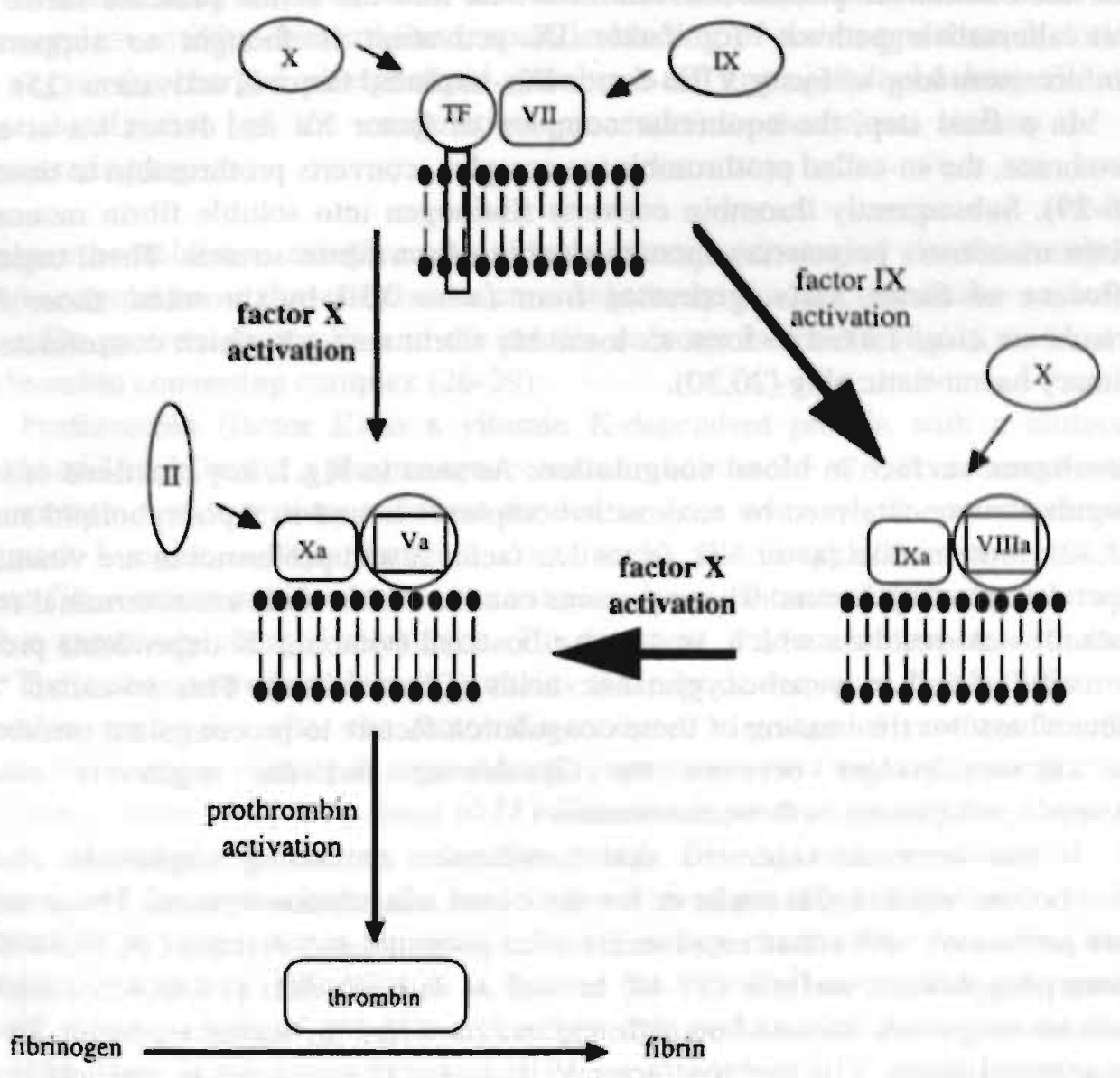

Figure 1. Sehematic view of the bioxd coagulation proces, 
The generation of factor Xa by the tissue factor-factor VIIa complex is readily shut off by the inhibitor Tissue Factor Pathway Inhibitor (TFPI). However, additional amounts of factor $\mathrm{Xa}$ are generated by the factor VIIIa-factor IXa complex (21-23). The importance of this route for factor $\mathrm{X}$ activation in vivo, is shown by patients with hemophilia A (deficiency of factor VIII) or hemophilia B (deficiency of factor IX) whom are confronted with serious bleeding problems. It was recently shown that thrombin-mediated factor XI activation can take place in plasma (24). Activated factor XI in tum converts factor IX into the serine protease factor IXa. This alternative pathway for factor IX activation is thought to support the reinforcement loop of factor VIIla-factor IXa-mediated factor $\mathrm{X}$ activation (25).

In a final step, the equimolar complex of factor $\mathrm{Xa}$ and factor $\mathrm{Va}$ at a cell membrane, the so-called prothrombinase complex, converts prothrombin to thrombin (26-29). Subsequently thrombin converts fibrinogen into soluble fibrin monomers. Fibrin monomers polymerize spontaneously to form fibrin strands. Then, under the influence of factor XIIIa, generated from factor XIII by thrombin, those fibrin strands are cross-linked to form an insoluble fibrin network which consolidates the primary haemostatic plug $(20,30)$.

Membrane surface in blood coagulation. As seen in Fig.1, key reactions of blood coagulation are catalyzed by enzymatic complexes bound to a phospholipid surface $(31,32)$. Proteins like factor VII, factor IX, factor $\mathrm{X}$ and prothrombin are vitamin $\mathrm{K}$ dependent clotting factors. These proteins contain within their aminoterminal region glutamic acid residues which, in a post-ribosomal (vitamine $\mathrm{K}$ dependent) process, are carboxylated to $\gamma$-carboxyglutamic acids (Gla-residues). This so-called "Gladomain" assures the binding of these coagulation factors to procoagulant membranes via calcium bridges between the Gla-domain and the negatively charged phospholipids present in these membranes (33).

It has been demonstrated that membranes containing negatively charged phospholipid are suitable surfaces for the blood coagulation system. Those studies were performed with either small unilamellar phospholipid vesicles $(16,17,34-36)$ or planar phospholipid surfaces (37-40) as well as with platelets (19,41,42). Although, these investigations focussed on different enzymes like the factor Va-factor Xa, the tissue factor-factor VIIa and the factor VIIla-factor IXa complexes, the conclusions were the same: a) due to their high affinity for anionic phospholipid, the membrane binds the protein cofactors VIIIa and Va (TF is a transmembrane protein), which in tum act as receptors for the serine protease factor VIIa, factor IXa and factor Xa, respectively and their substrates factor IX, factor X, and prothrombin, respectively (18), and b) phospholipid membranes increase the catalytic efficiency of the enzyme complexes, mainly because of a dramatic decrease in $\mathrm{K}_{\mathrm{m}}$. 
This procoagulant surface is provided by activated platelets. When a platelet becomes activated the membrane loses its assymetric distribution of lipids. The negatively charged phospholipids, like phosphatidylserine, are transferred by a rapid transbilayer movement (flip-flop) from the inner to the outer leaflet of the membrane $(19,43,44)$. It is important to mention that it is generally believed that a potent procoagulant surface can also be provided by microparticles shedded by activated platelets (45-47). However, Sword et al (45) demonstrated that, released microvesicles from VWF-adherent and thrombin-stimulated platelets did not show procoagulant activity. Nevertheless, specific binding of the coagulation factors on the negatively charged phospholipid membrane of aggregated platelets, allows a space localization of the coagulation processes to the close vicinity of the haemostatic plug.

The prothrombinase complex. As already mentioned, one of the final steps of blood coagulation is the association on a negatively charged membrane surface of the serine protease factor $\mathrm{Xa}$ and the protein cofactor factor $\mathrm{Va}$ (fig.1), to form the prothrombin converting complex (26-29).

Prothrombin (factor II) is a vitamin K-dependent protein with a molecular weight of $71.6 \mathrm{kDa}$ and a plasma concentration of about $2.5 \mu \mathrm{M}$. It is a single-chain glycoprotein with a tertiary structure divided in three domains. The amino-terminal fragment 1 region or "Gla domain", contains $10 \gamma$-carboxyglutamic acid residues. Those Gla residues are involved in the calcium-dependent interaction of prothrombin with a negatively charged membrane. The fragment 2 domain interacts with factor Va. The carboxy-terminal domain contains the peptide sequence that will form the thrombin active site after the factor Xa-catalyzed cleavage of prothrombin (26). Factor $\mathrm{Xa}$ is also a vitamin $\mathrm{K}$-dependent glycoprotein with a molecular weight of 44 $\mathrm{kDa}$ that consists of a heavy chain of $27 \mathrm{kDa}$ and a light chain of $18 \mathrm{kDa}$. Those two chains are linked together via a disulfide bridge. The light chain contains the Gla residues and therefore assures the association with negatively charged surfaces. The active site of factor $\mathrm{X}_{\mathrm{a}}$ is positioned on the heavy chain (49). Factor $\mathrm{Va}$ has a molecular weight of $180 \mathrm{kDa}$. It is formed by two $\mathrm{Ca}^{2+}$-associated glycoprotein chains: a heavy chain of $105 \mathrm{kDa}$ and a light chain of $74 \mathrm{kDa}$. Factor $\mathrm{Va}$ binds via the light chain, in a calcium-independent manner, to negatively charged membranes, whereas the heavy chain has affinity for factor $\mathrm{Xa}$ and prothrombin (50).

Factor $\mathrm{Xa}$ alone is a very slow activator of prothrombin. Formation of the factor $\mathrm{Xa}$-factor $\mathrm{Va}$ complex on membranes containing anionic phospholipids is required for optimal prothrombin activation (51). Moreover, the highest prothrombinase activities have been reported for factor Va-factor $\mathrm{Xa}$ complexes associated with membranes that contain phosphatidylserine. 
The phospholipid membrane not only provides a surface for the assembly of the factor Va-factor Xa complex but also promotes the interaction between the substrate prothrombin and the enzymatic complex. Factor $\mathrm{Va}$ interacts, with both factor $\mathrm{Xa}$ and prothrombin $(17,50)$, thereby also promoting the binding and interaction between the enzyme and its substrate $(18,52)$. This results in an increase of $\mathbf{k}_{\text {cat }}$ of about 3,000 -fold (53). Furthermore, the interaction of the substrate prothrombin with the membrane is responsible for a dramatic decrease in the $\mathrm{K}_{\mathrm{m}}$, namely from more than $2 \mu \mathrm{M}$ in the absence of phospholipid $(17,53)$ to $170 \mathrm{nM}$ on small unilamellar phospholipid vesicles $(20-30 \mathrm{~nm})$ and 3 to $5 \mathrm{nM}$ on planar macroscopic phospholipid surfaces $(39,54)$. This marked difference was attributed to the ability of both enzyme and substrate to bind membranes, which raises the local. prothrombin concentration in the proximity of the enzyme complex. Compared to free prothrombin, phospholipidbound protein very efficiently diffuses on the catalytic surface which increases the number of successful collisions between the enzyme and its substrate. In case of a planar macroscopic surface, the large surface areal surrounding the prothrombinase complex is able to collect a high amount of prothrombin that subsequently diffuses to the enzyme; the membrane which acts as a funnel (39) becomes a very efficient procoagulant surface which may explain the large decrease of $K_{m}(39,54)$.

\section{Regulation of blood coagulation.}

The different reactions involved in the mechanism of blood coagulation must be regulated and limited to the site of injury. As mentioned before, activated platelets provide a procoagulant surface which is normaly not accessible for clotting factors. The availability of a negatively charged surface is restricted to the site of injury. Furthermore, an efficient regulatory system, composed of anticoagulant proteins, exists in order to prevent undesired thrombus formation in the circulatory system.

Feedback inhibition. Thrombin activates protein $\mathrm{C}$ which, in turn, inactivates the cofactors Va and VIIa. Thrombin forms a complex with the membrane glycoprotein thrombomodulin, present on endothelial cells. The cell-bound complex thrombinthrombornodulin converts protein $\mathrm{C}$ to its activated form (APC). Then, APC provides its anticoagulant function by limited proteolysis of factor $\mathrm{Va}$ and factor VIIIa (5557). Activated protein $\mathrm{C}$, which is a vitamin $\mathrm{K}$-dependent serine proteinase, functions as a potent anticoagulant in the presence of protein $\mathrm{S}$ (58), another vitamin $\mathrm{K}$-dependent protein, and in the presence of calcium ions and a negatively charged surface. Some doubt has been raised concerning the cofactor function of protein $\mathrm{S}$. Moreover, it was demonstrated that protein S could participate in another inhibitory action: inhibition of the prothrombinase complex (59). However, the physiological importance of protein $\mathrm{S}$ in the regulation of blood coagulation is clearly 
demonstrated by the relationship between the increased risk of recurrent venous thromboembolism and its deficiency. Identical symptoms were found for patients who presented resistance to the anticoagulant action of APC (60). It was shown that, in most of cases, the APC resistance was caused by a genetic mutation of factor V (61), resulting in a mutated factor $\mathrm{Va}$, which is less sensitive than normal factor $\mathrm{Va}$ to APC-mediated inactivation (62).

Tissue factor-factor VIIa activity is regulated by tissue factor pathway inhibitor (TFPI). Since tissue factor-factor VIla is thought to be the major initiator of the blood coagulation in vivo $(7,21,22)$ this inactivation supports the idea that further maintenance of sufficient concentrations of factor Xa is supplied by the factor VIIlafactor IXa complex pathway (Fig.1). This makes TFPI a physiologically important factor in blood coagulation. TFPI has a molecular weight of $42 \mathrm{kDa}$ and a plasma concentration of about $1.2 \mathrm{nM}$. It is a glycoprotein consisting of three tandems Kunitz-type inhibitor domains, a negatively charged $\mathrm{N}$-terminus and a positively charged C-terminus (63). The inhibitory activity of TFPI occurs in two steps: first TFPI binds to the active site of factor Xa resulting in an inactivated factor $\mathrm{Xa}$ and second, the factor Xa-TFPI complex inhibits tissue factor-factor VIIa complex by forming a quaternary Xa/TFPI/VIIa/TF complex $(21,64,65)$.

Inactivation of thrombin and factor $\mathrm{Xa}$. The serine proteases factor $\mathrm{Xa}$ and thrombin are in the plasma inactivated by antithrombin, $\alpha_{2}$-macroglobulin and $\alpha_{1}$ antitrypsin. However, with $64 \%$ of the antithrombin activity, antithrombin is considered as the principal plasma antiprotease (66). It is a single-chain glycoprotein of the serpin family, synthesized in the liver with a molecular weight of about 60 $\mathrm{kDa}$. This inhibitor is present in plasma at concentration of $2 \mu \mathrm{M}(20,67,68)$. The importance of antithrombin in vivo is indicated by occurrence of antithrombin deficiency, which is often associated with increased risk of thrombosis (69). Antithrombin neutralizes the activity of thrombin and factor Xa by formation of a 1:1 stoichiometric complex. The anticoagulant activity of antithrombin is significantly enhanced by heparins. Heparins are polysaccharides composed of sulfated glycosaminoglycans: repeating disaccharide units of D-glucosamine residues and uronic acid (D-glucuronic or L-iduronic acids) (70). It is thought that the interaction between heparin, with a minimum of 5 monosaccharides, and antithrombin is performed in two steps: initial formation of the complex, followed by a conformational change in antithrombin that stabilizes the complex (68). Only heparins with a specific pentasaccharide sequence are able to induce a conformational change in antithrombin, which leads to an increased affinity of antithrombin for factor $\mathrm{Xa}(20,71)$. However, for an increased inactivation of thrombin, the heparin molecule must be also composed of a minimal length of 18 
monosaccharide units (molecular weight of $5.4 \mathrm{kDa} \mathrm{(72).} \mathrm{In} \mathrm{this} \mathrm{case,} \mathrm{heparin} \mathrm{acts} \mathrm{as}$ a surface that promotes the interaction between antithrombin III and thrombin. Moreover, an increase of the heparin size induces an increase in rate of both inactivation of thrombin and factor Xa $(73,74)$. Therefore, unfractionated heparin (UFH), with a mean molecular weight of $15 \mathrm{kDa}$ was shown to have a higher anticoagulant specific activity than low molecular weight heparin, LMWH (mean molecular weight of 4 to $6 \mathrm{kDa}$ ). After the formation of the antithrombin-serine protease complex, the heparin molecule is liberated and participates in a new inhibition cycle.

Because thrombin is formed by the activation of prothrombin via the factor Xafactor Va complex, several studies were conducted on the effects of factor $\mathrm{Va}$ and phospholipid on the kinetic of inhibition of factor Xa by antithrombin. It was demonstrated that phospholipids (unilamellar phospholipid vesicles) and factor $\mathrm{Va}$ protect factor $\mathrm{Xa}$ from inactivation (75-78). Moreover, this protection was even more important when prothrombin activation was performed in a tubular flow reactor (79). Our studies on macroscopic surfaces, using the same flow system, demonstrated that the substrate prothrombin efficiently competes with antithrombin and antithrombinheparin for the prothrombinase complexes $(80,81)$.

\section{Part 2: Transport phenomena in the flow reactor.}

Blood coagulation is initiated on cell surfaces. These macrescopic surfaces are exposed to flowing blood which makes the blood coagulation processes to be influenced by dynamic events (82-85). Indeed, at an injured surface area, contractions of the vessel induce turbulences, changes in fluid transport rates and local shear forces.

In this study we used a tubular flow reactor to investigate the conversion of prothrombin at a macroscopic surface under flow conditions (Fig.1). The next section, therefore is aimed to provide the reader with the principles of transport phenomena in capillaries with immobilized enzymes at the wall.

When pressure forces a fluid into a round tube, a parabolic velocity profile develops as a result of frictional forces, known as the viscous drags, exerted by the wall on the flowing fluid. These frictional effects reduce the flow nearby the wall close to zero, while it reaches a maximum at the tube axis. Inversely, although the velocity is greatest in the middle of the tube, maximum shear forces are exerted at the wall. Wall shear rate $\left(\gamma_{w}\right)$, the derivative of the parabolic flow profile, is zero at the middle and maximum at the wall: 


$$
\gamma_{\mathrm{w}}=4 \mathrm{Q} / \pi^{3}
$$

With $\mathrm{Q}$ the volumetric flow rate $(\mathrm{ml} / \mathrm{s})$ and $\mathbf{r}$ the internal radius of the tube $(\mathrm{cm})$.

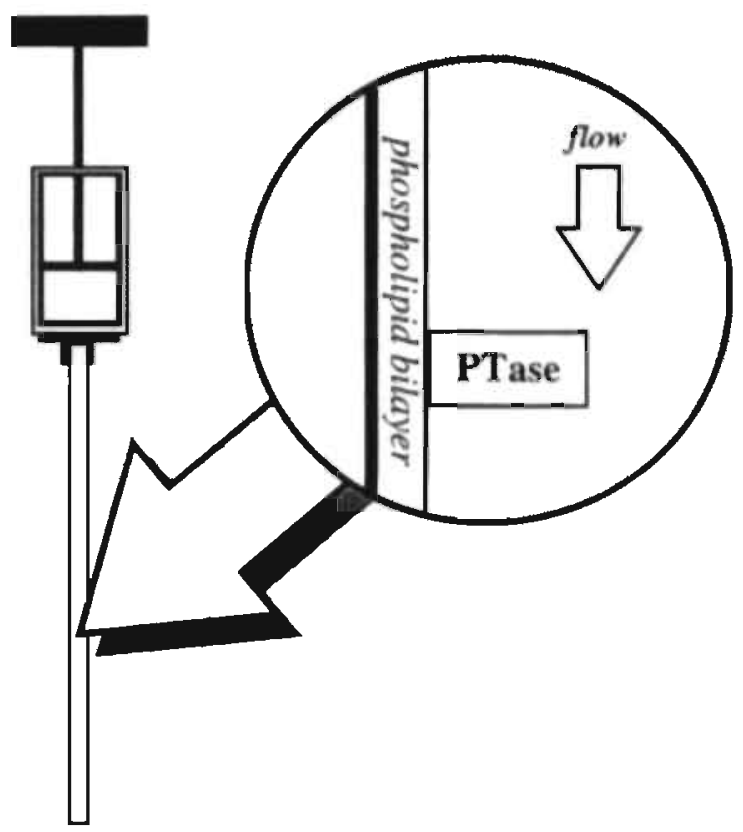

Figure 1. The tubular flow reactor.

The enzyme is attached to the inner wall of the tube and therefore, can be only supplied with substrate by diffusion towards and at the surface. For simplification, it is convenient to assume that a diffusion layer (boundary layer), is established at the inner surface of the tube (see Fig.2). Due to the catalytic activity of the enzyme and diffusion-limited transport, the substrate concentration near the catalytic surface will be lower than in the perfusion solution. A typical substrate concentration gradient is then established between the bulk solution and the catalytic surface: the 


\section{Chapter 2}

concentration of substrate is constant in the central part of the tube , but gradually decrease to the wall

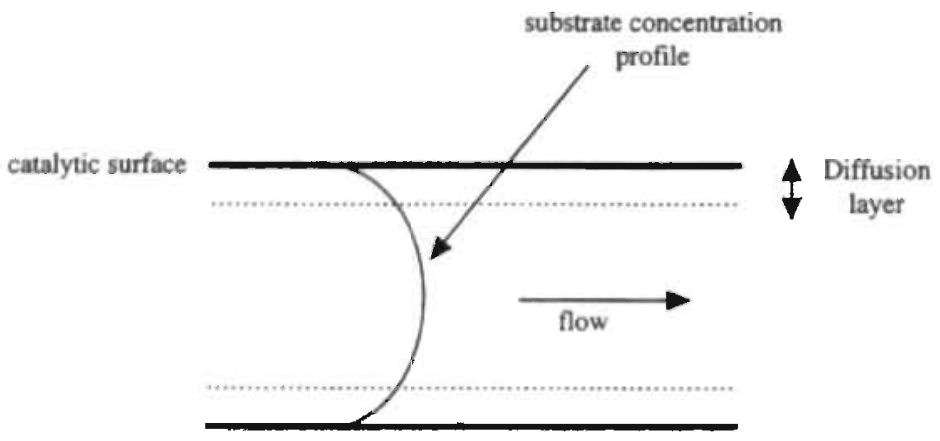

Figure 2. The diffusion layer

Under such condition the mass transfer rate of the substrate to the surface has to be considered when one examines the catalytic efficiency of an immobilized enzyme. The maximum rate of substrate transport toward the catalytic surface $\left(\mathrm{V}_{\mathrm{s}}\right)$ can be calculated from:

$$
V_{s}=\Delta C_{b}
$$

with the mass transfer coefficien:

$$
\Delta=0.8 \mathrm{I}\left(\gamma_{w} \mathrm{D}^{2} / \mathrm{L}\right)^{1 / 3}
$$

where $C_{b}$ is the concentration of protein in the bulk (pmol/ml), D is the diffusion coefficient of the protein $\left(\mathrm{cm}^{2} / \mathrm{s}\right), \gamma_{w}$ the wall shear rate $\left(\mathrm{s}^{-1}\right.$, equation 1$)$ and $\mathrm{L}$ the tube length $(\mathrm{cm})$.

In a diffusion-controlled situation all the substrate transfered to the surface is converted into product by the immobilized enzyme. In this case the depletion of substrate near the surface is nearly complete and the rate of its conversion is equal to its transport rate towards the catalytic surface (equation 2).

In a kinetic-controlled situation, the rate of substrate conversion is smaller than the rate of supply of substrate towards the surface. Under such conditions, the rate of product formation $(\mathbf{J})$ is given by the Michaelis-Menten kinetic equation: 


$$
\mathrm{J}=\mathrm{k}_{\mathrm{cat}} \mathrm{E}_{\mathrm{w}} \mathrm{C}_{\mathrm{d}} /\left(\mathrm{C}_{\mathrm{o}}+\mathrm{K}_{\mathrm{m}}\right)
$$

$\mathrm{C}_{\mathrm{o}}$ is the substrate concentration near the surface and is always smaller than the substrate concentration in the bulk $\left(\mathrm{C}_{\mathrm{b}}\right)$ because of transport limitations and substrate conversion:

$$
\mathrm{C}_{0}=\mathrm{C}_{\mathrm{b}}-\mathrm{J} / \Delta
$$

A detailed theoretical treatment of these two limiting conditions concerning the prothrombin activation by the prothrombinase complex, is developed in chapter 3 .

\section{References}

1. White J.G. 1994: Platelet ultrastructure. Bloom AL. Thomas DP (eds.): Haemostasis and Thrombosis, 2nd ed. Churchill Livingstone, p. 49-87.

2. Crawfort N.. Scrutton M.C. 1994: Biochemistry of the blood platelet. Bloom AL. Thomas DP (eds.): Haemostasis and Thrombosis, 2nd ed. Churchill Livingstone, p. 89-114.

3. Sixma JJ. 1994: Interaction of blood platelets with the wessel wall. Bloom AL. Thomas DP (eds.) Haemostasis and Thrombosis, 2nd ed. Churchill Livingstone, p. 259-284.

4. Stel H.V., Sakariassen K.S., de Groot P.G., van Mourik I.A., Sixma J.J. 1985: Von Willebrand Factor in the vessel wall mediated platelet adherence. Blood 65: 85 .

5. Sims P.J., Ginsberg M.H., Plow E.F., Shattil S.J. 1991: Effect of platelet activation on the conformation of the plasma membrane glycoprotein IIb-IIla complex. J. Biol. Chem 266: 7345-7352.

6. Nurden A.T. 1994: Human platelets membrane glycoproteins. Bloom AL. Thomas DP (eds.): Haemostasis and Thrombosis, 2nd ed. Churchill Livingstone, p. 115-164.

7. Nemerson Y. 1988: Tissue factor and hemostasis. Blood 71: 1-8.

8. Mann K.G., Krishnaswamy S., Lawson J.H. 1992: Surface-dependent haemostasis. Sem. Hematoli. 29: 213-226.

9. Nemerson Y., Repke D. 1985: Tissue factor accelerates the activation of coagulation factor VII: the role of a bifunctional coagulation factor. Throm. Res. 40: 351-358.

10. Rao L.V.M.. Rapaport S.I. 1988: Activation of factor VII bound to tissue factor: A key early step in the tissue factor patway of blood coagulation. Proc. Natl. Acad. Sci. USA 85: 6687-6691.

11. Osterud B., Rapaport S. 1977: Activation of factor DX by the reaction product of tissue-factor and factor VII: additional pathway for initiating coagulation. Proc. Natl. Acad. Sci. USA 74: 5260 .

12. Bom V.J.J., Bertina R.M. 1990: The contribution of $\mathrm{Ca}^{2 *}$, phospholipids and tissue factor apoprotein to the activation of human blood coagulation factor $\mathrm{X}$ by activated factor VII. Biochem. J. 265:327.

13. Lawson J.H., Mann K.G. 1991: Cooperative activation of human factor IX' by human extrinsic pathway of blood coagulation. J. Biol. Chem. 266: 11317-11327.

14. Monkovic D.D.. Tracy P. 1990: Activation of human factor V by factor Xa and thrombin. Biochemistry 29: 11181128 


\section{Chapter 2}

15. Lollar P., Knutson G.J., Fass D.N. 1985: Activation of porcine factor VIII:C by thrombin and factor $\mathrm{Xa}_{\mathrm{a}}$ Biochemistry 24: 8056-8064.

16. Nesheim M.E., Taswell J.B., Mann K.G. 1979: The contribution of bovine factor V and factor Va to the activity of prothrombinase. J. Biol. Chem. 254: 10952-10962.

17. Rosing J., Tans G., Govers-Riemslag J.W.P., Zwaal R.F.A., Hemker H.C. 1980: The role of phospholipids and factor $V_{a}$ in the prothrombinase complex. J. Biol. Chem. 255: 274-283.

18. Mann K.G., Jenny R.J., Krishnaswamy S. 1988: Cofactor proteins in the assembly and expression of blood clotting enzyme complexes. Ann. Rev. Biochem. 57: 915-956.

19. Bevers E.M." Comfurius P., Van Rijn J.L.M.L., Hemker H.C., Zwaal R.F.A. 1982: Generation of prothrombin converting activity and the exposure of phosphatidylserine at the outer surface of platelets. Eur. J. Biochem. 122 429-436.

20. Hemker H.C. 1994: Thrombin formation, an essential step in haemostasis and thrombosis. Bloom AL, Thomas DP (eds.): Haemostasis and Thrombosis, 2nd ed. Churchill Livingstone, p. 477-489.

21. Broze G.J.Jr. 1994: The tissue factor pathway of coagulation: factor VII, tissue-factor, and tissue factor pathway inhibitor. Bloom AL, Thomas DP (eds.): Haemostasis and Thrombosis, 2nd ed. Churchill Livingstone, p. 349-377.

22. Mann K.G., Kalafatis M. 1995: The coagulation explosion. Cerebrovasc Dis 5: 93-97.

23. Mann K.G., Jenny R.J., Krishnaswamy S. 1988: Cofactor proteins in the assembly and expression of blood clotting enzyme complexes. Ann. Rev. Bioch. 57: 915-956.

24. Von der Borne P.A.Kr., Meijer J.C.M., Bouma B.N. 1995: Feed-back activation of factor XI by thrombin in plasma results in formation of additional thrombin that protects fibrin clots from fibrinolysis. Thromb. Haemostas 73: 1207.

25. Gailani D., Broze G.J.Jr. 1991: Factor XI activation in a revised model of blood coagulation. Science 253: 909 912.

26. Jakson C.M. 1994: Physiology and biochemistry of prothrombin. Bloom AL, Thomas. DP (eds.): Haemostasis and Thrombosis, 2nd ed. Churchill Livingstone, p. 397-437.

27. Papahadjopoulos D. Hanahan D.J. 1964: Observations on the interaction of phospholipids and certain clotting factors in prothrombin activator formation. Biochem. Biophys. Acta 90: 436-439.

28. Hemkei H.C., Esnouf M.P. Hemker P.W., Swart A.C.W., Mac Farlane R.G. 1967: Formation of prothrombin converting activily. Nature 215: 248-251.

29. Mann K.G. Jenny R.J., Krishnaswamy S. 1988: Cofactor proteins in the assembly and expression of blood clotting enzyme complexes. Annu. Rev. Biochem. 57: 915-956.

30. Doolittle R.F. 1994: Fibrinogen and fibrin. Bloom AL. Thomas DP (eds.): Haemostasis and Thrombosis, 2nd ed Churchill Livingstone, p. 491-513.

31. Zwaal R.F.A., Hemker H.C. 1982: Blood cell membranes and haemostasis. Haemostasis 11: 12-39.

32. Mann K.G. Krisnaswamy S., Lawson J.H. 1992: Surface-dependent hemostasis. Sem. Hematol. 29: 213-226.

33. Mann K.G.. Nesheim M.E., Church W.R., Haley P., Krisnaswamy S. 1990: surface-dependent reactions of the vitamin K-dependent enzyme complexes. Blood 76: 1-16.

34. Nelsestuen G.L. 1978: Interaction of vitamin K-dependent proteins with calcium ion and phospholipid membranes Fed Proc 37: 2621-2625. 


\section{Chapter 2}

35. van Dieijen G., Tans G., Rosing J., Hemker H.C. 1981: The role of phospholipid and factor VIIla in the activation of bovin factor X. J. Biol. Chem. 256: 3433-3442.

36. van Dieijen G., van Rijn J.L.M.L., Govers-Riemslag J.W.P., Hemker H.C., Rosing J. 1985: Assembly of intrinsic factor X activation complex-interactions between factor IXa, factor VIIla and phospholipid. Thromb. Haemostas. 53: $396-400$.

37. Gernmell C.H. Nemerson Y., Turnito V.T. 1990: The effect of shear rate on the enzymatic activity of the tissue factor-factor VIla complex. Microvesc. Res, 40: 327-340.

38. Schoen P., Lindhout T., Willems G. Hemker H.C. 1990: Continuous flow and the prothrombinase-catalyzed activation of prothrombin. Thromb. Hacmostas. 64: 542-547.

39. Giesen P.L.A., Willems G.M., Hermens W.Th. 1991: Production of thrombin by the prothrombinase complex is regulated by membrane-mediated transport of prothrombin. J. Biol. Chem. 266: 1379-1382.

40. Willems G.M., Giesen P.L.A., Hermens W.Th. 1993: Adsorbtion and conversion on a rotating disk. Blood 82: 497-504.

41. Kane W.H. Lindhout T., Jackson C.M., Majerus P.W. 1980: Factor Va-dependent binding of factor Xa to human platelets. J. Biol. Chem. 255: 1170-1174.

42. Rosing J., van Rijn J.L.M.L., Bevers E.M., van Dieijen G., Comfurius P.. Zwaal R.F.A. 1985: The role of activated human platelets in prothrombin and factor $\mathrm{X}$ activation. Blood 65: 319-332.

43. Zwaal R.F.A., Bevers E.M., Comfurius P., Rosing. J., Tilly R.H.J., Verhallen P.F.J. 1989: Loos of membrane phospholipid asymetry during activation of blood platelets and sickled red cells; Mechanism and physiological significance. Mol. Cell. Biochem. 91: 23-31.

44. Bevers E.M., Comfurius P., Zwaal R.F.A. 1991: Platelet procoagulant activity: physiological significance and mechanisms of exposure. Blood Review 5: 146-154.

45. Sandberg H., Andersson L., Hoglund S. 1982: Isolation and characterization of lipidprotein particles containing platelet factor 3 released from human platelets. Biochem. J. 203: 303-31I.

46. Tans G., Rosing J. Thomasseen M.C.L.G.D., Heeb M.J., Zwaal R.F.A., Griffin J.H. 1991: Comparison of anticoagulant and procoagulant activities of stimulated platelets and platelet-derived microparticles. Blood 77 : 2641-2648.

47. Zwaal R.F.A., Comfurius P., Bevers E.M. 1992: Platelet procoagulant activity and microvesicle formation. Its putative role in hemostasis and thrombosis. Biochim. Biophys. Acta 1180, 1-8.

48. Sword N.A., Tracy P.B., Mann K.G. 1993: Intact platelet membranes, not platelet-released microvesicles, support the procoagulant activity of adherent platelets. Arterioscler. Thromb, 13: 1613-1622.

49. James H.L. 1994: Physiology and biochemisty of factor X. Bloom AL. Thomas DP (eds.): Hacmostasis and Thrombosis. 2nd ed. Churchill Livingstone, p. 439-464.

50. Jenny R.J., Tracy P.B., Mann K.G. 1994: The physiology and biochemistry of factor V. Bloom AL. Thomas DP (eds.): Haemostasis and Thrombosis. 2nd ed'. Churchill Livingstone, p. 465-476.

51. Tans G., Rosing J. 1986: Multicomponent enzyme complexes of blood coagulation. in Blood Coagulation: New Comprehensive Biochemistry (Zwaal R.F.A., Hemker H.C., eds), Elsevier. Amsterdam Vol. 13: 59-85.

52. Lindhout T., Govers-Riemslag J.W.P., van de Waart P., Hemker H.C., Rosing J, 1982: Factor Va-factor Xa: interaction. Effects of phospholipid vesicles of varying composition. Biochemistry 21: 5494-5502. 


\section{Chapter 2}

53. van Rijn J.L.M.L., Govers-Riemslag J.W.P., Zwaal R.F.A., Rosing J. 1984: Kinetic studies of prothrombin activation: effect of factor $\mathrm{V}_{\mathrm{a}}$ and phospholipids on the formation of the enzyme substrate complex. Biochemistry 23: 4557-4564.

54. Billy D., Speijer H., Willems G.M., Hemker H.C., Lindhout T. 1995: Prothrombin activation by prothrombinase in a tubular flow reactor. J. Biol. Chem. 270: 1029-1034.

55. Esmon N.L., Owen W.G., van Esmon C.T. 1982: Isolation of a membrane-bound cofactor for thrombin-catalysed activation of protein C. J. Biol. Chem. 257: 859-864.

56. Esmon C.T. 1989: The roles of protein C and thrombomodulin in the regulation of blood coagulation. J. Biol. Chem. 264: 4743-4746.

57. Esmon C.T. 1993: Molecular events that control the protein C anticoagulant pathway. Thromb. Haemostas. 70: 29. 35.

58. Walker F.J. 1980: Regulation of activated protein C by a new protein: a possible function for bovine protein S J.Biol. Chem. 255: 5521-5524.

59. Heeb M.J., Mester R.M., Tans G., Rosing J., Griffin J.H. 1993: Binding of protein S to factor Va associated with inhibition of prothrombinase that is independent of activated protein C. J. Biol. Chem. 268: 2872-2877.

60. Dahlback B., Carlsson M., Svensson P.J. 1993: Familial thrombophilia due to a previously unrecognized mechanism characterized by poor anticoagulant response to activated protein C. Proc. Natl. Acad. Sci. USA 90 1004.

61. Bertina R.M., Koeleman B.P.C., Koster T., Rosendaal F.R., Dirven R.J., de Ronde H., van der Velden P.A. Reitsma P.H. 1994: Mutation in blood coagulation factor $\mathrm{V}$ associated with resistance to activated protein C Nature 369: 64-67.

62. Dahlback B. 1995: Inherited thrombophilia: resistance to activated protein C as a pathogenic factor of venou thromboembolism. Blood 85: 607.614.

63. Wun T.C., Kretzmer K.K., Girard T.J., Miletisch J.P., Broze G.J. 1988: Cloning and characterisation of a cDNA coding for the lipoprotein associated coagulation inhibitor shows that it consists of three tandem Kunitz-typ inhibitory domains. J. Biol. Chem. 263: 6001-6004.

64. Broze G.J., Warren L.A., Noyotny W.F., Higuchi D.A., Girard J.J., Miletich J.P. 1988: The lipoprotein-associated coagulation inhibitor that inhibits the factor VIla-tissue factor complex, also inhibits factor Xa: insight into its possible mechanism of action. Blood 71: 335-343.

65. Lindhout T., Franssen J. Willems G.M. 1995: Kinetics of the inhibition of tissue factor-factor VIIla by tissu: factor pathway inhibitor. Thromb Haemostas 74: 910-915

66. Hemker H.C., Willems G.M.. Beguin S.. 1986: A computer assisted method to obtain the prothrombin activation velocity in whole plasma independent of thrombin decay processes. Thromb. Haemostas. 56: 9-17.

67. Rosenberg R.D., Rosenberg J.S. 1984: Perspectives: natural anticoagulant mechanisms. J. Clin. Invest. 74: 1-6.

68. Barrowcliffe T.W., Thomas D.P. 1994: Antithrombin III and heparin. Bloom AL. Thomas DP. (eds.): Haemostasi and Thrombosis. 2nd ed. Churchill Livingstone, p. 712-725.

69. Blajchman M.A., Austin R.C., Fernandez-Rachubinski F., Sheffield W.P. 1992: Molecular basis of inherited human antithrombin deficiency. Blood 80: 2159. 


\section{Chapter 2}

69. Blajchman M.A., Austin R.C., Fernandez-Rachubinska F.. Sheffield. W.P. 1992: Molecular basis of inherited human antithrombin deficiency. Blood 80: 2159.

70. Choay J. 1989: Structure and activity of beparin and its fragment: an overview. Sem. Thromb. Haemostas. 15: 359-364.

71. Craig P.A., Olson S.T., Shore J.D. 1989: Transient kinetics of heparin-catalyzed protease inactivation by antithrombin. III. Characterization of assembly, product formation, and heparin dissociation steps in the factor $\mathrm{X}$ reaction. J. Biol. Chem. 263: 5442-5461.

72. Andersson L.O., Barroweliffe T.W., Holmer E., Johnson E.A., Sodenstrom G. 1979: Molecular weight dependency of the heparin potentiated inhibition of thrombin and activated factor X. Effect of heparin neutralization in plasma. Thromb. Res. 15: 531-541.

73. Bendetowicz A.V., Pacaud E., Beguin S., Uzan A., Hemker H.C. 1992: On the relationship between molecular mass and anticoagulant activity in a low molecular weight heparin (enoxaparin). Thromb. Haemostas. 67: 556562.

74. Beguin S., Wielders S., Lormeau J.C., Hemker H.C. 1992: The mode of action of CY 216 and CY 222 in plasma. Thromb. Haemostas. 67: 33-41.

75. Ellis V.,Scully M.F., Kakkar V.V. 1984: Inhibition of prothrombinase complex by plasma proteinase inhibitors. Biochemistry, 23:5882-5887.

76. Marciniak E. 1973: Factor Xa inactivation by antithrombin III: evidence for biological stabilization of factor $\mathrm{Xa}$ by factor V-phospholipid complex. Br. J. Hacmatol. 24:391-400.

77. Lindhout. T., Baruch D., Schoen P., Franssen J., Hemker H.C. 1986: Thrombin generation and inactivation in the presence of antithrombin III and heparin. Biochemistry 25: 5962-5969.

78. Schoen P., Lindhout T., Willems G.M., Hemker H.C. 1989: Antithrombin III dependent anti-prothrombinase activity of heparins of various molecular weight. J. Biol. Chem. 264: 10002-10007.

79. Schoen P., Lindhout T. 1991: Flow and the inhibition of prothrombinase by antithrombin III and heparin. Blood. 78: $118-124$.

80. Speijer H., Billy D., Willems G., Hemker H.C., Lindhout T. 1995: Inhibition of prothrombinase by antithrombinheparin at a macroscopic surface. Thromb. Haemostas. 73: 648-653.

S1. Billy D., Speijer H., Lindhout T., Hemker H.C., Willems, G. 1995: Inhibition of prothrombinase at macroscopic lipid membranes: competition between antithrombin and prothrombin. Biochemistry 34: 13699-13704

82. Goldsmith H.L. Turitto V.T. 1986: Rheological aspects of thrombosis and hacmostasis: basic principles and applications Thromb. Haemostas. 55: 415-435.

83. Leonard E.F. 1987: Rheology of trombosis. Haemostasis and. Thrombosis. Basic principles and clinical practice. Colman R.W., Hirsh J., Marder V.J.. Salzman E.W., second edition. J.B. Lippincott Company, Philadelphia. Chapter 70: $1111-1122$.

84. Nemerson Y. Turrito V.T. 1991: The effect of flow on hemostasis and thrombosis. Thromb. Haemostas. 66: 272-276

85. Slack S.M. Cui Y. Turitto V.T, 1993: The effect of flow on blood coagulation and thrombosis. Thromb. Haemostas. $70 \cdot 129 \cdot 134$ 



\section{Chapter 3}

\section{Prothrombin Activation by Prothrombinase in a Tubular Flow Reactor.}

Didier Billy, Han Speijer, George Willems, H. Coenraad Hemker, and Theo Lindhout, 1995. J. Biol. Chem. 270: 1099-1034.

\section{Summary}

Thrombin production by the phospholipid bound complex of blood clotting factors Xa and Va (prothrombinase) was studied in a tubular flow reactor. The inner wall of a glass capillary was coated with a phospholipid bilayer of $25 \%$ phosphatidylserine and $75 \%$ phosphatidylcholine. Prothrombinase was assembled on this bilayer by perfusion with a mixture containing an excess of factor $\mathrm{Va}(2 \mathrm{nM})$ and a limiting amount of factor Xa (1-100 pM), either in the absence or presence of prothrombin. The rate of assembly of prothrombinase in the presence of prothrombin appeared to be limited by the transfer rate of factor Xa to the phospholipid surface. A good agreement was found between the predicted mass transfer coefficient for factor $\mathrm{Xa}$ and the observed pre-steady state rate of thrombin production. The eventuaily obtained steady state rates of thrombin production were proportional to the prothrombin concentration and independent of the surface density of prothrombinase. The observed rate of thrombin production was in excellent agreement with the predicted mass transfer rate for prothrombin. Transport limited prothrombin conversion was observed for prothrombinase densities exceeding 1 $\mathrm{fmol} / \mathrm{cm}^{2}$, which corresponds to $0.05 \%$ occupation of available binding sites. The kinetic parameters of the reaction were determined at low prothrombinase densities $\left(0.02-0.04 \mathrm{fmol} / \mathrm{cm}^{2}\right)$. Even in this situation the Michaelis-Menten equation had to be corrected for substrate depletion near the catalytic surface. We hereto employed an accurate approximation of the mass transfer coefficient. The kinetic parameter $k_{\text {cat }}$ was $60 \mathrm{~s}^{-1}$ the intrinsic $\mathrm{K}_{\mathrm{m}}$ had a surprisingly low value of $3 \mathrm{nM}$. Both parameters were not influenced by the wall shear rate.

\section{Introduction}

The process of blood coagulation encompasses a complex system of enzymatic reactions in flowing blood at the surface of damaged biood vessels. One of the final steps in this process is the conversion of prothrombin to thrombin $(1,2)$. The activator of prothrombin is a multicomponent complex that consists of the serine protease factor $\mathrm{Xa}$ and the non-enzymatic cofactor factor $\mathrm{Va}$. In the presence of calcium ions, the complex of factor $\mathrm{Xa}$ and factor $\mathrm{Va}$ assembles on a membrane containing negatively charged phospholipids, i.e. phosphatidylserine $(3,4)$. These membranes become available when blood platelets are activated $(5,6)$. Other cells 
like monocytes and endothelial cells have also been reported to support prothrombin activation by providing such a procoagulant surface $(7,8)$.

Prothrombin activation at a macroscopic surface under flow conditions has been studied in our laboratory. We previously reported on prothrombin activation in a tubular flow reactor (9). The findings of that study seemed to contrast the findings on prothrombin activation at planar phospholipid bilayers $(10,11)$. That is, during continuous flow through the tubular flow reactor, the rate of thrombin production appeared to be dependent on the prothrombin concentration in the bulk solution upto about $1 \mu \mathrm{M}$. Studies with an uniformly accessible surface, as offered by the rotating disc, however, showed that the concentration of prothrombin in the bulk solution that is required for the half maximum rate of prothrombin conversion was about $7 \mathrm{nM}$ (10).

In the present paper we describe the results of a kinetic study on prothrombin activation in a tubular flow reactor. Our major goal was to identify the experimental settings, with respect to flow rate, substrate concentration and prothrombinase surface density, that allow us to derive kinetic parameters from the thrombir production data. Hereto we explored the conditions that gave rates of thrombin production proportional with the true catalytic activity of prothrombinase and thus independent of the rate of transfer of prothrombin from the bulk solution to the catalytic surface. We, therefore, have carefully evaluated the transport limit in the flow reactor and used the theoretical considerations of mass transfer given by Brown (12). Our findings support previous proposals that at a macroscopic phospholipid surface, prothrombin activation by prothrombinase is extremely efficient because very low concentrations of prothrombin (a few $\mathrm{nM}$ ) are required to obtain halfmaximal velocity of thrombin production $(10,11)$. We also addressed the question whether the catalytic efficiency of prothrombinase was influenced by the wall shear rate, as has been reported for factor $\mathrm{X}$ activation in a flow reactor $(13,14)$.

\section{Experimental Procedures}

Materials. Fatty acid free bovine serum albumin (BSA) was from Sigma, St Louis, Mo. The chromogenic substrate for thrombin, S2238, was from Chromogenix, Möhldal, Sweden. All chemicals used were of the highest grade commercially available.

Proteins. Human factor $\mathrm{Xa}$, human prothrombin and bovine factor $\mathrm{Va}$ were prepared and quantified as described (9). Bovine factor Va was further purified on a Mono S column (Pharmacia Biotech, Uppsala, Sweden) as described by Rosing et al (15). Briefly, after loading the column with bovine factor $\mathrm{Va}$, a linear gradient of $0.05-1 \mathrm{M} \mathrm{NH}_{4} \mathrm{Cl}$ was applied. Factor $\mathrm{Va}$ activity was eluted in two peaks at $0.45 \mathrm{M}$ and $0.75 \mathrm{M} \mathrm{NH}_{4} \mathrm{Cl}$. Throughout this study we used factor $\mathrm{Va}$ eluted at the higher sal: concentration. 
Preparation of phospholipid-coated capillaries. The glass capillaries $(0.65 \mathrm{~mm}$ and $0.29 \mathrm{~mm}$ internal diameter and $127 \mathrm{~mm}$ length) obtained from Brand AG, Wertheim, Germany were boiled for $10 \mathrm{~min}$ in a 1:1:5 solution of $\mathrm{NH}_{4} \mathrm{OH}(25 \%)$, $\mathrm{H}_{2} \mathrm{O}_{2}(30 \%)$ and $\mathrm{H}_{2} \mathrm{O}$ for $10 \mathrm{~min}$ and rinsed in deionized water. They were then boiled in a 1:1:6 solution of $\mathrm{HCl}(37 \%), \mathrm{H}_{2} \mathrm{O}_{2}(30 \%)$ and $\mathrm{H}_{2} \mathrm{O}$ for $10 \mathrm{~min}$ and rinsed in deionized water. The clean and hydrophilic capillaries were kept at $4^{\circ} \mathrm{C}$ in deionized water. Before use the capillaries were dried under a stream of $\mathrm{N}_{2}$. The capillary was filled with a suspension of unilamellar phospholipid vesicles composed of $75 \mathrm{~mol} \%$ egg phosphatidylcholine and $25 \mathrm{~mol} \%$ brain phosphatidylserine, prepared as described before (15). After $20 \mathrm{~min}$ of incubation with the $1 \mathrm{mM}$ phospholipid suspension, the capillary was rinsed with Tris-buffer $(50 \mathrm{mM}$ Tris- $\mathrm{HCl}$, $175 \mathrm{mM} \mathrm{NaCl}$, and $0.5 \mathrm{mg} \mathrm{BSA} / \mathrm{ml}, \mathrm{pH} 7.9$ ) containing $3 \mathrm{mM} \mathrm{CaCl}_{2}$ at a flow rate of $1.2 \mathrm{ml} / \mathrm{min}$ for $2 \mathrm{~min}$ to remove non-bound phospholipid $(9,13)$.

The flow system. The flow system was as described by Contino et al (16). Briefly, the phospholipid-coated capillary is attached to a Hamilton gas-tight syringe. The flow is controlled by a syringe pump (Harvard Apparatus Co., Massachusetts, USA). An XYZ translation table (Isel, Eiterfelt, Germany) is used to collect samples (typically $30 \mu \mathrm{l}$ ) from the tip of the flow reactor into disposable cuvettes (Sarstedt, Nümbrecht, Germany) containing $20 \mathrm{mM}$ EDTA in Tris-buffer. Thrombin was measured in the cuvette after the addition of the chromogenic substrate S2238 as previously described (9). All procedures were performed at $37^{\circ} \mathrm{C}$.

Determination of factor Xa-bound to the surface of the flow reactor. The amount of factor Xa bound to the phospholipid bilayer in the flow reactor was determined at the end of each experiment. To this end the capillary was rinsed with Tris-buffer containing $3 \mathrm{mM} \mathrm{CaCl}_{2}$ and factor $\mathrm{Va} .(2 \mathrm{nM})$ at a flow rate of $30 \mu \mathrm{l} / \mathrm{min}$ for $5 \mathrm{~min}$ to remove prothrombin and thrombin. The capillary was then eluated with Tris-buffer containing $5 \mathrm{mM}$ EDTA at $30 \mu \mathrm{l} / \mathrm{min}$ for $5 \mathrm{~min}$. The effluent was collected and assayed for factor $\mathrm{Xa}$. The factor $\mathrm{Xa}$ containing samples were diluted in Tris-buffer containing $3 \mathrm{mM} \mathrm{CaCl} \mathrm{m}_{2}$. An aliquot $(30 \mu 1)$ of the dilution was added to a cuvette containing $108 \mu \mathrm{l}$ of Tris-buffer containing $1.4 \mathrm{nM}$ factor $\mathrm{Va}, 14 \mu \mathrm{M}$ phospholipid (25\%PS/75\%PC) and $3 \mathrm{mM} \mathrm{CaCl}_{2}$. Thrombin production was started by the addition of $12 \mu \mathrm{l}$ of a $5 \mu \mathrm{M}$ prothrombin solution and stopped after $4 \mathrm{~min}$ by the addition of $390 \mu \mathrm{l}$ of $20 \mathrm{mM}$ EDTA in Tris-buffer. The amount of thrombin formed was determined by adding $60 \mu \mathrm{l}$ of S2238 $(2.5 \mathrm{mM})$ and reading of the optical density at $405 \mathrm{~nm}$. Reference curves were constructed from known amounts of factor Xa.

Prothrombin transport from perfusion solution to the catalytic surface as rate limiting step of thrombin production. The transfer of prothrombin by convection and diffusion to the capillary wall becomes easily rate limiting $(17,18)$. This results in 
depletion of the prothrombin in the solution near the wall and thus a steady state concentration $C(r, z)$ is established, which depends on the radial co-ordinate $r$ and on the axial co-ordinate $z$. The concentration $\mathrm{C}(r, z)$ is a solution of the convective diffusion equation $(17,18)$ :

$$
\mathrm{D}\left(\frac{\delta^{2} C}{\delta^{2} r}+\frac{1 \delta C}{r \delta r}+\frac{\delta^{2} C}{\delta^{2} z}\right)-2 V_{f}\left(1-\frac{r^{2}}{R^{2}}\right) \frac{\delta C}{\delta z}=0
$$

with $\mathrm{D}$ the diffusion constant of the protein, $V_{f}$ the mean fluid flow velocity and $R$ the radius of the capillary. At the entrance of the capillary, $z=0, C$ is equal to the perfusion concentration $\mathrm{C}_{\mathrm{b}}$ :

$$
\mathrm{C}(\mathrm{r}, 0)=\mathrm{C}_{\mathrm{b}}
$$

and at the capillary wall the diffusional flux must balance the conversion rate:

$$
\mathrm{D} \frac{\delta \mathrm{C}(\mathrm{R}, \mathrm{z})}{\delta}=V_{m}(z) \frac{C(R, z)}{C(R, z)+K_{m}}
$$

with $V_{m}$ the maximal conversion rate per unit area and $K_{m}$ the Michaelis constant.

Diffusion controlled prothrombin conversion. For high values of $\mathrm{V}_{\mathrm{m}}$, i.e. for high densities of prothrombinase at the capillary wall, maximal thrombin production and therefore maximal mass transfer of prothrombin by convection and diffusion is attained. According to boundary condition (Eq.1c), this corresponds to a concentration at the wall that approaches zero. The boundary condition (Eq.1c) thus can be replaced by

$$
\mathrm{C}(\mathrm{R}, \mathrm{z})=0
$$

A convenient and simple approximate solution of the boundary value problem (Eq. 1a, 1b, 1d) was derived by Leveque (19) using the assumption that the boundary layer of substrate depletion is small compared to the capillary diameter. With this so called Leveque approximation the total mass transfer, $\mathrm{J}_{\mathrm{t}}(\mathrm{mol} / \mathrm{s})$, is given by:

$$
J_{t}=5.4 D^{2 / 3} Q^{1 / 3} \mathrm{~L}^{2 / 3} \mathrm{C}_{b}=\Delta \mathrm{C}_{\mathrm{b}}
$$


where D is the diffusion constant of the substrate $\left(\mathrm{cm}^{2} / \mathrm{s}\right), \mathrm{Q}$ the volumetric flow rate $\left(\mathrm{cm}^{3} / \mathrm{s}\right)$, L the length of the capillary $(\mathrm{cm})$ and $\mathrm{C}_{\mathrm{b}}$ the substrate concentration at the inlet $\left(\mathrm{mol} / \mathrm{cm}^{3}\right)$. The total mass transfer can thus expressed as the mass transfer coefficient $\Delta_{i}\left(\mathrm{~cm}^{3} / \mathrm{s}\right)$ times the substrate concentration, $C_{b}$. It should be noted that the mass transfer rate $J_{z}$, expressed in $\mathrm{mol} / \mathrm{cm}^{2} / \mathrm{s}$, depends on the distance $\mathrm{z}$ downstream from the capillary inlet:

$$
\mathrm{J}_{z}=\mathrm{D} \frac{\delta \mathrm{C}_{0}}{\delta z} \mathrm{C}_{b}=0.57 \mathrm{D}^{2 / 3}\left(\mathrm{Q}^{1 / 3} / \mathrm{R}\right) \mathrm{z}^{-1 / 3} \mathrm{C}_{\mathrm{b}}=\Delta_{2} \mathrm{C}_{\mathrm{b}}
$$

with $\mathrm{C}_{0}$ the solution of boundary value problem (Eq.1a, 1b, 1d) with $\mathrm{C}_{b}=1$ and $\Delta_{2}$ the local mass transfer coefficient $(\mathrm{cm} / \mathrm{s})$ which declines steeply in the downstream direction.

For low flow rates and relatively long capillaries of small diameter the depletion layer, however, spans the entire capillary and the Leveque approximation becomes invalid. The depletion at the end of the capillary can be estimated by Equation 2 as:

$$
\mathrm{C}_{\text {end }} / \mathrm{C}_{\mathrm{b}}=1-\mathrm{J} /\left(\mathrm{QC}_{\mathrm{b}}\right)=1-5.4 \mathrm{D}^{2 / 3} \mathrm{Q}^{-2 / 3} \mathrm{~L}^{2 / 3}
$$

For a capillary with $\mathrm{R}=0.032(\mathrm{~cm}), \mathrm{L}=12.7(\mathrm{~cm})$, a diffusion constant $\mathrm{D}=10^{-6}$ $\left(\mathrm{cm}^{2} / \mathrm{s}\right)$ and a flow rate $\mathrm{Q}=5 \times 10^{-4}\left(\mathrm{~cm}^{3} / \mathrm{s}\right)$ this amounts to $\mathrm{C}_{\text {end }} / \mathrm{C}_{\mathrm{b}}=0.53$ and Equation 2 will overestimate the transport rate by about $20 \%$. Errors of this size can be avoided by employing the semi-analytical approximate solution to the full problem (Eq.1a, b, d) as presented by Brown (12, and Equation 15 and Table I therein). The equation, which allows the calculation of the total mass transfer coefficient $\Delta_{1}$ for a given flow rate and diffusion coefficient, is rather unwieldy. We, therefore, should like to confine ourselves to refer the reader to the paper of Brown (12). Table I lists the numerical values calculated on basis of Brown's semi-analytical approximate solution for the total mass transfer coefficient, $\Delta_{\mathrm{t}}$, for prothrombin and factor $\mathrm{Xa}$ under the flow conditions used in our experiments. Also given are the mass transfer coefficients calculated on basis of the Leveque approximation (19). It is apparent that prothrombin transport is overestimated by $10-30 \%$ in the latter approximation.

Intermediate kinetics of prothrombin conversion. For lower surface concentrations of prothrombinase a partial depletion of prothrombin near the capillary wall is obtained, i.e. $C_{b}>C(R, z)>0$, and in this situation the thrombin generation rate is determined by the solution of the boundary value problem (Eq.1a, lb, lc). Due to the non-linearity in the boundary condition (Eq.1c) this boundary value problem is intractable for analytical solutions for general distributions of enzyme activity $\mathrm{V}_{\mathrm{m}}(\mathrm{z})$ and requires a numerical treatment (18). The special situation, 


\section{Chapter 3}

however, that the enzyme activity on the capillary wall is proportional to the local mass transfer rate:

$$
\mathrm{V}_{\mathrm{m}}(\mathrm{z})=\beta \mathrm{D} \frac{\delta \mathrm{C}_{0}(\mathrm{R}, \mathrm{z})}{\delta \mathrm{z}}
$$

with $\beta$ as proportionality constant, allows a simple solution of this problem. It is easily verified that

$$
C(r, z)=\left(C_{b}-C_{w}\right) C_{0}(r, z)+C_{w}
$$

with $C_{w}$ the substrate concentration at the capiliary wall (independent of $z$ ) and $C_{0}$ the solution of $(1 \mathrm{a}, 1 \mathrm{~b}, 1 \mathrm{~d})$ with $\mathrm{C}_{\mathrm{b}}=1$ satisfies Equation $1 \mathrm{a}$ and the boundary condition (Eq.1b). Boundary condition (Eq.1c) is equivalent to second order equation in $\mathrm{C}_{\mathrm{w}}$, which is independent of $\mathrm{z}$ :

$$
\left(C_{b}-C_{w}\right) D \frac{\delta C_{0}(R, z)}{\delta z}=\beta D \frac{\delta C_{0}(R, z)}{\delta_{z}} \cdot C_{w} /\left(C_{w}+K_{m}\right)
$$

Integration of this expression over the inner surface of the capillary results in

$$
\mathrm{J}_{\mathrm{l}}=\Delta_{\mathrm{l}}\left(\mathrm{C}_{\mathrm{b}}-\mathrm{C}_{\mathrm{w}}\right)=\mathrm{V}_{\mathrm{m}} \mathrm{C}_{\mathrm{w}} /\left(\mathrm{C}_{\mathrm{w}}+\mathrm{K}_{\mathrm{m}}\right)
$$

with $\mathrm{J}_{\mathrm{i}}$ the total thrombin generation $(\mathrm{mol} / \mathrm{s})$ and $\mathrm{V}_{\mathrm{m}}$ the maximal thrombin production rate $(\mathrm{mol} / \mathrm{s})$ of the capillary. Equation 8 allows the following explicit solution:

$$
J_{t}=0.5 \Delta_{t}\left[C_{b}+K_{m}+V_{m} / \Delta_{t}-\sqrt{\left.\left\{\left(C_{b}-K_{m}-V_{m} / \Delta_{t}\right)^{2}+4 K_{m} C_{b}\right\}\right]}\right.
$$

Non-linear regression of this equation to measured thrombin production rates as function of the perfusion concentration $C_{b}$ of prothrombin then allows the determination of the parameters $V_{m}$ and $K_{m}$.

\section{Results}

Rate of thrombin production as a function of the surface prothrombinase density. Phospholipid-coated capillaries were perfused with solutions containing factor Va $(2 \mathrm{nM})$, prothrombin $(0.2 \mu \mathrm{M})$ ) and varying amounts of factor Xa (5-50 pM). It was expected that ongoing perfusion would result in assembly of increasing 
amounts of prothrombinase at the inner wall of the phospholipid-coated capillary which in turn results in increasing rates of thrombin production.

Fig.1 illustrates that the time to reach the steady state levels of thrombin production, decreased with increasing amounts of factor $\mathrm{Xa}$ in the perfusion solution. Evidently, because a molar excess of factor Va over factor Xa was used, the rate of assembly of the prothrombinase complex at the macroscopic surface, is limited by the transport of factor Xa and/or preformed factor Xa-factor Va complexes from the bulk solution to the surface. The initial part of the thrombin generation curve, therefore, reflects the rate of formation of prothrombinase activity at the phospholipid bilayer and this rate will increase with increasing amounts of factor Xa in the perfusion mixture.

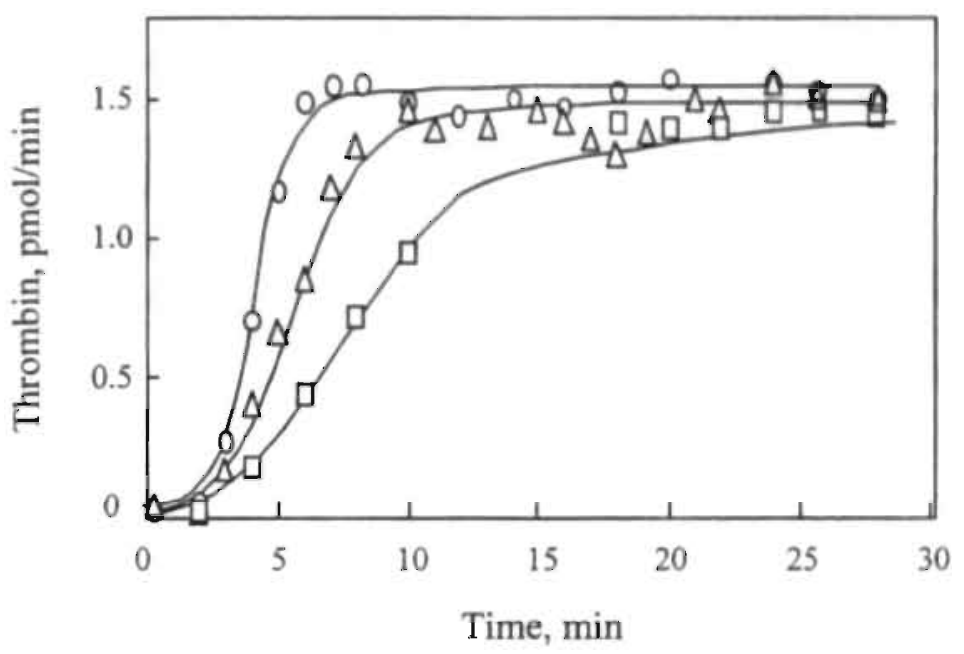

Figure 1. Rate of thrombin production as a function of factor $\mathrm{Xa}$ concentration. Phospholipid coated capillaries (internal diameter of $0.32 \mathrm{~mm}$ ) were perfused at $30 \mu \mathrm{V} / \mathrm{min}$ (wall shear rate $\left.20 \mathrm{~s}^{-1}\right)$ with Tris-buffer containing prothrombin $(0.2 \mu \mathrm{M}$ ), factor $\mathrm{Va}(2 \mathrm{nM}), 3 \mathrm{mM} \mathrm{CaCl}$ and varying concentrations of factor $\mathrm{Xa}: 5 \mathrm{pM}(\mathrm{D}), 10 \mathrm{pM}(\Delta)$ and $20 \mathrm{pM}(\mathrm{O})$.

It is also evident from Fig. 1 that the rate of thrombin formation reached a steady state value independent of the amount of factor Xa present. Under the flow conditions used and with $0.2 \mu \mathrm{M}$ prothrombin in the perfusion solution, the maximum rate of thrombin formation was $1.5 \mathrm{pmol} / \mathrm{min}$. Table I predicts a maximal mass transfer of $2.2 \mathrm{pmol}$ prothrombin/min for a prothrombin concentration of 0.2 $\mu \mathrm{M}$. Therefore an obvious explanation for the identical steady state levels is that in each experiment the prothrombin converting capacity of the capillary wall ultimately exceeded the transport limit. The alternative explanation that in all experiments the 
prothrombinase concentration at the wall surface reached a maximal value was refuted by determination of the prothrombinase densities attained in these experiments. The amount of phospholipid-bound factor $\mathrm{Xa}$ at the end of the perfusion increased linearly with the factor $\mathrm{Xa}$ concentration in the perfusion mixture. Thus, $0.34,0.65$ and 1.13 fmol factor $\mathrm{Xa}$ per $\mathrm{cm}^{2}$ was bound after $28 \mathrm{~min}$ perfusion with a mixture containing $0.2 \mu \mathrm{M}$ prothrombin, $2 \mathrm{nM}$ factor $\mathrm{Va}$ and 5,10 or $20 \mathrm{pM}$ factor $\mathrm{Xa}$, respectively. Thus, despite widely different surface densities of prothrombinase we observed identical rates of thrombin production. It is important to note that when factor $\mathrm{Xa}$ was perfused in the absence of factor $\mathrm{Va}$, no factor $\mathrm{Xa}$ could be detected in the EDTA-effluent of the capillary. Thus, the amount of prothrombinase in the phospholipid-coated capillary is represented by the amount of factor Xa found in the EDTA effluent.

Table I. The total mass transfer coefficient. $\Delta_{t}$, for the capillary flow reactor. The mass transfer coefficient $\Delta_{t}$ was calculated according to Brown (12, cf. Equation 15) with $D_{37}=9.510^{-7} \mathrm{~cm}^{2} / \mathrm{s}$, and $D_{37}=10.410^{-7} \mathrm{~cm}^{2} / \mathrm{s}$, for the diffusion constants for prothrombin and factor $\mathrm{Xa}$, respectively. The diffusion constants were calculated from known values at $20^{\circ} \mathrm{C}$ (10, 24). $R$ and $Q$ are the radius of the capillaries and thevolumetric flow rate, respectively, used in our experiments.

\begin{tabular}{ccccc}
\hline Protein & $\mathrm{R}$ & $\mathrm{Q}$ & $\Delta_{\mathrm{t}}$ & $\frac{\Delta_{\mathrm{t}}{ }^{\mathrm{z}}}{}$ \\
\hline & $\mathrm{cm}$ & $\mu l / \min$ & $\mu \mathrm{l} / \mathrm{min}$ & $\mu \mathrm{l} / \mathrm{min}$ \\
prothrombin & 0.0325 & 30 & 10.8 & 13.8 \\
prothrombin & 0.0145 & 440 & 30.7 & 33.6 \\
factor Xal & 0.0325 & 30 & 11.4 & 14.6 \\
\hline
\end{tabular}

The mass transfer coefficient as determined according to Equation 2.

Since the rate of thrombin production seemed to be limited not by the prothrombinase binding capacity of the phospholipid-coated capillary, but by the rate of supply of substrate to the catalytic surface, we expected to find that the steady state rate of thrombin production should be proportional to the concentration of prothrombin in the perfusion solution (see Equation 2). Thus, phospholipid-coated capillaries were perfused with varying concentrations of prothrombin in the presence of fixed amounts of factor $\mathrm{Xa}(50 \mathrm{pM})$ and factor $\mathrm{Va}(2 \mathrm{nM})$. The steady state rates of thrombin production are presented in Table II as a function of the prothrombin concentration. It is seen that the rate of thrombin production increased linearly with the prothrombin concentration. Table II also gives the rate of transport of prothrombin to the catalytic surface as a function of the prothrombin concentration in the perfusion solution. These values were calculated as described under Experimental Procedures. The mass transfer coefficient was taken from Table I. The close agreement between experimental rate of thrombin production and the rate of 
prothrombin transport to the catalytic surface strongly indicates that the system employed behaves as predicted by the hydrodynamic theory.

Table II. Transport limited production of thrombin in the capillary flow reactor. The thrombin production was measured in a capillary of $12.7 \mathrm{~cm}$ length and a radius of $0.0325 \mathrm{~cm}$ as described under "Experimental Procedures". The flow rate was $30 \mu \mathrm{V}$ min and the transport limit was calculated as the mass transfer coefficient $(\Delta)$ times the prothrombin concentration with $\Delta_{-}=10.8 \mu \mathrm{l} / \mathrm{min}$ (Table $\mathrm{I}$ ).

\begin{tabular}{ccc}
\hline Prothrombin & Thrombin production & Transport limit \\
\hline$\mu M$ & pmol/min & pmol/min \\
0.2 & 2.6 & 2.2 \\
0.5 & 5.0 & 5.4 \\
1.0 & 10.5 & 10.9 \\
2.0 & 19.6 & 21.8 \\
\hline
\end{tabular}

Steady State Rate of Thrombin Production as a Function of Prothrombinase Surface Density. Phospholipid-coated capillaries were first perfused with factor $\mathrm{Va}$ $(2 \mathrm{nM})$ and varying concentrations of factor Xa $(2.5-100 \mathrm{pM})$ during $10 \mathrm{~min}$ at a flow rate of $30 \mu \mathrm{l} / \mathrm{min}$ to obtain controlled amounts of prothrombinase. Subsequently, the prothrombinase-containing capillaries were perfused with prothrombin $(0.5 \mu \mathrm{M})$ in the presence of factor $\mathrm{Va}(2 \mathrm{nM})$. An increase of the factor $\mathrm{Xa}$ concentration in the first perfusion solution from 2.5 to $25 \mathrm{pM}$ gave an increase of the steady state rate of thrombin production upon perfusion with $0.5 \mu \mathrm{M}$ prothrombin. Pre-perfusion of the phospholipid capillaries with factor $\mathrm{Xa}$ concentrations higher than $25 \mathrm{pM}$ did not result in higher rates of thrombin production. To assess the amount of prothrombinase in the capillary, we rinsed the capillary at the end of the perfusion experiment with EDTA and assayed the effluent for factor Xa activity. Fig.2 clearly shows that whereas the amount of factor Xa bound to the inner wall of the phospholipid coated capillary increased proportionally with the factor $\mathrm{Xa}$ concentration of the first perfusion mixture, that also contained a fixed amount of factor $\mathrm{Va}(2 \mathrm{nM})$, the steady state rate of thrombin production did not further increase when the factor $\mathrm{Xa}$ (prothrombinase) surface density was greater than $0.6 \mathrm{fmol}$ factor $\mathrm{Xa} / \mathrm{cm}^{2}$. We note that the maximum steady state rate of thrombin production in this experiment was 2.5 fold higher than the maximum rate found when a phospholipid-coated capillary was perfused with a mixture that contained factor $\mathrm{Xa}$, factor $\mathrm{Va}$ and prothrombin as shown in Fig.1. This difference in rates of thrombin production is readily explained by a 2.5 fold difference in prothrombin concentration of the perfusion solutions. It is apparent that under the conditions of this experiment (wall shear rate of $20 \mathrm{~s}^{-1}$ and prothrombin concentration of $0.5 \mu \mathrm{M}$ ) 
the rate of thrombin production becomes independent on the amount of phospholipid bound enzyme when the prothrombinase density exceeded $0.6 \mathrm{fmol} / \mathrm{cm}^{2}$.

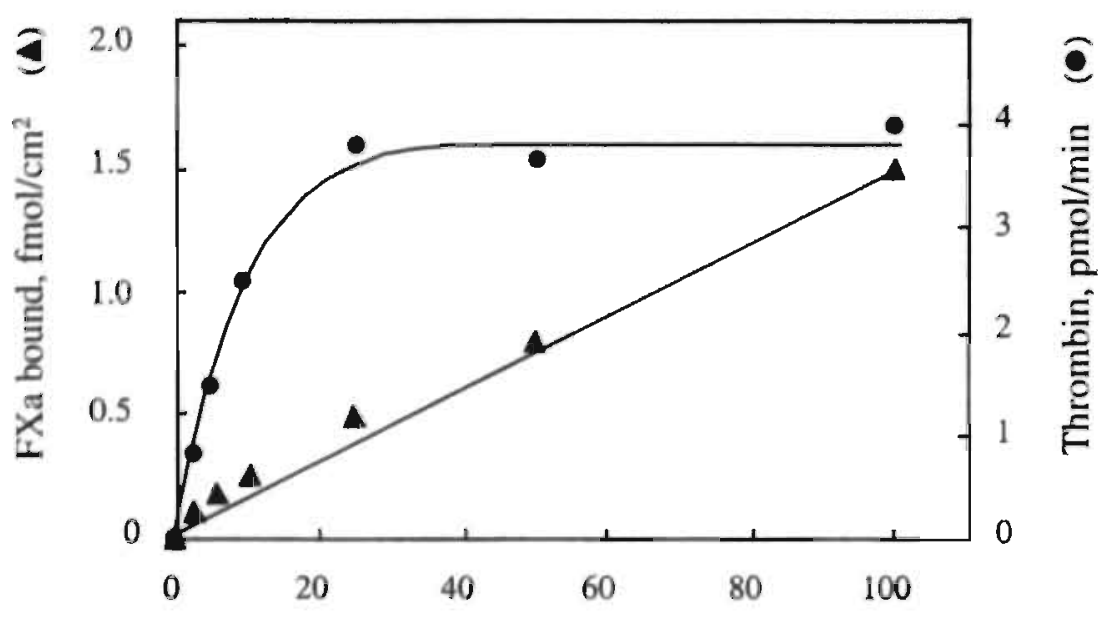

Factor Xa, pM

Figure 2. Rate of thrombin production as a function of prothrombinase density. Capillaries were first perfused with Tris. buffer containing factor $\mathrm{Xa}$, at the concentrations indicated, factor $\mathrm{Va}(2 \mathrm{nM})$ and $3 \mathrm{mM} \mathrm{CaCl}$. Steady state rates of thrombin production $(\Theta)$ were determined by perfusion with $0.5 \mu \mathrm{M}$ prothrombin and $2 \mathrm{nM}$ factor $\mathrm{Va}$. At the end of the periusion experiment the amount of phospholipid-bound factor $\mathrm{Xa}(\boldsymbol{\Delta})$ was determined by rinsing the capillary with EDTA containing Tris-buffer. The wall shear rate was $20 \mathrm{~s}^{-1}$. Further experimental conditions were as described under "Experimental Procedures".

Determination of the Kinetic Parameters of Thrombin Production by Prothrombinase in the Flow Reactor. To assess the kinetic parameters of prothrombinase bound to a macroscopic phospholipid bilayer under flow, phospholipid-coated capillaries were first perfused with $0.5 \mathrm{pM}$ factor $\mathrm{Xa}$ in the presence of $2 \mathrm{nM}$ factor $V$ a during $10 \mathrm{~min}$ at a wall shear rate of $20 \mathrm{~s}^{-1}$. This preperfusion resulted in about $0.02 \mathrm{fmol}$ prothrombinase per $\mathrm{cm}^{2}$ which was assumed to be sufficiently low to avoid significant depletion of prothrombin near the catalytic surface (Fig.2). Subsequently, the capillaries were perfused with varying concentrations of prothrombin in the presence of factor $\mathrm{Va}(2 \mathrm{nM})$ and rates of thrombin production were determined from the steady state levels of thrombin at the outlet of the flow reactor. At the end of each perfusion experiment, factor Xa was quantitatively recovered from the flow reactor to establish the prothrombinase surface density. Fig. 3 gives the rates of thrombin production obtained from perfusion experiments in which a capillary with a prothrombinase density of $0.014 \mathrm{fmol} / \mathrm{cm}^{2}$ 
was perfused with increasing prothrombin concentrations $(2-80 \mathrm{nM})$ at a wall shear rate of $20 \mathrm{~s}^{-1}$ and another capillary $\left(0.018 \mathrm{fmol}\right.$ prothrombinase $\left./ \mathrm{cm}^{2}\right)$ at a wall shear rate of $3000 \mathrm{~s}^{-1}$. The different wall shear rates were obtained by using capillaries with an internal diameter of $0.65 \mathrm{~mm}$ at a flow rate of $30 \mu \mathrm{l} / \mathrm{min}$ and capillaries with an internal diameter of $0.29 \mathrm{~mm}$ at a flow rate of $440 \mu \mathrm{l} / \mathrm{min}$.

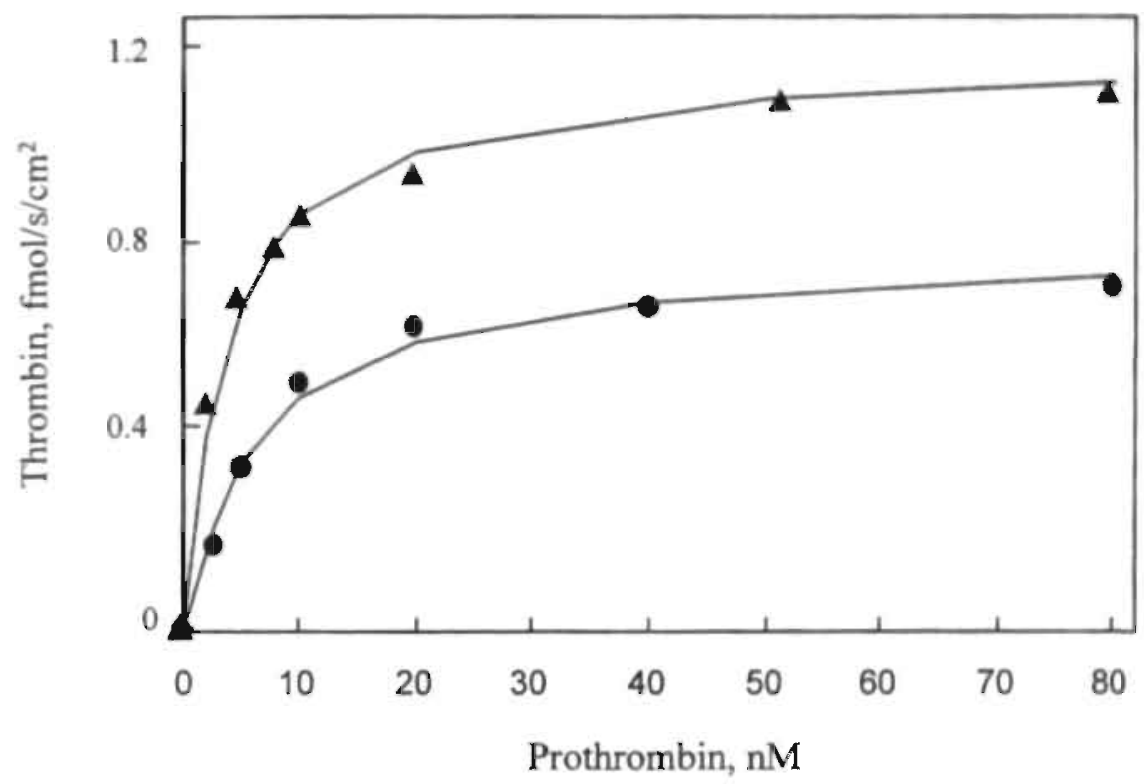

Figure 3. Rate of thrombin production as function of prothrombin concentration, shear rate and prothrombinase density Capillaries containing phospholipid bound prothrombinase, $0.014 \mathrm{fmol} / \mathrm{cm}^{2}(-)$ and $0.018 \mathrm{fmol} / \mathrm{cm}^{2}(\mathbf{A})$ were perfused with Tris-buffer containing the indicated concentrations of prothrombin, $2 \mathrm{nM}$ factor $\mathrm{Va}$ and $3 \mathrm{mM} \mathrm{CaCl}$, at a wall shear rate of $20 \mathrm{~s}^{-1}(\boldsymbol{)})$ and $3000 \mathrm{~s}^{-1}(\boldsymbol{\Delta})$. The solid lines represent the result of a non-linear fit to the Michealis-Menten equation. The estimated kinetic parameters are listed in Table III.

The data as shown in Fig.3 were analysed by a non-linear fit to a rectangular hyperbola to obtain apparent $\mathrm{K}_{\mathrm{m}}$ and $\mathrm{V}_{\max }$ values. The calculated data points are presented by the solid line. The same experiment was performed with a 2-3 fold higher prothrombinase density in the flow reactor. Table III summarizes the apparent kinetic constants that were determined under the different experimental conditions. A large variation in $\mathrm{K}_{\mathrm{m}}$ as well as $\mathrm{k}_{\text {cat }}$ is seen. Note-worthy is the high $\mathrm{K}_{\mathrm{m}}$ when a small-diameter capillary with a high prothrombinase density is perfused with prothrombin at a low wall shear rate. This difference is readily explained by depletion of prothrombin near the catalytic surface. That is, when thrombin production is partly limited by the transport of prothrombin to the catalytic surface, higher prothrombin concentrations in the perfusion solution are required to saturate half the 
prothrombinase in the flow reactor. Kinetic parameters should be calculated from the steady state rate of thrombin production and the prothrombin concentration near the catalytic surface. Therefore, $\mathbf{K}_{\mathrm{m}}$ and $\mathrm{k}_{\mathrm{cat}}$ values were obtained by fitting observed rates of thrombin production and prothrombin concentrations in the perfusion solution to Equation 9 (see Experimental Procedures). The intrinsic kinetic parameters thus obtained are also listed in Table III. From these data we conclude that both $\mathrm{K}_{\mathrm{m}}$ and $\mathrm{k}_{\mathrm{cat}}$ are independent of the experimental conditions such as the prothrombinase density and the wall shear rate. Of particular interest is the low $\mathrm{K}_{\mathrm{m}}$ of $3 \mathrm{nM}$.

Table III. Intermediate kinetics of thrombin production in the capillary flow reactor. The thrombin production as function of the prothrombin concentration was measured in a capillary of $12.7 \mathrm{~cm}$ length at the indicated capillary radius ( $R$ ), flow rate (Q) and surface enzyme density $\left(E_{\mathrm{s}}\right)$. The mass transfer coefficient $\Delta$ is expressed in $\left(\mu 1 / \mathrm{cm}^{2} / \mathrm{min}\right)$ in order to facilitate comparison between different capillaries. Further details are described in the text.

\begin{tabular}{cccccccc}
\hline & \multicolumn{3}{c}{ Experimental conditions } & \multicolumn{4}{c}{ Kinetic parameters } \\
\hline $\mathrm{E}_{\mathrm{w}}$ & $\mathrm{R}$ & $\mathrm{Q}$ & $\Delta$ & $\mathrm{K}_{\mathrm{m}}$ & $\mathrm{k}_{\text {cat }}$ & $\mathrm{K}_{\mathrm{m}}$ & $\mathrm{k}_{\text {cat }}$ \\
\hline $\mathrm{fmol} / \mathrm{cm}^{2}$ & $\mathrm{~cm}$ & $\mu \mathrm{l} / \mathrm{min}$ & $\mu \mathrm{l} / \mathrm{cm}^{2} / \mathrm{min}$ & $\mathrm{nM}$ & $\mathrm{s}^{-1}$ & $\mathrm{nM}$ & $\mathrm{s}^{-1}$ \\
0.014 & 0.0325 & 30 & 4.2 & 6.6 & 57.5 & 1.3 & 51.6 \\
0.018 & 0.0145 & 440 & 26.6 & 3.9 & 67.5 & 2.8 & 66.5 \\
0.047 & 0.0325 & 30 & 4.2 & 75.4 & 138.0 & 3.1 & 74.4 \\
0.035 & 0.0145 & 440 & 26.6 & 4.6 & 54.2 & 2.0 & 49.8 \\
\hline
\end{tabular}

\section{Discussion}

We have characterized the kinetics of prothrombin activation by the complex of factor $\mathrm{Va}$ and factor $\mathrm{Xa}$ assembled at the macroscopic phospholipid surface of a tubular flow reactor. The present study confirms an earlier observation from our group $(10,11)$ that on macroscopic lipid bilayers the Michaelis constant, $K_{m}$, is much lower than reported for prothrombin activation at the surface of unilamellar vesicles with a radius of 20-30 nm. It was noticed that the $K_{m}$ decreased with increasing phospholipid area per molecule of the factor $\mathrm{Xa}$-factor $\mathrm{Va}$ complex. Indeed the $\mathrm{K}_{\text {m }}$ was depressed by a factor of 4 when large unilamellar vesicles (radius of $60-80 \mathrm{~nm}$ ) were used. Moreover, it was shown that on planar phospholipid bilayers, with an area of $1 \mu \mathrm{m}^{2}$ per prothrombinase complex, the $K_{\mathrm{m}}$ was 6-7 nM and thus 25 -fold smaller than the $\mathrm{K}_{\mathrm{m}}(170 \mathrm{nM})$ on small unilamellar vesicles. This marked difference was attributed to an efficient collection of prothrombin from solution by a macroscopic surface, whereas the $\mathrm{K}_{\mathrm{m}}$ on small unilamellar vesicles represents an apparent value reflecting the limited transport rate of prothrombin from solution to 
the vesicle $(10,11)$. The phospholipid bilayers in these studies were present on a slide opposite a stirring bar or on a rotating disc. Especially the latter system has the advantage that it presents an uniform accessible surface, with a uniform mass transfer coefficient over the entire surface. The capillary flow system used in the present study, has the advantage of an extremely stable and well defined fluid flow. Another advantage is the high surface/volume ratio $\left(0.05 \mathrm{~cm}^{2} / \mu \mathrm{l}\right)$ of the capillary. Its potential disadvantage is the steep decline of the mass transfer rate in the down stream direction (Equation 3 ). This could complicate the analysis of the intermediate enzyme kinetics. This potential disadvantage is however largely circumvented by the transport limited assembly of prothrombinase (see below), which implies a local prothrombinase activity proportional to the mass transfer coefficient and therefore the applicability of Equations 8 and 9 (see Experimental Procedures) for the analysis of the experimental data.

Our initial experiments, in which the phospholipid-coated capillary was perfused with a solution of factor $\mathrm{Xa}$, factor $\mathrm{Va}$ and prothrombin showed that at a shear rate of $20 \mathrm{~s}^{-1}$ the rate of thrombin production became independent of the prothrombinase density at the surface when that density was greater than $1 \mathrm{fmol} / \mathrm{cm}^{2}$ and the prothrombin concentration of the perfusion solution was $0.5 \mu \mathrm{M}$. From reported binding data (20-22) we could calculate a maximum binding capacity of our phospholipid bilayer between 2 and 10 pmol prothrombinase $/ \mathrm{cm}^{2}$. Thus, a fractional occupation of about $0.05 \%$ is sufficient to enter a regime of thrombin production that is controlled by the mass transfer rate of prothrombin. From the data shown in Fig. I we also could estimate the rate at which prothrombinase was assembled during the initial phase of the thrombin production curve. If we assume a turnover of $60 \mathrm{~s}^{-1}$ (Table III) then the initial slopes of thrombin production indicate rates of prothrombinase formation of $0.05,0.10$ and $0.18 \mathrm{fmol} / \mathrm{min}$ with respectively 5,10 and $20 \mathrm{pM}$ factor $\mathrm{Xa}$ in the perfusion mixtures. As a matter of fact these rates of prothrombinase formation are in good agreement with the mass transfer of $0.01 \mathrm{fmol}$ factor $\mathrm{Xa} / \mathrm{min} / \mathrm{pM}$ factor $\mathrm{Xa}$ in the perfusate (Table I).

The validity of our theoretical considerations regarding the thrombin production data in the flow reactor became also evident from the excellent agreement between the observed steady state rates of thrombin production under diffusion-controlled conditions (high prothrombinase density and low wall shear rate) and the calculated mass transfer of prothrombin as shown in Table II. We like to note that the theory was developed for reactions at a homogeneously catalytic surface like that of platinum. The fact that catalysis at a macroscopic surface with a very low enzyme density follows the same theory is compatible with the notion that the lateral diffusion of reactants at the surface exceeds the flux of reactants towards the apparent non-homogeneously catalytic surface (11). 
When capillaries with prothrombinase density below $0.6 \mathrm{fmol} / \mathrm{cm}^{2}$ were perfused with $0.5 \mu \mathrm{M}$ prothrombin at a wall shear rate of $20 \mathrm{~s}^{-1}$, the steady state rate of thrombin production became a linear function of the surface density of prothrombinase (Fig.2). Yet, we have to emphasize that this observation does not exclude prothrombin depletion at the catalytic surface. As outlined under Experimental Procedures, thrombin production causes a partial dependency of the rate of thrombin production on the mass transfer rate of prothrombin to the catalytic surface. This is clearly demonstrated by the results presented in Table III. The apparent $\mathrm{K}_{\mathrm{m}}$ for prothrombin is much higher at a low shear rate and high prothrombinase density than the $\mathrm{K}_{\mathrm{m}}$ determined under conditions where much less depletion of prothrombin near the catalytic surface was expected. The apparent difference in $\mathrm{K}_{\mathrm{m}}$ disappeared when the prothrombin concentration was corrected for depletion of prothrombin near the catalytic surface (Equation 9). The results as summarized in Table III, show that both the $\mathrm{V}_{\max }$ and $\mathrm{K}_{\mathrm{m}}$ did not vary with the shear rate. In this respect prothrombinase bound to a macroscopic surface seems to behave differently from the factor $\mathrm{X}$ converting complex, tissue factor-factor VIla Nemerson and co-workers reported that the $\mathrm{V}_{\max }$ of factor $\mathrm{X}$ activation in a tubular flow reactor increased with increasing wall shear rate $(13,14)$.

Whereas the $\mathrm{k}_{\text {cat }}$ value for prothrombin activation in the tubular flow reactor is in accordance with those reported for prothrombin activation by prothrombinase in a vesicle system $(3,4)$, we found a much lower $K_{m}$. However, the value, $3 \mathrm{nM}$, is in close agreement with the $\mathrm{K}_{\mathrm{m}}$ value $(6 \mathrm{nM})$ determined for phospholipid bilayers on a rotating disc (10).

The Michaelis constant observed for macroscopic lipid bilayers, which is about thousand fold lower than the plasma concentration of prothrombin, might have interesting implications for the regulation of thrombin generation in vivo. This low value of $\mathrm{K}_{\mathrm{m}}$ implies the existence of two control regimes: i) for low surface densities of prothrombinase, with $\mathrm{V}_{\max }$ below the mass transfer coefficient times the plasma concentration of prothrombin, the thrombin generation is completely determined by the amount of prothrombinase and ii) for high surface concentrations of prothrombinase the thrombin generation rate is completely determined by the transport limit and thus by the plasma concentration of prothrombin. The two regimes might also have consequences for the inhibitor-regulated thrombin production. Because of the high catalytic efficiency of prothrombinase for prothrombin, inhibition by pseudo-substrates, like antithrombin, is hardly to be expected. However, when thrombin production is limited by the supply of substrate, inhibition by pseudo-substrates has to be expected, but will not result in a reduced rate of thrombin production. In this respect, it is of interest to see that these transport 
phenomena have the very same implications for other surface-bound reactions involved in blood coagulation, like the activation of factor X (23).

\section{References}

1. Jackson, C. M., and Nemerson, Y. 1980. Annu. Rev. Biochem. 49: 765-811

2. Mann, K. G., Nesheim, M. E., Church, W. R., Haley, P., and Krishnaswamy, S. 1990. Blood 76: 1-16

3. Nesheim, M. E., Taswell, J. B., and Mann, K. G. 1979. J. Biol. Chem. 254: 10952-10962.

4. Rosing. J., Tans, G., Govers-Riemslag, J. W. P., Zwaal, R. F. A., and Hemker, H. C. 1980. J. Biol. Chem. $255: 274-283$.

5. Bevers, E, Comfurius, P. van Rijn, J. M. M. L, Hemker, H. C., and Zwaal, R. F. A. 1982. Eur. J. Biochem. $122: 429-436$.

6. Mann, K. G. (1987). Trends Biochem. Sci. 12 229-233.

7. Tracy, P. B., Nesheim, M. E., and Mann, K. G. 1981. J. Biol. Chem. 256: 743-751

8. Rodgers, G. M., and Shuman, M. A. 1983. Proc. Natl. Acad. Sci. USA 80: 7001-7005

9. Schoen, P., Lindhout, T., Willems, G., Hemker, H. C. 1990 Thromb. Haemostas. 64: 542-547.

10. Willems, G. M., Giesen, P.L. A., and Hermens, W. Th. 1993. Blood 82: 497-504

11. Giesen, P. L. A., Willems, G. M., and Hermens, W. Th. 1991. J. Biol. Chem. 266: 1379-1382

12 Brown, G. M. 1960. A. I. Ch. E. Journal 6. p.179-183

13. Gemmell, C. H., Turitto, V. T., and Nemerson, Y. 1988. Blood 72: 1404-1406

14. Gemmell, C. H. Nemerson, Y., and Turitto, V. 1990. Microvascular Research 40: 327-340

15. Rosing, J., Balder, H. M., Thomasen, M. C. L. G. D. Hemker, H. C, and Tans, G. 1993. J. Biol. Chem. $268: 21130-21136$.

16. Contino, P., Repke, D, and Nemerson, Y. 1991. Thromb. Haemostas. 66: 138-140

17. Levich, V. G. 1962. Physicochemical Hydrodynamics, pp 112-116, Prentice-Hall, Englewood Cliffs, NJ.

18. Kobayashi, T., and Laidler, K. J. 1974. Biotechn. and Bioeng. 66: 99-118

19. Leveque, M.A. 1928. Ann. Mines Mem. 13: 201-239

20. Pusey, M.L., Mayer, L.D., Wei, G.J., Bloomfield, V.A. and Nelsestuen, G.L. 1982. Biochemistry 21, $5262-5269$

21. Higgins, D. L., and Mann, K.G. 1983, J. Biol. Chem. 258, 6503-6508

22. Krishnaswamy. S. 1990. J. Biol. Chem. 265, 3708-3718

23. Andree. H. A. M., Contino, P. B., Repke, D., Gentry, R., and Nemerson, Y. 1994. Biochemistry 33. 4368-4374

24. Lim, T. K., Bloomfield, V. A., and Nelsestuen, G. L. 1977. Biochemistry 16, 4177-4181 



\section{Chapter 4}

\section{Inhibition of Prothrombinase by Antithrombin-Heparin at a Macroscopic Surface.}

Han Speijer, Didier Billy, George Willems, H. Coenraad Hemker and Theo Lindhout, 1995. Thrombosis and Haemostasis, 73: 648-653.

\section{Summary}

The antithrombin-dependent inhibition of prothrombinase, assembled at a macroscopic surface, was studied under flow conditions utilizing a tubular flow reactor that consists of a phospholipid-coated glass capillary. Prothrombinase activity was determined from steady-state rates of thrombin production upon perfusion with prothrombin and from factor $\mathrm{Va}$-associated factor $\mathrm{Xa}$ activity present in the flow reactor. The prothrombinase density was maintained at a low level $(0.03$ $\mathrm{fmol} / \mathrm{cm}^{2}$ ) to assure that the rate of thrombin production reflected the amount of prothrombinase present in the capillary. Perfusion of the flow reactor with antithrombin resulted in an exponential decrease of prothrombinase activity in time. The second order rate constant $\left(8.5 \times 10^{4} \mathrm{M}^{-1} \mathrm{~min}^{-1}\right)$ is comparable with the rate of inactivation of free factor $\mathrm{Xa}$. Inhibition was much faster when antithrombin was complexed with heparin. The second order rate constants of inhibition decreased with decreasing heparin chain length: $9.6 \times 10^{7}, 4.5 \times 10^{7}$ and $0.39 \times 10^{7} \mathrm{M}^{-1} \mathrm{~min}^{-1}$ for unfractionated heparin, low molecular weight heparin and synthetic pentasaccharide heparin, respectively. In the presence of prothrombin $(0.2 \mu \mathrm{M})$, however, the heparin-dependent rate of inhibition of prothrombinase was about 50-fold lower. The heparin-independent inhibition of prothrombinase by antithrombin $(4 \mu \mathrm{M})$ in the presence of prothrombin $(0.2 \mu \mathrm{M})$ was virtually negligible. At a 70 -fold higher surface density of prothrombinase $\left(2 \mathrm{fmol} / \mathrm{cm}^{2}\right)$ prothrombinase activity was much faster inactivated. The rate of thrombin production, however, was not affected. In conclusion, at low prothrombinase densities, prothrombin efficiently protects prothrombinase from inhibition. At high densities, prothrombinase is much less protected but the higher rate of prothrombinase inactivation has no consequences for the thrombin production because of the transport-limited regime.

\section{Introduction}

Upon vessel wall damage, blood coagulation is triggered, leading to a number of proteolytic reactions which finally result in the formation of fibrin. One of the central reactions in the cascade of coagulation reactions is the factor Xa-catalyzed activation of prothrombin. The rate of this thrombin-forming reaction is enhanced dramatically by the non-enzymatic cofactor factor $\mathrm{Va}$, calcium ions and phospholipid 
surfaces (1-3). In vivo, the phospholipid surface is thought to be provided by activated blood platelets or damaged cells present at the site of injury (4-6). In this way propagation of blood coagulation may be restricted to the region of the damaged vessel wall. Termination of the process of thrombin generation is thought to be caused by the thrombin-mediated elimination of the cofactors Va and VIIIa (7) and by the inactivation of the serineproteases factor $\mathrm{Xa}$ and thrombin by the plasma inhibitor antithrombin $(8,9)$. The latter reactions are dramatically enhanced by heparin (10-13), a widely used anticoagulant drug. Yet, inhibition of clot-bound thrombin and factor Xa are hardly affected by heparin (14-16).

A number of studies have demonstrated that phospholipids and factor $\mathrm{Va}$ protect factor Xa from inhibition by antithrombin-heparin (17-23). This protection was even more pronounced when the reaction was studied in a tubular flow reactor (24). Recent work from our laboratory (25) has indicated that the catalytic efficiency of prothrombinase in a tubular flow reactor is about two orders of magnitude higher than in a vesicle system. Consequently, inhibition of prothrombinase in a tubular flow reactor could be subject to protection by substrate competition. On the other hand, however, it has also to be expected that because of the extremely high catalytic efficiency of prothrombinase at a macroscopic surface, prothrombin activation can become easily diffusion-controlled (25). Prothrombin concentrations near the catalytic surface then fall to values below the $\mathrm{K}_{\mathrm{m}}$ value and protection by prothrombin will be abolished.

In this report, we present the results of a kinetic study on the inhibition of prothrombinase by antithrombin and heparin in a tubular flow reactor. Using different enzyme surface densities, we studied inhibition under conditions where the catalytic activity of prothrombinase sets the pace and under conditions where transport of prothrombin to the catalytic surface limits the reaction rate. As long as thrombin formation was not significantly limited by the transport rate of prothrombin, no inhibition of prothrombinase by plasma concentrations of antithrombin was observed. Only in the presence of heparin significant inhibition of thrombin generation was found.

\section{Experimental Procedures}

Materials. S2238, chromogenic substrate for thrombin, was obtained from Chromogenix (Mölndal, Sweden). Bovine serum albumin (fatty acid-free), egg phosphatidylcholine (PC) and brain phosphatidylserine (PS) were from Sigma (St. Louis, USA). Glass capillaries with a length of $127 \mathrm{~mm}$ and an internal diameter of $0.65 \mathrm{~mm}$ ( $42 \mu \mathrm{I}$ volume) were obtained from Brand AG (Wertheim, Germany). The $4^{\text {th }}$ international Standard for Heparin (UFH) was a gift from the National Institute for Biological Standards and Control (Potters Bar, UK). Its potency was stated as 
193 I.U. per mg. The low molecular weight heparin (LMWH), enoxaparin (98 antiXa IU/mg), was obtained from Rhône-Poulenc Rorer, France. The synthetic pentasaccharide heparin (1140 anti-Xa IU/mg) was from the Choay Institute (Paris, France). The molar concentrations of heparin species with high affinity for antithrombin were determined in each of the preparations by stoichiometric titration of antithrombin (26). The molar amounts of antithrombin high affinity material in $1 \mathrm{~g}$ of UFH, LMWH and pentasaccharide were $35 \mu \mathrm{mol}, 29 \mu \mathrm{mol}$ and $470 \mu \mathrm{mol}$, respectively. Bovine factor $\mathrm{Va}$, human prothrombin, human factor $\mathrm{Xa}$ and human antithrombin were purified and quantified as described $(23,27)$.

Flow reactor. The preparation of phospholipid-coated capillaries and the flow system were as described previously (25). Briefly, the capillary $(0.65 \mathrm{~mm}$ internal diameter and $127 \mathrm{~mm}$ length) was filled with a suspension of unilamellar phospholipid vesicles composed of $75 \mathrm{~mol} \%$ egg phosphatidylcholine and $25 \mathrm{~mol} \%$ brain phosphatidylserine in Tris-buffer ( $50 \mathrm{mM}$ Tris- $\mathrm{HCl}, 175 \mathrm{mM} \mathrm{NaCl}, 0.5 \mathrm{mg} / \mathrm{ml}$ bovine serum albumin, $\mathrm{pH}$ 7.9). After $20 \mathrm{~min}$ of incubation with the $1 \mathrm{mM}$ phospholipid suspension, the capillary was rinsed with Tris-buffer containing $3 \mathrm{mM}$ $\mathrm{CaCl}_{2}$ at a flow rate of $1.2 \mathrm{~mL} / \mathrm{min}$ for $2 \mathrm{~min}$ to remove non-bound phospholipid. The phospholipid-coated capillary was attached to a Hamilton gas-tight syringe. The flow was controlled by a syringe purnp (Harvard Apparatus Co., South Natick, Massachusetts, USA). An XYZ translation table (Isel AG, Eiterfelt, Germany) was used to collect samples (typically $30 \mu \mathrm{l}$ ) from the tip of the flow reactor into disposable cuvettes (Sarstedt, Nymbrecht, Germany) containing $20 \mathrm{mM}$ EDTA in Tris-buffer. Thrombin was measured in the cuvette after the addition of the chromogenic substrate S2238. All procedures were performed at $37^{\circ} \mathrm{C}$.

Inhibition of prothrombinase activity. The phospholipid-coated capillaries were perfused with a mixture of factor $\mathrm{Xa}$ and factor $\mathrm{Va}(2 \mathrm{nM})$ for $10 \mathrm{~min}$ at $30 \mu \mathrm{l} / \mathrm{min}$ (shear rate $20 \mathrm{~s}^{-1}$ ) to bind a fixed amount of prothrombinase. The factor $\mathrm{Xa}$ concentration in the perfusion mixture was varied to obtain prothrombinase surface densities of about 0.03 and $2 \mathrm{fmol} / \mathrm{cm}^{2}$. The thrombin production was measured by perfusion of the capillaries with factor $\mathrm{Va}(2 \mathrm{nM})$ and prothrombin $(200 \mathrm{nM})$. Samples $(30 \mu \mathrm{l})$ of the effluent were collected every minute into cuvettes containing $500 \mu \mathrm{l}$ Tris-buffer containing $20 \mathrm{mM}$ EDTA. After addition of $60 \mu \mathrm{l}$ chromogenic substrate S2238 (2.5 mM) thrombin was measured as described (25). Inhibition of prothrombinase was studied by perfusion with a mixture containing factor Va ( $2 \mathrm{nM})$ and varying amounts of antithrombin or antithrombin-heparin, either in the absence or presence of $200 \mathrm{nM}$ prothrombin.

Determination of factor Xa activity bound to the surface of the phospholipidcoated capillaries. The residual factor $\mathrm{Xa}$ activity bound to the phospholipid bilayer was determined at the end of an inhibition experiment. The capillaries were washed 


\section{Chapter 4}

for $5 \mathrm{~min}$ at $30 \mu \mathrm{l} / \mathrm{min}$ with Tris buffer ( $50 \mathrm{mM}$ Tris- $\mathrm{HCl}, 175 \mathrm{mM} \mathrm{NaCl}$, and $0.5 \mathrm{mg}$ $\mathrm{BSA} / \mathrm{ml}, \mathrm{pH} 7.9$ ) to remove thrombin and were subsequently perfused for $5 \mathrm{~min}$ at 30 $\mu \mathrm{l} / \mathrm{min}$ with a Tris-EDTA buffer $(50 \mathrm{mM}$ Tris, $175 \mathrm{mM} \mathrm{NaCl}, 5 \mathrm{mM}$ EDTA, 0.5 $\mathrm{mg} / \mathrm{ml} \mathrm{BSA}$ ) to remove all bound factor $\mathrm{Xa}$. The factor $\mathrm{Xa}$ activity present in the effluent was determined via a bioassay as described (25).

Effect of transport limit on the kinetics of prothrombin activation in the flow reactor. Thrombin generation by prothrombinase bound to macroscopic surfaces easily becomes limited by the transfer of prothrombin from bulk solution to the catalytic surface. Efficient conversion of the prothrombin at the surface results in depletion of the protein in the solution near the surface. The transport of protein to the wall of the tubular flow reactor, $J$ ( $\mathrm{pmol} / \mathrm{min}$ ), is proportional to the difference between the protein concentration $\mathrm{C}_{\mathrm{b}}(\mathrm{pmol} / \mathrm{ml})$ in the bulk solution and $\mathrm{C}_{\mathrm{b}}$ (pmol/ml), the protein concentration near the capillary wall (28):

$$
\mathrm{J}=\Delta\left(\mathrm{C}_{\mathrm{b}}-\mathrm{C}_{0}\right)
$$

with the transport coefficient $\Delta\left(\mathrm{cm}^{3} / \mathrm{min}\right)$ as a function of the geometry of the capillary, the volumetric flow rate, the kinematic viscosity of the fluid and the diffusion coefficient of the protein. For the flow rate of $30 \mu \mathrm{l} / \mathrm{min}$ and the capillary (length $12.7 \mathrm{~cm}$ and inner diameter of $0.065 \mathrm{~cm}$ ) used in this study, the transport coefficient for prothrombin equals $0.0108 \mathrm{~cm}^{3} / \mathrm{min}(25)$.

The resulting thrombin production is further determined by the intrinsic conversion kinetics $J_{\text {intr }}$ ( $\mathrm{pmol} / \mathrm{min}$ ) which depends on the concentration of prothrombin $\left(\mathrm{C}_{0}\right)$ at the capillary wall, on the amount of prothrombinase bound to the phospholipid bilayer in the capillary $(\mathrm{E})$, the turnover number of the enzyme $\left(\mathrm{k}_{\mathrm{cat}}\right)$ and the Michaelis constant $\left(\mathrm{K}_{\mathrm{m}}\right)$ :

$$
\mathrm{J}_{\text {intr }}=\mathrm{k}_{\mathrm{cat}} \mathrm{EC}_{0} /\left(\mathrm{K}_{\mathrm{m}}+\mathrm{C}_{0}\right)
$$

In a previous study (25) we showed that equations 1-2 allow an adequate description of observed prothrombin conversion kinetics with values $\mathrm{k}_{\mathrm{car}}=3600 \mathrm{~min}^{-1}$ and $\mathrm{K}_{\mathrm{m}}=3 \mathrm{nM}$.

\section{Results}

Inhibition of prothrombin activation by antithrombin. Phospholipid-coated capillaries were perfused with factor $\mathrm{Xa}(! \mathrm{pM})$ and factor $\mathrm{Va}(2 \mathrm{nM})$ for $10 \mathrm{~min}$ at $30 \mu \mathrm{l} / \mathrm{min}$. These capillaries were then perfused with prothrombin $(0.2 \mu \mathrm{M})$ and factor $\mathrm{Va}(2 \mathrm{nM})$. The average steady state thrombin concentration at the outlet was $12 \pm 0.2 \mathrm{nM}(\mathrm{n}=5)$ and resulted from a steady state rate of thrombin production at the wall of the capillary of about $0.36 \mathrm{pmol} / \mathrm{min}$. This steady state rate of thrombin 


\section{Chapter 4}

production is well below the transport limit, $\Delta \mathrm{C}_{\mathrm{b}}=2.2 \mathrm{pmol} / \mathrm{min}$ (see Experimental Procedures). We previously demonstrated that under these conditions thrombin production is proportional to the prothrombinase activity (25). The prothrombinase concentration as measured from the amount of factor Xa bound to the phospholipid surface in the tubular flow reactor was $0.09 \pm 0.01 \mathrm{fmol}($ mean $\pm S D, n=5)$.

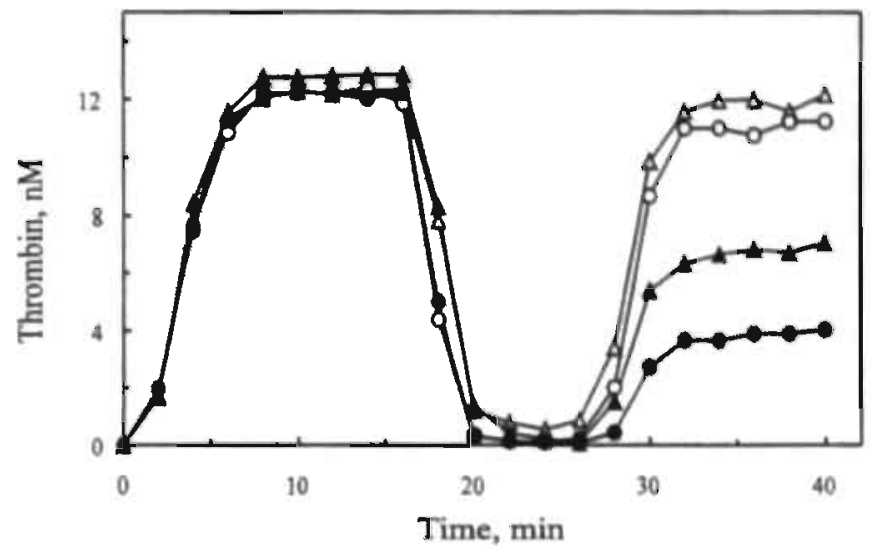

Figure 1. Inhibition of prothrombinase by antithrombin. Prothrombinase-containing capillaries were prepared by perfusing phospholipid-coated capillaries with 1 pM factor $\mathrm{Xa}$ and $2 \mathrm{nM}$ factor $\mathrm{Va}$ for 10 min. Prothrombinase densities were $0.037 \mathrm{fmol} / \mathrm{cm}^{2}$. Then thrombin production was started by perfusion with prothrombin $(0.2 \mu \mathrm{M})$ and factor $\mathrm{Va}(2$ $\mathrm{nM}$ ). After 16 min the perfusion mixture was changed to a mixture containing $2 \mathrm{nM}$ factor $\mathrm{Va}(\Delta)$, and $2 \mu \mathrm{M}$ antithrombin and $0.2 \mu \mathrm{M}$ prothrombin (O); $4 \mu \mathrm{M}$ antithrombin and $0.2 \mu \mathrm{M}$ prothrombin; $(\boldsymbol{\Lambda}), 2 \mu \mathrm{M}$ antithrombin; or $(\boldsymbol{O}), 4 \mu \mathrm{M}$ antithrombin. After $24 \mathrm{~min}$ the perfusion was continued with prothrombin $(0.2 \mu \mathrm{M})$ and factor $\mathrm{Va}(2 \mathrm{nM})$, Thrombin concentrations at the outlet are plottedversus the perfusion time. Flow rate was $30 \mu \mathrm{l} / \mathrm{min}$ with a wall shear rate of $20 \mathrm{~s}^{\prime}$.

As shown in Fig.1, perfusion with prothrombin $(0.2 \mu \mathrm{M})$ and factor $\mathrm{Va}(2 \mathrm{nM})$ resulted after $7 \mathrm{~min}$ in a stable level of thrombin formation. When perfusion was continued with a mixture containing prothrombin $(0.2 \mu \mathrm{M})$, factor $\mathrm{Va}(2 \mathrm{nM})$ and antithrombin $(2 \mu \mathrm{M})$, thrombin levels at the outlet of the capillary decreased. The disappearance of the amidolytic activity was due to neutralization of formed thrombin by antithrombin. We emphasize that the absence of thrombin activity at the outlet of the capillary because of inactivation by antithrombin during its residence time of more than $1 . \mathrm{min}$ in the capillary does not necessarily mean that the level of active thrombin is reduced at the site of its production. Continuation of the perfusion with prothrombin $(0.2 \mu \mathrm{M})$ and factor $\mathrm{Va}(2 \mathrm{nM})$ resulted in the same thrombin level as before the inhibition step. Perfusion of the capillary at the end of the experiment with EDTA and determination of factor Xa activity in the effluent demonstrated the same molar concentration of factor $\mathrm{Xa}\left(0.034 \mathrm{fmol}\right.$ factor $\left.\mathrm{Xa} / \mathrm{cm}^{2}\right)$ as in an untreated capillary $\left(0.037 \mathrm{fmol}\right.$ factor $\left.\mathrm{Xa} / \mathrm{cm}^{2}\right)$. Increasing the antithrombin concentration in 
the inhibitory perfusion step to $4 \mu \mathrm{M}$ did not affect the thrombin generating capacity, nor the amount of factor $\mathrm{Xa}\left(0.034 \mathrm{fmol}\right.$ factor $\left.\mathrm{Xa} / \mathrm{cm}^{2}\right)$ bound to the phospholipid layer in the capillary. These results thus indicate that prothrombinase inhibition during prothrombin activation by antithrombin is negligible small.

However, when prothrombin was omitted from the perfusion mixture during the perfusion with factor $\mathrm{Va}$ and antithrombin, we found that upon perfusion with 2 and $4 \mu \mathrm{M}$ antithrombin the factor $\mathrm{Xa}$ activity in the capillaries decreased from $0.037 \mathrm{fmol}$ factor $\mathrm{Xa} / \mathrm{cm}^{2}$ to $0.020 \mathrm{fmol}$ factor $\mathrm{Xa} / \mathrm{cm}^{2}$ and 0.012 fmol factor $\mathrm{Xa} / \mathrm{cm}^{2}$, respectively. These values paralleled the reduction of the thrombin activity at the outlet of the capillary (Fig.1).

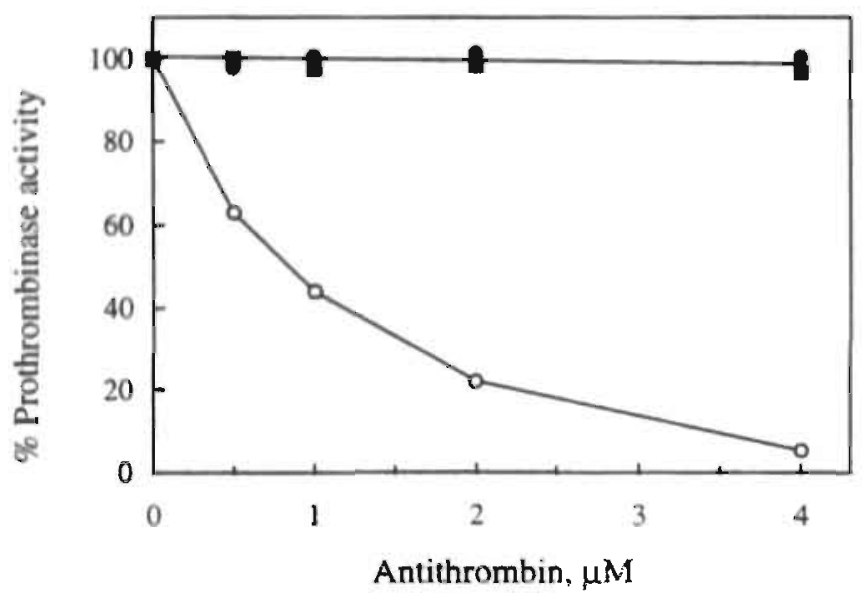

Figure 2. Effect of antithrombin concentration on prothrombinase inhibition. Prothrombinase-containing capillaries were prepared as described in the legend to Fig. 1. To assess the inhibition of prothrombinase by antithrombin in the absence of prothrombin, the capillaries were first rinsed by a 5-mini perfusion with factor $\mathrm{Va}(2 \mathrm{nM})$, followed by 8 min perfusios with antithrombin and factor $\mathrm{Va}(2 \mathrm{nM})$. Then the capiliaries were rinsed again with factor $\mathrm{Va}(2 \mathrm{nM})$ and percentage of residual prothrombinase activity (Q), was determined as bound factor $\mathrm{Xa}$ activity (see Experimental Procedures) Înhibition of prothrombinase by varying antithrombin concentrations was also examined during prothrombin activation. Residual prothrombinase activities (-) were determined by comparing the steady state of thrombin production before and after an 8-min perfusion with antithrombin, prothrombin $(0.2 \mu \mathrm{M})$ and factor $\mathrm{Va}(2 \mathrm{nM})$. Alternatively, inhibition of prothrombinase in these capillaries was also assessed from the amount of factor Xa activity that could be eluted with Tris EDTA (a). Wall shear rate was $20 \mathrm{~s}^{-1}$

Fig.2 summarizes the residual prothrombinase activities as assessed from the steady state of thrombin production and factor Xa measurements, after perfusion with varying amounts of antithrombin either in the absence or presence of $0.2 \mu \mathrm{M}$ prothrombin. It is clearly shown that during prothrombin activation, prothrombinase bound at the phospholipid surface in the flow reactor was virtually insensitive to inhibition by antithrombin. In the absence of prothrombin, prothrombinase 


\section{Chapter 4}

inactivation by antithrombin is much faster and increased with the antithrombin concentration.

In order to obtain quantitative data on prothrombinase inhibition in the flow reactor, inhibition by antithrombin in the absence of prothrombin was measured as function of the perfusion time with inhibitor. Capillaries containing prothrombinase at a surface density of $0.022 \mathrm{fmol} / \mathrm{cm}^{2}$ were perfused with antithrombin $(0.5 \mu \mathrm{M})$ and factor Va $(2 \mathrm{nM})$ for different time periods. The extent of inhibition of prothrombinase was assessed from the factor Xa activity that was eluted from the capillaries with EDTA. As expected for pseudo-first order kinetics a linear relationship was found between the logarithm of residual factor $\mathrm{Xa}$ activity and the perfusion time (data not shown). A replot of the pseudo first order rate constant of inhibition versus the antithrombin concentration (Fig.3) yields a second order rate constant of prothrombinase inhibition of $0.85 \times 10^{5} \mathrm{M}^{-1} \mathrm{~min}^{-1}$. For prothrombinase inactivation during prothrombin activation the extent of inhibition was too small to allow estimation of this rate constant with acceptable accuracy. Only a upper limit can be given. In the presence of $0.2 \mu \mathrm{M}$ prothrombin the second order rate constant of prothrombinase inhibition is less than $2 \times 10^{3} \mathrm{M}^{-1} \mathrm{~min}^{-1}$.

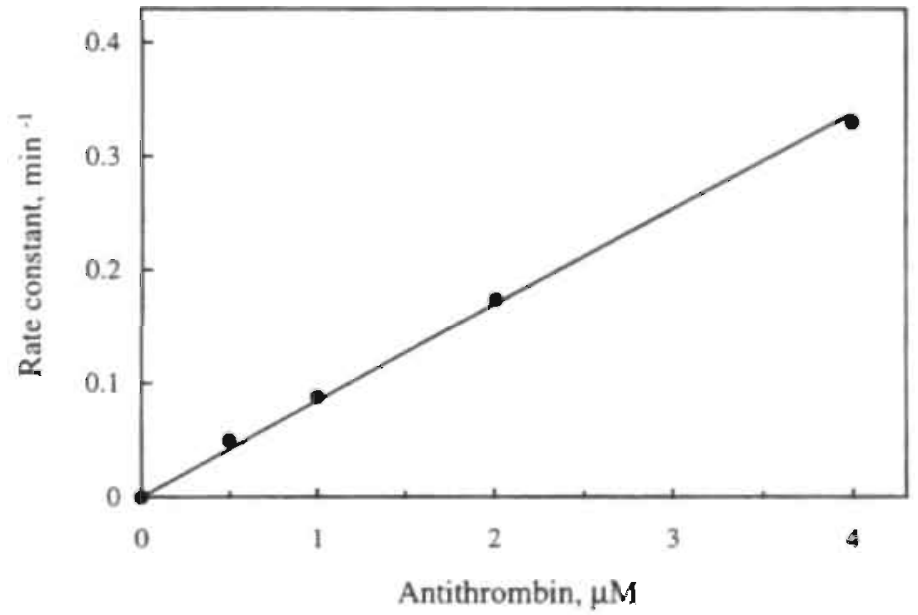

Figure 3. Rate constant of prothrombinase inhibition as a function of the antithrombin concentration. Prothrombinasecontaining capillaries were prepared as described in the legend to Fig.1. Pseudo-first order rate constants of prothrombinase inhibition by antithrombin in the absence of prothrombin were calculated from the data in Fig. 2 . Further details are described in the text.

Inhibition of prothrombin activation by antithrombin/heparin. in similar experiments as described before for antithrombin alone, we perfused capillaries containing prothrombinase $\left(0.035 \mathrm{fmol} / \mathrm{cm}^{2}\right)$ with prothrombin $(0.2 \mu \mathrm{M})$ and factor $\mathrm{Va}(2 \mathrm{nM})$ to establish the initial prothrombinase activity of the capillary. 


\section{Chapter 4}

Subsequently, antithrombin $(0.5 \mu \mathrm{M})$ and varying concentrations of heparin were included in the perfusion mixture for $8 \mathrm{~min}$. Residual prothrombinase activity was measured by continuation of the perfusion with prothrombin and factor $\mathrm{Va}$ after the inhibition step. At the end of each experiment the capillaries were perfused with EDTA to determine the amount of residual factor Xa activity. We verified, as described for antithrombin alone, that the inhibitory reaction followed pseudo first order kinetics.

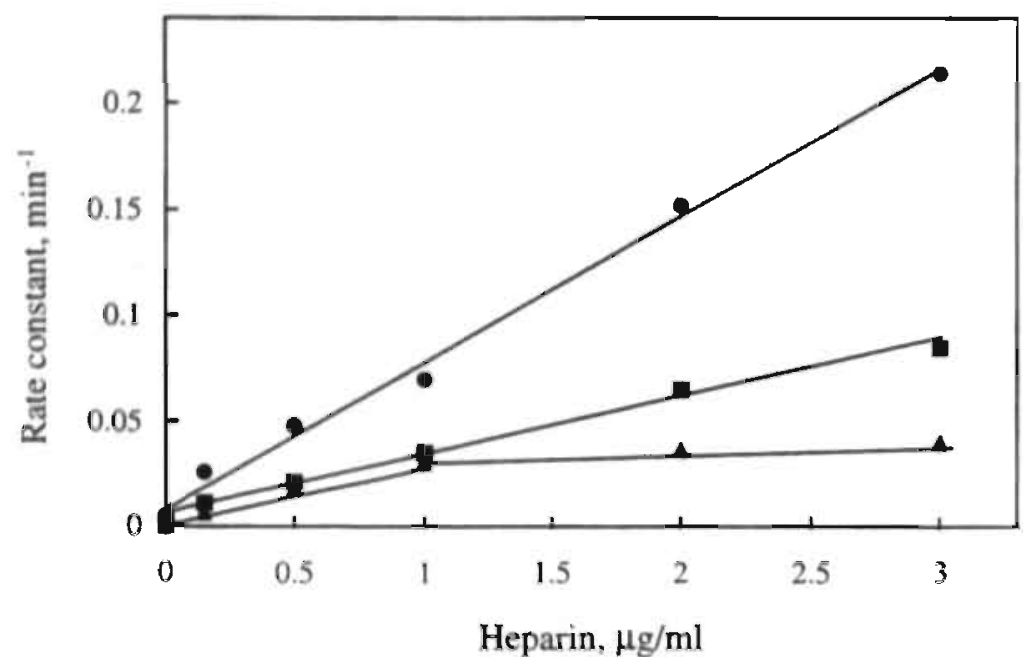

Figure 4. Rate constant of prothrombinase inhibition as a function of the antithrombin/heparn concentration. Prothrombinase-containing capillaries were prepared as described in the legend to Fig.1. Pseudo-first order rate constants of prothrombinase inhibition by antithrombin in the presence of varying amounts of UFH (-), LMWH (D) and pentasaccharide (M) were calculated as described in the text.

Fig.4 shows the rate constant of inhibition as a function of the heparin concentration. The heparins studied were unfractionated heparin (UFH), the low molecular weight heparin (LMWH) enoxaparin and the synthetic heparin pentasaccharide which contains the antithrombin binding site. Because the antithrombin concentration $(0.5 \mu \mathrm{M})$ was far above the reported dissociation constant of the heparin-antithrombin complexes $(10 \mathrm{nM})$, we assumed that all antithrombin high affinity heparins were complexed with antithrombin $(26,29)$. Indeed, the rate constant of the UFH catalyzed reaction increased linearly with the heparin concentration up to $3 \mu \mathrm{g} / \mathrm{ml}$ (100 $\mathrm{nM}$ antithrombin high affinity material). The inhibitory activity of the LMWH expressed per mol of antithrombin high affinity material was about half that of UFH. Interestingly, no further increase in the rate constant was seen with pentasaccharide above $1 \mu \mathrm{g} / \mathrm{ml}$. This amount of pentasaccharide 
corresponds to a molar concentration of $0.5 \mu \mathrm{M}$ and above this concentration all antithrombin $(0.5 \mu \mathrm{M})$ is saturated with the synthetic heparin.

The second order rate constants of inhibition of prothrombinase were calculated from the initial slopes of the plots as shown in Fig. 4 using the molar concentration of heparin as determined by stoichiometric titration with a known amount of antithrombin. We found that the rate constant for the inhibition reaction between prothrombinase and antithrombin-UFH, either in the absence or presence of $0.2 \mu \mathrm{M}$ prothrombin, was about 30 -fold higher than the rate constant of the inhibition reaction with antithrombin-pentasaccharide (Table I).

Table 1. Second-order rate constants for the reactions of antithrombin or antithrombin-heparin with prothrombinase.

\section{Rate Constant \pm SE}

Presence of prothrombin

Absence of prothrombin

$\mathrm{M}^{-1} \min ^{-1} \times 10^{6}$

AT

$<0.002$

$0.085 \pm 0.002$

AT-H5

$0.061 \pm 0.001$

$3.9 \pm 0.4$

AT-LMWH

$0.69 \pm 0.01$

$45 \pm 4$

AT-UFH.

$2.1 \pm 0.1$

$96 \pm 10$

H5, pentasaccharide

AT, antithrombin

Prothrombinase inhibition during transport limited prothrombin activation. We next examined the inhibition of prothrombinase by antithrombin/heparin under conditions where thrombin production was limited by the transport of prothrombin to the catalytic surface. To this end, the amount of prothrombinase in the capillary was increased from 0.09 to $5.2 \mathrm{fmol}$ prothrombinase. With this surface density of prothrombinase the intrinsic rate of thrombin production amounts $\mathrm{k}_{\text {cat }}$. [prothrombinase] $=18.7 \mathrm{pmol} / \mathrm{min}$, which is about 9 fold higher than the transport limit at a prothrombin concentration of $0.2 \mu \mathrm{M}: \mathrm{J}=2.2 \mathrm{pmol} / \mathrm{min}$ (see Experimental Procedures). After assembly of prothrombinase, the thrombin production of the capillary was measured during perfusion with factor $\mathrm{Va}(2 \mathrm{nM})$ and prothrombin $(0.2$ $\mu \mathrm{M})$. Next, the capillary was perfused with $0.5 \mu \mathrm{M}$ antithrombin and heparin concentrations as indicated in Fig.5. Finally, the remaining prothrombinase activity was assessed by determination of the thrombin production during perfusion with prothrombin $(0.2 \mu \mathrm{M})$ and factor $\mathrm{Va}(2 \mathrm{nM})$. At the end of the experiment the amount of non-inhibited prothrombinase in the capillary was determined. 


\section{Chapter 4}

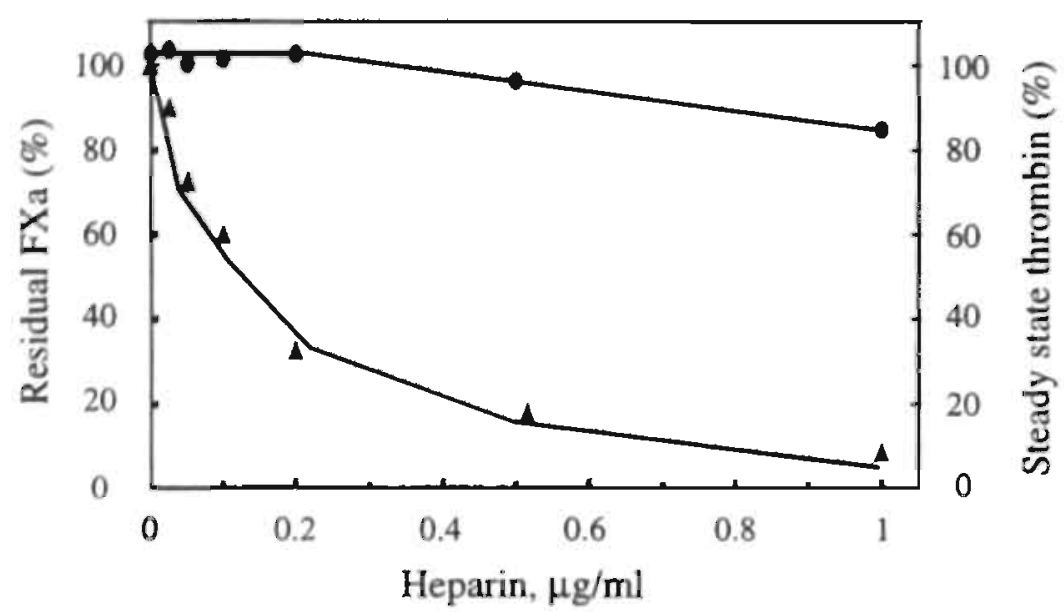

Figure 5. Inhibition of prothrombinase by antithrombin-UFH under transport-limited conditions of prothrombin activation. Capillaries containing $5.2 \mathrm{fmol}$ prothrombinase were prepared by perfusing phospholipid-coated capillaries with $0.1 \mathrm{nM}$ factor $\mathrm{Xa}$ and $2 \mathrm{nM}$ factor $\mathrm{Va}$ for $10 \mathrm{~min}$ at a wall sheas rate of $20 \mathrm{~s}^{-1}$. The capillaries, were then perfused for 10 min with $0.5 \mu \mathrm{M}$ antithrombin and UFH at the indicated concentrations and with a wall shear rate of $20 \mathrm{~s}^{-1}$. The residual prothrombinase activity was assessed as described in the text. Symbols indicate: (-), thrombin production expressed as percentage of the uninhibited steady state thrombin production and $(\mathbf{A})$, remaining factor Xa activity bound to the capillary as a percentage of factor Xa activity bound to the uninhibited capillaries.

Fig. 5 shows that under these conditions the inhibition of prothrombinase in the flow reactor had almost no effect on thrombin generation. It is evident that more than $80 \%$ of the prothrombinase had to be inactivated to decrease the rate of thrombin production below the mass transfer rate of prothrombin. This is consistent with our theoretical analysis that the initial amount of prothrombinase was 9-fold the amount at which prothrombin activation becomes transport limited. Haif-maximal decrease of prothrombinase was found with $0.14 \mu \mathrm{g} / \mathrm{ml}$ UFH, which equals $5 \mathrm{nM}$ of heparin species with high affinity for antithrombin. It is apparent that in the diffusioncontrolled situation, when prothrombinase is only partially saturated with prothrombin, factor $\mathrm{Xa}$ is much less protected from inhibition by antithrombin/ heparin. Interestingly, at heparin concentrations higher than $0.2 \mu \mathrm{g} / \mathrm{ml}$ the rate of inhibition of prothrombinase slowed down. It is apparent that sufficient prothrombinase was inactivated to enter a kinetically-controlled situation. That is, the rate of thrombin production became lower than the rate of prothrombin transport to the surface and full protection of prothrombinase by prothrombin is then feasible. 


\section{Discussion}

We studied the inhibition by antithrombin-heparin of thrombin production in a tubular flow reactor containing prothrombinase assembled on a macroscopic phospholipid surface. It is demonstrated that under experimental conditions where thrombin production is proportional with the surface density of prothrombinase, antithrombin is a very poor inhibitor of prothrombinase during prothrombin activation. Even at a concentration of antithrombin that exceeds the plasma concentration and a prothrombin concentration that is only one-tenth of the plasma concentration, inhibition of prothronbinase after an $8 \mathrm{~min}$ perfusion is almost negligible. The rate constant of inhibition by antithrombin was estimated to be lower than $2 \times 10^{3} \mathrm{M}^{-1} \mathrm{~min}^{-1}$. We showed that this protection from inhibition is caused to a large extent to the presence of prothrombin, because in the absence of prothrombin we measured a much higher second order rate constant of antithrombin-dependent prothrombinase inhibition $\left(0.85 \times 10^{5} \mathrm{M}^{-1} \mathrm{~min}^{-1}\right)$. This rate constant is somewhat lower than the reported rate constant of factor Xa inhibition of $1.2 \times 10^{5} \mathrm{M}^{-1} \mathrm{~min}^{-1}$ (30). Unfortunately, inhibition studies on factor Xa bound to the phospholipid layer in the flow reactor could not be performed because factor Xa readily dissociates from the surface in the absence of factor $\mathrm{Va}$ (25). We thus could not establish whether the interaction between factor $\mathrm{Va}$ and factor $\mathrm{Xa}$ at the phospholipid surface also contributes to the protecting effect on factor $\mathrm{Xa}$ inactivation. An alternative explanation for the observed protection could be that antithrombin near the surface becomes neutralized by locally high concentrations of thrombin (24). However, at an antithrombin concentration of $0.5 \mu \mathrm{M}$ the maximal mass transfer equals $5.5 \mathrm{pmol} / \mathrm{min}$ (equation 1) which is more than 10 fold higher than the thrombin production of 0.4 $\mathrm{pmol} / \mathrm{min}$ at the surface. This makes that depletion of antithrombin near the surface is highly unlikely.

Heparin, in the absence of prothrombin, caused a significant acceleration of prothrombinase-antithrombin reaction at the macroscopic surface. Rate constants of inactivation were proportional with the heparin concentration, indicating a second order reaction of prothrombinase with heparin-antithrombin complexes. The second order rate constant for the reaction between prothrombinase and antithrombin-UFH heparin, antithrombin-LMWH and antithrombin-pentasaccharide complexes were $9.6 \times 10^{7} \mathrm{M}^{-1} \mathrm{~min}^{-1}, 4.5 \times 10^{7} \mathrm{M}^{-1} \mathrm{~min}^{-1}$, and $0.39 \times 10^{7} \mathrm{M}^{-1} \mathrm{~min}^{-1}$, respectively. It is of interest to see that the anti-prothrombinase activity of heparin decreased with decreasing heparin chain length. We examined whether this difference between pentasaccharide and unfractionated heparin was the result of an antithrombinindependent effect of the heparins on prothrombinase activity and found that the steady-state rate of thrombin production was not affected by heparin in the absence of antithrombin (data not shown). Earlier studies (31) from our laboratory with factor 


\section{Chapter 4}

$\mathrm{Xa}$ in the presence of $\mathrm{Ca}^{2+}$,but in the absence of factor $\mathrm{Va}$ and phospholipids revealed about the same differences, namely rate constants of $2 \times 10^{8} \mathrm{M}^{-1} \mathrm{~min}^{-1}$, and $2 \times 10^{7} \mathrm{M}^{-1} \mathrm{~min}^{-1}$, for UFH and pentasaccharide-antithrombin complexes, respectively.

As demonstrated for the heparin-independent inhibition reaction, prothrombin protects prothrombinase also in the heparin-stimulated inhibition reaction. The second order rate constants of inhibition for UFH and pentasaccharide in the presence of $0.2 \mu \mathrm{M}$ prothrombin were about 50-fold lower compared to those in the absence of prothrombin (Table I). The difference in anti-prothrombinase activity between UFH and pentasaccharide reported here for prothrombinase bound to a macroscopic phospholipid surface during prothrombin activation appears to be of the same magnitude (30-fold) as found for prothrombinase in the absence of prothrombin. At present we have no explanation for this marked difference in antiprothrombinase activity. However, our findings suggest a role for heparinprothrombinase interactions, in addition to the pentasaccharide-induced antithrombin conformational change, as contributors to heparin acceleration of the antithrombinprothrombinase reaction (30).

It is of interest to note that because of the competition between prothrombin and antithrombin for the active center of prothrombinase, saturation of the enzyme with substrate determines to what extent the enzyme is sensitive to the inhibitory action of antithrombin. This was nicely demonstrated for conditions where the enzyme is only partially saturated with substrate, because of substrate depletion near the surface (Fig.5).

Collectively, our observations suggest that thrombin formation by prothrombinase at a macroscopic surface such as thrombi can hardly be regulated by heparinantithrombin complexes for two reasons: i) when prothrombinase is saturated with its substrate prothrombin, high concentrations of heparin are needed to cope with the protective effect of prothrombin and ii) when prothrombinase activity is limited by the supply of prothrombin, prothrombinase is readily inactivated by heparinantithrombin complexes but thrombin formation remains unaffected.

\section{References}

1. Hemker H.C., Esnouf M.P., Hemker P.W., Swart A.C.W. and MacFarlane R.G. 1967. Nature 215: 248-251.

2. Nesheim M.E., Taswell J.B., Mann K.G. 1979. J Biol Chem 254: 109952-10962.

3. Rosing J., Tans G., Govers-Riemslag J.W.P. Zwaal R.F.A, Hemker H.C. 1980. J Biol Chem 255: $274-283$.

4. Rosing J., van Rijn J.L.M.L., Bevers E.M., van Dieijen G., Comfurius P., Zwaal R.F.A. 1990. Blood 65: $319-332$.

5. Mann K.G., Nesheim M.E., Church W.R., Haley P., Krishmswamy S. 1990. Blood 76: 1-16.

6. Zwaal R.F.A. Comfurius P.. Bevers E.M. 1992. Biochim Biophys Acta 1180: 1-8.

7. Esmon C.T. 1989. J Biol Chem 264: 4743-4746.

8. Egeberg O. 1965. Thromb Diath Haemorrh 13:516-530. 


\section{Chapter 4}

9. Abilgaard U. 1969. Scand J Clin Lab 24: 23-27.

10. Rosenberg R.D., Damus P.S. 1973. J Biol Chem 248: 6490-6505.

11. Danielsson A., Raub E., Lindahl U., Bjšrk I. 1986. J Biol Chem 261: 15467-15473.

12. Olson S.T. 1988. J Biol Chem 263: 1698-1708.

13. Craig P.A., Olson. S.T., Shore J.D. 1989. JBiol Chem 264: 5452-5461.

14. Hogg PJ., Jackson C.M. 1989. Proc Natl Acad Sci USA 86: 3619-3623.

15. Weitz J.1., Hudoba M., Massel D., Maraganora J.M., Hirsh J. 1990. J Clin Invest 86: 385-391.

16. Eisenberg P.R., Siegel J.E., Abendschein D.R., Miletich J.P. 1993. J Clin Invest 91: 1877-1883.

17. Marciniak E. 1973. Br J Haematol 24: 391-400.

18. Miletich J.P., Jackson C.M., Majerus P.W. 1978. J Biol Chem 253: 6908-6916.

19. Teitel J.M., Rosenberg R.D. 1983. J Clin Invest 71: 1383-1391.

20. Lindhout T., Baruch D., Schoen P., Franssen J., Hemker H.C. 1986. Biochemistry 25: 5962-5969.

21. Ellis V., Scully M.F., Kakkar V.V. 1986. Biochem J 233: 161-165.

22. Barrowcliffe T.W., Havercroft S.J., Kemball-Cook G., Lindahl U. 1987. Biochem J 243: 31-37.

23. Schoen P., Lindhout T., Willems G.M., Hemker H.C. 1989. J Biol Chem 264: 10002-10007.

24. Schoen P., Lindhout T. 1991. Blood 78: 118-124.

25. Billy D., Speijer H., Willems G., Hemker H.C., Lindhout T. 1995. J Biol Chem 270, 1029- I034.

26. Schoen P., Wielders S., Petitou M., Lindhout T. 1990. Thromb Res 57: 415-423.

27. Lindhout T., Govers-Riemslag J.W.P., van de Waart P., Hemker H.C., Rosing J. 1982. Biochemistry 21: 5494-5502.

28. Levich V.G. 1962: Physiochemical Hydrodynamics. Englewood Cliffs, NJ. Prentice-Hall, p 75.

29. Atha D.H., Lormeau J.C., Petitou M., Rosenberg R.D., Choay J. 1985. Biochemistry 24: 6723-6729.

30. Olson S.T., Bjšrk I., Sheffer R., Craig P.A., Shore J.D., Choay J. 1992. J Biọl Chem 267: 12528-12538.

31. Schoen P., Lindhout T., Hemker H.C. 1992. Brit J Haematol 81: 255-262. 



\section{Chapter 5}

\section{Inhibition of Prothrombinase at Macroscopic Lipid Mernbranes: Competition between Antithrombin and Prothrombin.}

Didier Billy, Han Speijer, Theo Lindhout, H. Coenraad Hemker and George Willems, 1995. Biochemistry 34: 13699-13704.

\section{Summary}

The kinetics of inhibition of prothrombinase during prothrombin conversion by antithrombin and antithrombin-heparin complexes was studied in a tubular flow reactor. Prothrombinase was assembled at a macroscopic phospholipid membrane, composed of $25 \mathrm{~mol} \%$ phosphatidylserine and $75 \mathrm{~mol} \%$ phosphatidylcholine, deposited on the inner wall of a glass capillary, by perfusion with a factor Xa-factor Va mixture. Measurement of thrombin production allowed estimation of the amount of prothombinase present at the capillary wall. Perfusion with a mixture of prothrombin and antithrombin or antithrombin-heparin complexes caused a progressive decline of the prothrombinase activity. The rate of inactivation steeply decreased with increasing prothrombin concentrations, indicating competitive inhibition. Analysis of competitive inhibition data requires estimation of the timedependent substrate concentration, $\mathrm{C}_{0}$, near the prothrombin converting surface using earlier developed transport theory [Billy D. et al. (1995), J. Biol. Chem. 270, 1029 1034]. It appears that the inhibition rate is proportional to the fraction of enzyme, $\mathrm{K}_{\mathrm{m}} /\left(\mathrm{K}_{\mathrm{m}}+\mathrm{C}_{0}\right)$, not occupied by substrate. The value of $\mathrm{K}_{\mathrm{m}}$ of prothrombinase estimated from the dependence of the inhibition rate on the prothrombin concentration $\left(K_{m}=2-3 n M\right)$ is in excellent agreement to the value estimated from the substrate conversion rate $\left(K_{\mathrm{m}}=3 \mathrm{nM}\right)$. Therefore inhibition of prothrombinase by antithrombin and antithrombin-heparin complexes is fully competitive with the substrate: prothrombin. Our results show that prothrombinase assembled on macroscopic lipid surfaces by virtue of its low $\mathrm{K}_{\mathrm{m}}$ value is protected for inhibition due to highly effective competition of prothrombin with antithrombin for the active site of factor $\mathrm{Xa}$.

\section{Introduction}

The activation of prothrombin to thrombin is a central reaction of the blood coagulation that finally results in the formation of a hemostatic plug $(1,2)$. Effective activation of prothrombin requires prothrombinase, the complex of the serine protease factor $\mathrm{Xa}$ and cofactor $\mathrm{Va}$ assembled on a phosphatidylserine containing phospholipid membrane (3-5). The spatial propagation of the coagulation activation reactions is restricted by the requirement of phosphatidylserine containing 


\section{Chapter 5}

membranes, in vivo presumably provided by activated platelets and vascular lesions $(2,6-8)$. Furthermore the coagulation is down-regulated in time by several inactivation reactions. The cofactors Va and VIIIa are eliminated by activated protein C (9), that becomes available during thrombin generation. The extrinsic pathway is inhibited by tissue factor pathway inhibitor (10). The serine proteases of the blood coagulation are primarily inhibited by antithrombin $(11,12)$. This protein, with a plasma concentration of about $2 \mu \mathrm{Ml}$ forms equimolar complexes with serine proteases. The principal targets of antithrombin are factor Xa and thrombin. Heparin, widely in use as anticoagulant drug, up to 1000 -fold enhances the rate of inactivation of these enzymes by antithrombin (13-15).

Kinetics of prothrombin conversion by prothrombinase bound to macroscopic phospholipid surfaces has recently been studied in our laboratory both on uniformly accessible surfaces, i.e. the rotating disc, and in the tubular flow reactor (16-19). It was shown that analysis of kinetics requires a careful account of mass transfer to the catalytic surface. The most important observation was the huge catalytic efficiency of prothrombinase bound to planar bilayers because of the extremely low value of the Michaelis constant $\left(K_{m}=3 \mathrm{nM}\right)$, which is nearly two orders lower than found for prothrombinase bound to small vesicles $(5,17)$. This could imply that inhibition of prothrombinase bound to macroscopic lipid membranes by pseudo-substrates like antithrombin can be easily counteracted by the presence of prothrombin. Indeed a recent study demonstrated a nearly complete protection from antithrombin-mediated inhibition by prothrombin (20).

This paper reports a detailed kinetic study on the competitive effect of prothrombin on the inactivation of prothrombinase by antithrombin. Our main goal was to elucidate to what extent the protection of prothrombinase could be attributed to competition between prothrombin and antithrombin for the active site of factor Xa. By restriction of our measurements to low densities of prothrombinase at the capillary wall we could use the earlier developed transport theory to estimate the prothrombin concentration at the catalytic surface. Our data show unequivocally that the inhibition of prothrombinase by antithrombin is fully competitive with prothrombin.

\section{Experimental Procedures}

Materials. Glass capillaries with an inner diameter of $0.65 \mathrm{~mm}$ and a length of $127 \mathrm{~mm}$ (volume of $42 \mu \mathrm{l}$ ) were obtained from Brand AG (Wertheim, Germany). 1,2Dioleoyl-sn-glycero-3-phosphatidylcholine (DOPC) and 1,2-Dioleoyl-sn-glycero-3phosphatidylserine (DOPS) were purchased from Avanti Polar Lipids, Inc. (Alabaster, AL.). S2238, chromogenic substrate for thrombin, was obtained from Chromogenix (Mölndal, Sweden). Bovine serum albumin was from Sigma (St. 
Louis, MO).. The $4^{\text {th }}$ International Standard for Heparin (UFH) was a gift from the National Institute for Biological Standards and Control (Potters Bar, UK). Its potency was stated as $193 \mathrm{U} \cdot \mathrm{mg}^{-1}$. The molar concentration of the heparin with high affinity for antithrombin, as determined by stoichiometric titration with antithrombin (21), was $35 \mathrm{mmol} \cdot \mathrm{g}^{-1}$. Bovine factor $\mathrm{Va}$, human prothrombin, human factor $\mathrm{Xa}$ and human antithrombin were purified and quantified as described $(22,23)$.

The flow reactor. The glass capillaries were cleaned and rendered hydrophilic as described (19). In order to deposit a phospholipid bilayer on the capillary wall, the glass capillary was filled and incubated for $20 \mathrm{~min}$ with a suspension of unilamellar phospholipid vesicles (25 mol\% DOPS- $75 \mathrm{~mol} \%$ DOPC) in Tris-buffer ( $50 \mathrm{mM}$ Tris$\mathrm{HCl}, 175 \mathrm{mM} \mathrm{NaCl}, \mathrm{pH} 7.9$ ). To remove non-bound phospholipid, the capillary was rinsed at a flow rate of $1.2 \mathrm{ml}$. $\mathrm{min}^{-1}$ with Tris-buffer containing $3 \mathrm{mM} \mathrm{CaCl}_{2}$ and 0.5 $\mathrm{mg} \cdot \mathrm{ml}^{-1}$ bovine serum albumin. The phospholipid-coated capillary was connected to a syringe and the flow was controlled by a syringe pump (Harvard Apparatus Co., South Natick, MA, USA). An XYZ translation table (Isel, Eiterfelt, Germany) was used to collect samples from the tip of the flow reactor into disposable cuvettes (Sarstedt, Nümbrecht, Germany). All procedures were performed at $37^{\circ} \mathrm{C}$.

Inhibition of phospholipid-bound prothrombinase. All perfusions were performed at $37^{\circ} \mathrm{C}$ and $\mathrm{pH} 7.9$ in Tris-buffer containing $50 \mathrm{mM}$ Tris- $\mathrm{HCl}, 175 \mathrm{mM}$ $\mathrm{NaCl}, 3 \mathrm{mM} \mathrm{CaCl}$ and $0.5 \mathrm{mg} \cdot \mathrm{ml}^{-1}$ bovine serum albumin. Prothrombinase was assembled at the capillary wall by perfusion with a solution containing $1 \mathrm{pM}$ factor Xa and $1 \mathrm{nM}$ factor Va for $10 \mathrm{~min}$ at a flow rate of $30 \mu \mathrm{l} \cdot \mathrm{min}^{-1}$ (wall shear rate of $20 \mathrm{~s}^{-1}$ ). Then the thronbin production was measured by perfusion with a mixture containing $1 \mathrm{nM}$ factor $\mathrm{Va}$ and prothrombin. Samples of $60 \mu \mathrm{l}$ effluent were collected, each 2 $\min$, into cuvettes containing $500 \mu \mathrm{L}$ Tris-buffer containing $20 \mathrm{mM}$ EDTA. The amount of thrombin in the sample were measured spectrophotometrically after addition of $60 \mu \mathrm{l}$ of the chromogenic substrate S2238 (2.5 mM). The inhibition of prothrombinase was studied by perfusion with a mixture containing antithrombin or antithrombin-heparin, $1 \mathrm{nM}$ factor $\mathrm{Va}$ and various concentrations of prothrombin.

Data analysis. In a previous study (19) we showed that the thrombin production $\mathrm{J}_{\mathrm{Ila}}\left(\mathrm{pmol} \cdot \mathrm{min}^{-1}\right)$ in a capillary flow reactor containing an amount $\mathrm{E}$ (pmol) of prothrombinase can adequately be described by Michaelis-Menten kinetics in terms of $\mathrm{k}_{\mathrm{cat}}\left(3600 \mathrm{~min}^{-1}\right), \mathrm{K}_{\mathrm{m}}(3 \mathrm{nM})$ and the prothrombin concentration $\mathrm{C}_{0}(\mathrm{nM})$ near the lipid membrane at the capillary wall:

$$
J_{11 \mathrm{a}}=\mathrm{k}_{\mathrm{cat}} \mathrm{EC} /\left(\mathrm{C}_{0}+\mathrm{K}_{\mathrm{m}}\right)
$$


The concentration $C_{0}$ is lower than the concentration $C_{b}$ in perfusion buffer at the inlet of the capillary due to the limited rate of mass transfer of protein from solution to the capillary wall:

$$
\mathrm{C}_{0}=\mathrm{C}_{\mathrm{b}}-\mathrm{J}_{\mathrm{Ila}} / \Delta
$$

with $\Delta$ the mass transfer coefficient $\left(1 \mathrm{~min}^{-1}\right)$, which depends on the capillary dimensions, the fluid flow rate, the kinematic viscosity of the fluid and the diffusion constant of the protein $(19,24)$. For the experimental conditions used in this study a theoretical value of $\Delta=10.8 \mu \mathrm{l} \cdot \mathrm{min}^{-1}$ can be calculated (19). For high densities of prothrombinase on the capillary wall the depletion of prothrombin is nearly complete, i.e. $\mathrm{C}_{0} \approx 0$, and thrombin production becomes entirely transport rate limited $J_{\mathrm{II}}=\Delta \mathrm{C}_{\mathrm{b}}$. Using this notion we determined the value of the mass transfer from measurements of the thrombin production at high surface density of prothrombinase (0.75 fmol), which is attained after a 60 min perfusion with $2 \mathrm{pM}$ factor $\mathrm{Xa}, 50 \mathrm{pM}$ factor $\mathrm{Va}$ and $50-200 \mathrm{nM}$ prothrombin. This resulted in a value $9.8 \pm 0.25 \mu \mathrm{min} \mathrm{m}^{-1}$ (mean \pm S.E.M., $\mathrm{n}=10$ ) for the mass transfer coefficient $\Delta$.

The eq. 1-2 can be used to predict the thrombin production for a given amount $\mathbf{E}$ of prothrombinase and a given prothrombin concentration $\mathrm{C}_{\mathrm{b}}$. Alternatively, one can estimate the amount of prothrombinase present in the capillary from the steady state thrombin production :

$$
\mathrm{E}=\left(\mathrm{J}_{\mathrm{lla}} / \mathrm{k}_{\mathrm{cat}}\right)\left(\mathrm{K}_{\mathrm{m}}+\mathrm{C}_{0}\right) / \mathrm{C}_{0}
$$

The applicability of the eq.2-3 for the assessment of the amount of prothrombinase is limited to low densities, i.e. situations with a thrombin production below $90 \%$ of the transport limit. The calculation of $\mathrm{C}_{0}$ near the transport limit involves large relative errors, because $J_{11 a} / \Delta$ approaches $C_{b}$. The eq.2-3 were used to measure the decline of prothrombinase bound to the capillary by assessment of the steady state rate of thrombin production before and after exposure to antithrombinprothrombin mixtures.

Analysis of competitive inhibition of prothrombinase in the flow reactor is complicated by the depletion of the substrate near the capillary wall. For purely competitive inhibition only the fraction of the enzyme not occupied by the substrate is susceptible to inhibition. According to eq.1 the fraction of enzyme not occupied by substrate depends on the substrate concentration, $\mathrm{C}_{0}$, near the wall and is equal to $\mathrm{K}_{\mathrm{m}} /\left(\mathrm{C}_{0}+\mathrm{K}_{\mathrm{m}}\right)$. The disappearance rate of the enzyme $\mathrm{E}$ thus is given by:

$$
d / d t E=-k_{i n h} I E K_{m} /\left(C_{0}+K_{m}\right)
$$


with $\mathrm{k}_{\text {inh }}$ the second order rate constant of inhibition of the unprotected enzyme and $\mathbf{I}$ the concentration of the inhibitor. As consequence of the progressive inhibition of the enzyme, the concentration $\mathrm{C}_{0}$, however, is not constant but increases in time, because a lower thrombin production results in a higher value of $\mathrm{C}_{0}$ according to eq 2. Therefore the term $k_{\text {inh }} \mathbf{I} \mathrm{K}_{\mathrm{m}} /\left(\mathrm{C}_{0}+\mathrm{K}_{\mathrm{m}}\right)$ is not constant and the decay of enzyme is not exponential. Formal integration of eq. 4 results in the expression

$$
-\ln \left(\mathrm{E}_{\mathrm{e}} / \mathrm{E}_{\mathrm{o}}\right)=\mathrm{k}_{\text {inh }} \mathrm{I} \mathrm{t}_{\mathrm{e}}\left[\left(1 / \mathrm{t}_{\mathrm{e}}\right) \int_{0}^{\omega} \mathrm{K}_{\mathrm{m}} /\left(\mathrm{C}_{0}(\tau)+\mathrm{K}_{\mathrm{m}}\right) \mathrm{d} \tau\right]
$$

for the residual enzyme activity $E_{e}$ after exposure time $\iota_{e}$ to the inhibitor. The term in square brackets represents the mean value of the protection factor, $\mathrm{K}_{\mathrm{m}} /\left(\mathrm{C}_{0}+\mathrm{K}_{\mathrm{m}}\right)$, during the inhibition step. Evaluation of this term would require intermediate values of $C_{0}(\tau)$, which are difficult to obtain because inhibition measurements only provide values of $\mathrm{E}$ and $\mathrm{C}_{0}$ at the start, $\mathrm{t}=0$, and the end, $\mathrm{t}=\mathrm{t}_{\mathrm{e}}$, of the perfusion with inhibitor. It appears, however, that the approximation $\mathrm{K}_{\mathrm{m}} /\left(\left[\mathrm{C}_{0}(0)+\mathrm{C}_{0}\left(\mathrm{t}_{\mathrm{e}}\right)\right] / 2+\mathrm{K}_{\mathrm{m}}\right)$ of the mean value of the protection factor provides sufficient accuracy (see below). Insertion of this approximation in eq.5 results in the following simple modification of the classical formula for competitive inhibition:

$$
-\ln \left(\mathrm{E}_{\mathrm{e}} / \mathrm{E}_{\mathrm{o}}\right)=\mathbf{k}_{\text {inh. }}\left[\epsilon_{\mathrm{e}} \mathrm{K}_{\mathrm{m}} /\left(\left[\mathrm{C}_{0}(0)+\mathrm{C}_{0}\left(\mathrm{t}_{\mathrm{e}}\right)\right] / 2+\mathrm{K}_{\mathrm{m}}\right)\right]
$$

Rearrangement of this equation results in

$$
-I t_{c} / \ln \left(E_{e} / E_{o}\right)=1 /\left(K_{m} k_{i n h}\right)\left[C_{0}(0)+C_{0}\left(L_{e}\right)\right] / 2+1 / k_{\text {inh }}
$$

Data thus can be analysed. in a plot of $-I t e / n\left(E_{e} / E_{0}\right)$ versus $\left[C_{0}(0)+C_{0}\left(t_{e}\right)\right] / 2$. The validity of the approximation of eq. 6 was assessed by numerical simulations of eq. 4 .

For known values of the rate constants, $\Delta, \mathrm{k}_{\mathrm{cat}}, \mathrm{K}_{\mathrm{m}}, \mathrm{k}_{\mathrm{inh}}$, and the prothrombinase density $\mathrm{E}$ the value of $\mathrm{C}_{0}$ can be calculated using eq. 1-2:

$$
\mathrm{C}_{0}=0.5\left[\mathrm{C}_{\mathrm{b}}-\mathrm{K}_{\mathrm{m}}-\mathrm{k}_{\mathrm{cat}} \mathrm{E} / \Delta+\sqrt{ }\left(\left(\mathrm{C}_{\mathrm{b}}-\mathrm{K}_{\mathrm{m}}-\mathrm{K}_{\mathrm{cat}} \mathrm{E} / \Delta\right)^{2}+4 \mathrm{C}_{\mathrm{b}} \mathrm{K}_{\mathrm{m}}\right)\right]
$$

Equation 4, therefore, can be solved numerically for given values of the rate constants and a given prothrombinase density $E_{0}$ at the start of the exposure to the inhibitor. Such numerical simulations showed that the error in the parameters $\mathrm{K}_{\mathrm{m}}$ and $\mathrm{k}_{\text {inh }}$ caused by the approximation used in eq. 6 amounted to less than $4 \%$ of the estimated values. 


\section{Results}

Inhibition of prothrombin activation by antithrombin. Our experimental approach requires the estimation of $\mathrm{C}_{0}$, the concentration of prothrombin near the capiliary wall. This is only possible for thrombin productions below $90 \%$ of the transport limit. It was calculated using eq.1-2 that this condition is satisfied for all values of the prothrombin concentrations in the perfusate if the amount of prothrombinase bound to the capillary remains below $0.09 \mathrm{fmol}$. We choose to target at a prothrombinase content of $0.08 \mathrm{fmol}$. This amount of prothrombinase can be assembled by perfusion $\left(30 \mu 1 . \mathrm{min}^{-1}\right)$ for $10 \mathrm{~min}$ with mixture containing $1 \mathrm{pM}$ factor $\mathrm{Xa}$ and $\mathrm{I} \mathrm{nM}$ factor $\mathrm{Va}$.

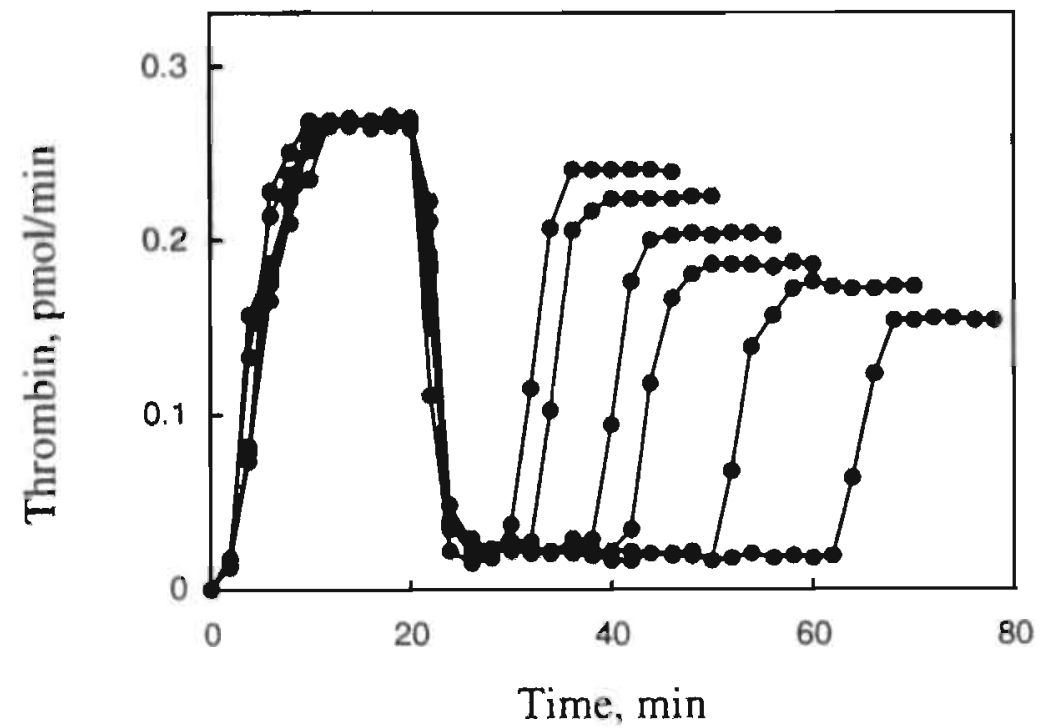

Figure 1. Inhibition of prothrombinase activity by antithrombin. Fixed amounts of prothrombinase were assembled on the. capillary wall in a perfusion with $1 \mathrm{pM}$ factor $\mathrm{Xa}$ and $1 \mathrm{nM}$ factor $\mathrm{Va}$ for $10 \mathrm{~min}$. Prothrombinase activity was measured upon perfusion with $50 \mathrm{nM}$ prothrombin and $1 \mathrm{nM}$ factor $\mathrm{Va}$. After 20 min the perfusion mixture was changed to a solution containing $2 \mu \mathrm{M}$ antithrombin, $50 \mathrm{nM}$ prothrombin and $1 \mathrm{nM}$ factor $\mathrm{Va}$ and the perfusion was continued for 6 , 10, 16, 20, 30 and $40 \mathrm{~min}$. Following this inhibition step remaining prothrombinase activity was determined by a second perfusion with $50 \mathrm{nM}$ prothrombin and $1 \mathrm{nM}$ factor $\mathrm{Va}$ for $20 \mathrm{~min}$. Volumetric flow of the perfusions was $30 \mu \mathrm{l} \cdot \mathrm{min}^{-1}$ (wall shear rate of $20 \mathrm{~s}^{-1}$ ). Experiments were performed at $37^{\circ} \mathrm{C}$ and $\mathrm{pH} 7.9$ in buffer, containing $50 \mathrm{mM}$ Tris-HCl, 175 $\mathrm{mM} \mathrm{NaCl}, 0.5 \mathrm{mgml}^{-1} \mathrm{BSA}$ and $3 \mathrm{mM} \mathrm{CaCl}_{2}$,

After this perfusion the prothrombinase activity in the capillary was measured from the steady state thrombin production upon perfusion with prothrombin ( $50 \mathrm{nM}$ ) and factor $\mathrm{Va}(1 \mathrm{nM})$ for $20 \mathrm{~min}$. Fig.1 shows that the thrombin production reached within $10 \mathrm{~min}$ a stable level of $0.27 \pm 0.001 \mathrm{pmol} \mathrm{min}^{-1}$ (mean \pm S.D., $\mathrm{n}=7$ ). Thus a 
reproducible amount of $0.084 \pm 0.0004 \mathrm{fmol}$ prothrombinase, calculated according to eq.2-3, is assembled at the capillary wall. The measured thrombin formation is about $50 \%$ of the transport limit, $0.49 \mathrm{pmol} \mathrm{min}^{-1}$ at $50 \mathrm{nM}$ prothrombin. Next, the prothrombinase was exposed to antithrombin for various times by continuation of the perfusion with a mixture containing antithrombin $(2 \mu \mathrm{M})$, prothrombin $(50 \mathrm{nM})$ and factor $\mathrm{Va}(1 \mathrm{nM})$. The thrombin concentration, measured at the outlet of the capillary, dropped to a low level, presumably because most of the thrombin generated is inactivated by antithrombin during the residence time of more than 1 $\min$ in the capillary. Finally, residual prothrombinase activity was measured during a second perfusion with prothrombin $(50 \mathrm{nM})$ and factor $\mathrm{Va}(1 \mathrm{nM})$. The thrombin generation was restored to a new steady-state level of thrombin production lower than the initial rate of thrombin production. It is apparent that the residual prothrombinase activity decreases with increasing duration of the antithrombin perfusion. Residual thrombin production after $6 \mathrm{~min}$ exposure was $90 \%$ and decreased to $58 \%$ after $40 \mathrm{~min}$ exposure. Control experiments showed that in absence of antithrombin the thrombin production remained stable during $50 \mathrm{~min}$ (residual production $>99 \%$ of the initial steady state production).

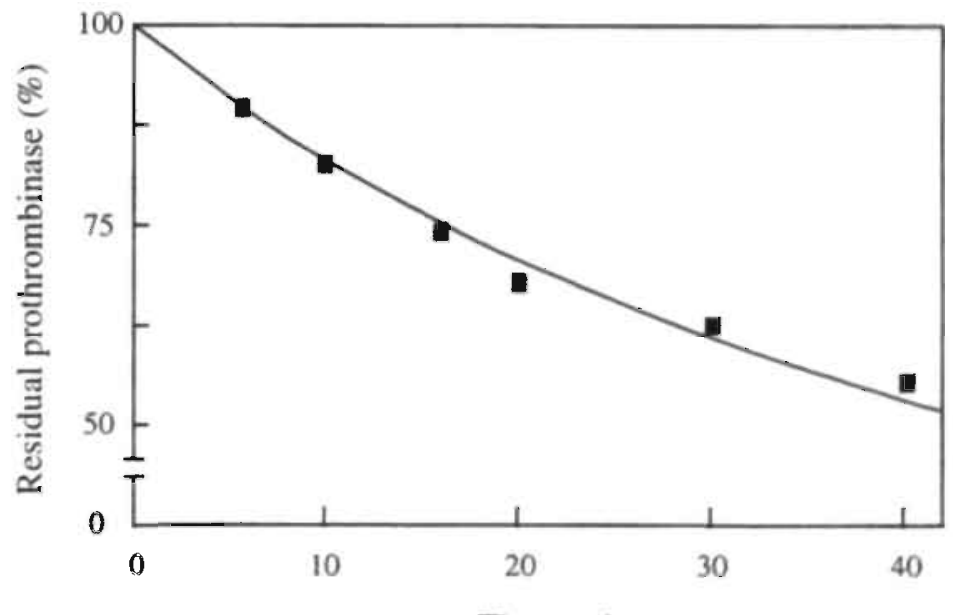

Time, $\min$

Figure 2. Extent of prothrombinase inhibition by antithrombin as function of inhibition time. The residual amount of prothrombinase bound to the capillary was calculated using oq -2-3 from the thrombin production shown in Fig. I. Also indicated is the best fitting curve, according to the competitive inhibition model (eq.4) with fixed value of $\mathrm{K}=3 \mathrm{nM}$

The thrombin production rates presented in Fig.1 permit the quantification of the amount of prothrombinase remaining in the capillary after inhibition using eq.2-3. Fig.2 shows a plot of the residual prothrombinase activity as function of the inhibition time. An exponential fit to these data results in an apparent first order rate 
constant of prothrombinase inhibition $\mathrm{k}_{\text {app }}=0.017 \mathrm{~min}^{-1}$, which corresponds to a second order rate constant of $0.008 \times 10^{6} \mathrm{M}^{-1} \mathrm{~min}^{-1}$. In contrast, a fit of the model for competitive inhibition to these data, according to eq. 4 and 7 , using a fixed value for $K_{m}=3 \mathrm{nM}(19)$, resulted in a value $\mathrm{k}_{\text {inh }}=0.085 \times 10^{6} \mathrm{M}^{-1} \mathrm{~min}^{-1}$ for the second order rate constant of inhibition. This ten-fold higher value, which is in excellent agreement with the value $0.085 \times 10^{6} \mathrm{M}^{-1} \mathrm{~min}^{-1}$ found for inhibition by antithrombin in absence of prothrombin (20), reflects the effective protection of prothrombinase by prothrombin: the prothrombin concentration $\mathrm{C}_{0}$ at the capillary wall, calculated according eq.2, in these experiments varied during the antithrombin perfusion between $23 \mathrm{nM}$, at the start, and $34 \mathrm{nM}$, at the end. This corresponds to an average fractional occupation, $\mathrm{C}_{0} /\left(\mathrm{K}_{\mathrm{m}}+\mathrm{C}_{0}\right)$, of the prothrombinase of about $90 \%$, resulting in a $90 \%$ protection of the prothrombinase for inhibition by antithrombin in the model for competitive inhibition, c.f. eq. 4 .

Analysis of competitive inhibition of prothrombinase by antithrombin. In order to obtain quantitative data on the effect of prothrombin on prothrombinase inhibition in the flow reactor, experiments as shown in Fig.1 were performed for several prothrombin concentrations (0-200 $\mathrm{nM})$. The inhibition step consisted of a perfusion during $10 \mathrm{~min}$ with a mixture containing. Factor $\mathrm{Va}(1 \mathrm{nM})$, prothrombin and antithrombin $(0-4 \mu \mathrm{M})$. The initial and residual amount of prothrombinase bound to the capillary, $E_{0}$ and $E_{e}$, were quantified by using eq.2-3 from the initial and final steady-state level of thrombin production, respectively. These experiments unequivocally showed that the inhibition kinetics of prothrombinase depends on the prothrombin concentration present in the perfusion mixture. For $10 \mathrm{nM}$ prothrombin the apparent second order rate constant of inhibition was $0.061 \times 10^{6} \mathrm{M}^{-1} \mathrm{~min}^{-1}$, while at $200 \mathrm{nM}$ prothrombin the apparent second order rate constant was 30 -fold lower $\left(0.002 \times 10^{6} \mathrm{M}^{-1} \mathrm{~min}^{-1}\right)$. A fit with the model for competitive inhibition to these data with a fixed $\mathrm{K}_{\mathrm{m}}$ value of $3 \mathrm{nM}$ resulted in a value $0.079 \times 10^{6} \mathrm{M}^{-1} \mathrm{~min}^{-1}$ for the true second order inhibition constant $k_{\text {inh. }}$.

The previous results indicate competition between antithrombin and prothrombin for the active site of the prothrombinase complex. In the analysis of these data with the competitive binding model we, however, used the $\mathrm{K}_{\mathrm{m}}$ value as obtained from the kinetics of prothrombin conversion. In order to analyse the data with the model for competitive inhibition and to identify the $\mathrm{K}_{\mathrm{m}}$ value independently using eq.6, we performed additional experiments at low prothrombin concentrations $(0-30 \mathrm{nM})$ and an antithrombin concentration of $4 \mu \mathrm{M}$ during the $10 \mathrm{~min}$ lasting inhibition perfusion. The results are presented in Fig.3, as the plot of $-1 \mathrm{t} / \mathrm{ln}\left(\mathrm{E}_{\mathrm{e}} / \mathrm{E}_{\mathrm{o}}\right)$ versus the average concentration $\mathrm{C}_{0}$ at the capillary wall, c.f. eq.6. According to this equation data should represent a straight line with a slope $1 /\left(\mathrm{K}_{\mathrm{m}} \mathrm{K}_{\text {inh }}\right)$ and an intercept at the vertical axis of $1 / \mathrm{k}_{\text {inh }}$, with $\mathrm{K}_{\mathrm{m}}$ the Michaelis constant and $\mathrm{k}_{\text {inh }}$ the true second 
order rate constant of inhibition. The good agreement between data and the model of competitive inhibition in eq. 6 is apparent. The best fitting straight line results in values $\mathrm{K}_{\mathrm{m}}=2.5 \mathrm{nM}$ and $\mathrm{k}_{\mathrm{inh}}=0.055 \times 10^{6} \mathrm{M}^{-1} \mathrm{~min}^{-1}$. A fit of eq. 1 to the steady state thrombin generation measured prior to the inhibition step as function of the prothrombin concentration resulted in a $\mathrm{K}_{\mathrm{m}}$ value of $3.2 \mathrm{nM}$. This excellent agreement between these independently determined $\mathbf{K}_{\mathrm{m}}$ values corroborates the validity of the competitive inhibition model.

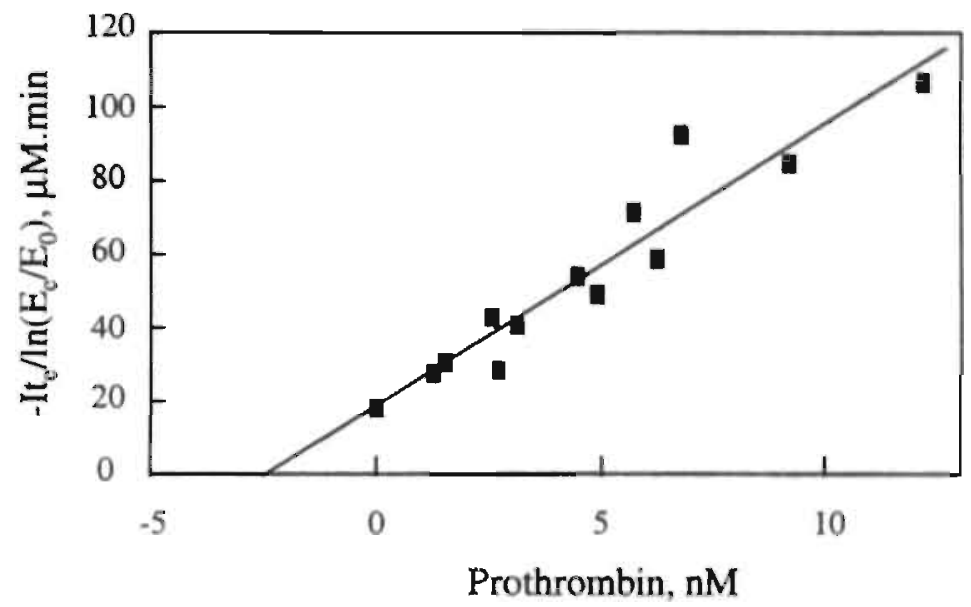

Figure 3. Competitive prothrombinase inhibition by antithrombin. The experimental protocol for the measurement of prothrombinase inhibition, as described in Fig.1, was executed for several prothrombin concentrations and an antithrombin concentration of $4 \mu \mathrm{M}$ during the $10 \mathrm{~min}$ inhibition step. Shown is a plot of $-1 \mathrm{l}_{e} / \mathrm{ln}\left(\mathrm{E}_{5} / \mathrm{E}_{0}\right)$ versus the mean prothrombin concentration, $C_{0}(0) / 2+C_{0}\left(L_{2}\right) / 2$, at the capillary wall during the perfusion with the prothrombin-antithrombin mixture. The straight line is the best fit of the model (eq.6) to these data with estimated values $k_{i m n}=0.055 \times 10^{6} \mathrm{M}^{\prime \prime} \min ^{\prime \prime}$ and $\mathrm{K}_{\mathrm{m}}=2.5 \mathrm{nM}$.

We further addressed the question whether inhibition of prothrombinase by antithrombin-heparin complexes also is fully competitive. In perfusion experiments the inhibition step was performed with a mixture containing antithrombin $(0.4 \mu \mathrm{M})$ and unfractionated heparin $\left(0.05 \mu \mathrm{g} \cdot \mathrm{ml}^{-1}\right)$. The antithrombin concentration was chosen 10 fold lower than in the previous experiments in order to minimise the inhibitory effect of antithrombin alone. Yet, the concentration of $0.4 \mu \mathrm{M}$ is sufficiently high to justify the assumption that all heparin is associated with antithrombin (21). The concentration of heparin-antithrombin complexes is $1.75 \mathrm{nM}$. The results, presented in Fig.4, show a good agreement between the data and the model of competitive inhibition. The best fitting straight line, corresponds to the values $\mathrm{K}_{\mathrm{m}}=2.0 \mathrm{nM}$ and $\mathrm{k}_{\text {inh }}=128 \times 10^{6} \mathrm{M}^{-1} \mathrm{~min}^{-1}$. Thus, also the heparin-dependent 
inhibition of prothrombinase in the presence of prothrombin can be described by a simple competition model.

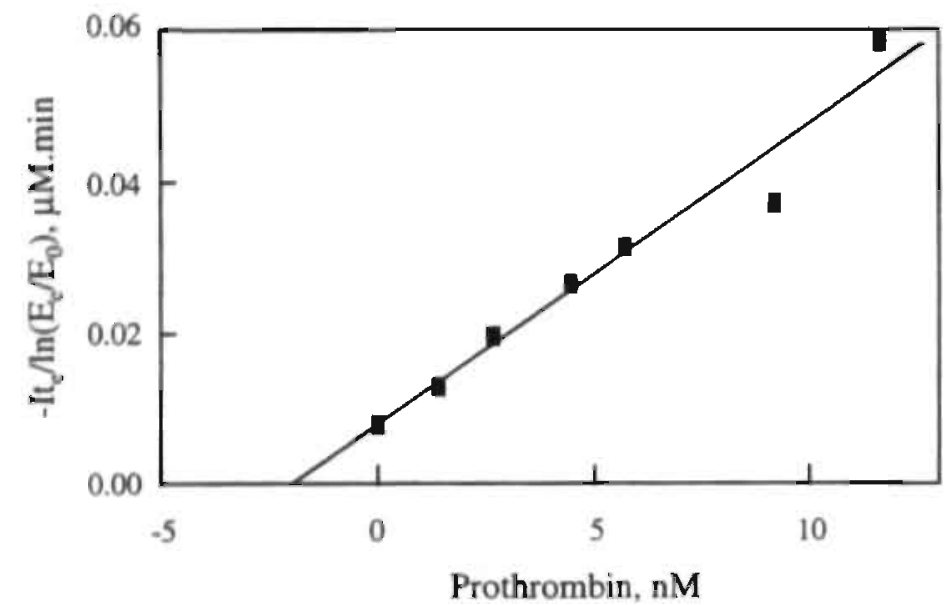

Figure 4. Competitive prothrombinase inhibition by antithrombin-heparin complexes. Inhibition experiments were performed as described in the legend of Figure.3: $0.4 \mu \mathrm{M}$ antithrombin and $0.05 \mathrm{mg} . \mathrm{I}^{-1}$ heparin; i.e $\mathrm{I}=1.75 \mathrm{nM}$ of heparinantithrombin complexes and $398 \mathrm{nM}$ antithrombin. Shown is a plot of $-\mathrm{l} \mathrm{l} / \mathrm{ln}\left(\mathrm{E}_{2} / \mathrm{E}_{0}\right)$ versus the mean prothrombin concentration, $\mathrm{C}_{0}(0) / 2+\mathrm{C}_{0}\left(\mathrm{~L}_{4}\right) / 2$, at the capillary wall during the inhibition step. The straight line is the best fit of the model (eq.6) to these data with estimated values $\mathrm{K}_{\mathrm{mh}}=128 \times 1 \mathrm{~d}^{-1} \mathrm{M}^{-1} \min ^{-1}$ and $\mathrm{K}_{\mathrm{m}}=2.0 \mathrm{nM}$.

\section{Discussion}

The present study demonstrates that the nearly complete protection by prothrombin of prothrombinase for inhibition by antithrombin and antithrombinheparin, reported earlier $(20,25)$, is completely explained by the competition of both proteins for the active site of factor $\mathrm{Xa}$. This finding stresses the significance of the extremely high catalytic efficiency of prothrombinase complex assembled on macroscopic phospholipid bilayers. The low value of the Michaelis constant, $\mathbf{K}_{\mathrm{m}}=3$ $\mathrm{nM}$, on these surfaces, nearly two orders of magnitude lower than found for small unilamellar vesicles, results in highly effective protection by prothrombin of the prothrombinase complex for active site directed inhibitors like antithrombin.

The simple formalism as presented in eq.1-3 could be developed because prothrombinase assembly in the flow reactor is transport rate limited (19). This circumstance enabled us to simplify the description of mass transfer of prothrombin from solution to the wall of the flow reactor as given in eq. 2 in terms of a mass transfer coefficient and a uniform (site independent) concentration $\mathrm{C}_{0}$ at the capillary wall. By using this formalism we could show that the kinetics of thrombin production conforms to simple Michaelis-Menten kinetics. In this paper we extended 
this formalism to enable the analysis of competitive inhibition, cf. eq.4-7. Our experimental approach exploits the facility to assemble reproducible amounts of prothrombinase on the wall of the flow reactor by a perfusion with a mixture of factor $\mathrm{Va}$ and factor $\mathrm{Xa}$, that remains bound and stable even during perfusions lasting more than $50 \mathrm{~min}$. Therefore, the rate of prothrombinase inactivation can be calculated from the amount of residual prothrombinase after exposure to a perfusion with antithrombin or antithrombin-heparin.

A point of concern for the interpretation of our data could be the competition for antithrombin between locally produced thrombin and factor Xa assembled in the prothrombinase complex at the capillary wall. One prothrombinase complex produces about 3000 thrombin molecules per min and the consumption of antithrombin by this thrombin potentially could result in depletion of antithrombin at the wall. Such depletion would result in a decreased inactivation rate of prothrombinase with increasing thrombin production and therefore would present a trivial alternative explanation for the observed decreasing rate of inhibition with increasing prothrombin concentration near the catalytic surface. However, the maximal thrombin production in this study was below $0.3 \mathrm{pmol} \mathrm{min}^{-1}$ and antithrombin consumption at the capillary wall is thus less than $0.3 \mathrm{pmol} \mathrm{min}{ }^{-1}$. Using eq. 2 it is calculated that the antithrombin concentration at the capillary wall is at most $31 \mathrm{nM}(<1.5 \%)$ below the bulk concentration of $2-4 \mu \mathrm{M}$. For the antithrombin-heparin complexes (concentration $1.75 \mathrm{nM}$ ) the same reasoning would erroneously suggest a massive depletion. In the steady state, however, no net heparin consumption takes place at the capillary wall as heparin from the antithrombinheparin-thrombin complexes is released and reassociates with antithrombin. Therefore thrombin production only results in a small ( $<7 \%$ at $0.4 \mu \mathrm{M}$ antithrombin) depletion of antithrombin at the capillary wall.

Limited protective effects of phospholipids and factor $\mathrm{Va}$ on the inhibition of factor Xa by antithrombin and antithrombin-heparin have been reported earlier (2629). A somewhat larger reduction of the inhibition rate, namely 4-8-fold compared to factor $\mathrm{Xa}$, was reported for factor $\mathrm{Xa}$ assembled in prothrombinase during thrombin generation $(23,30)$. These experiments were performed with prothrombinase assembled on small unilamellar vesicles in the presence of 0.5-1.5 $\mathrm{mM}$ prothrombin. The limited protection observed in these earlier studies is compatible with competitive inhibition, because of the relatively high value of $\mathrm{K}_{\mathrm{m}}$ (0.1-0.2 $\mathrm{mM}$ ) found for small vesicles (5.17). Also in clotting plasma the inhibition rate of prothrombinase is significantly lower than that of free factor $\mathrm{Xa}$ (31).

Interestingly, the inhibition rate found in the present study for prothrombinase not occupied by prothrombin is comparable to the inhibition rate reported for free factor $\mathrm{Xa}$ in the presence of $\mathrm{Ca}^{2+}$. For inhibition by antithrombin we observed a true 
second order rate constant of $0.06 \times 10^{6} \mathrm{M}^{-1} \mathrm{~min}^{-1}$, which is only $50 \%$ lower than the value, $0.12 \times 10^{6} \mathrm{M}^{-1} \mathrm{~min}^{-1}$, reported for free factor $\mathrm{Xa}$ (32) The value $\mathrm{k}_{\text {inh }}=130 \times 10^{6}$ $M^{-1}$ min ${ }^{-1}$ for antithrombin-heparin (UFH) is even closer to the value $\mathrm{k}_{\text {inh }}=180 \times 10^{6}$ $\mathrm{M}^{-1} \min ^{-1}$ calculated by interpolation from the rate constants $\mathrm{k}_{\mathrm{inh}}=260 \times 10^{6} \mathrm{M}^{-1} \mathrm{~min}^{-1}$ at $1.5 \mathrm{mM} \mathrm{CaCl}_{2}$ and $120 \times 10^{6} \mathrm{M}^{-1} \mathrm{~min}^{-1}$ at $4 \mathrm{mM} \mathrm{CaCl}_{2}$ found for free factor $\mathrm{Xa}$ (33).

Prothrombin activation is a more intricate process than most enzymatic reactions analysed in studies on competitive inhibition. First, the extremely high catalytic efficiency $\left(\mathrm{k}_{\mathrm{cal}} / \mathrm{K}_{\mathrm{m}}=2 \times 10^{10} \mathrm{M}^{-1} \mathrm{~s}^{-1}\right)$ of prothrombin activation by prothrombinase bound to the macroscopic lipid membrane (19) is considerably higher than the

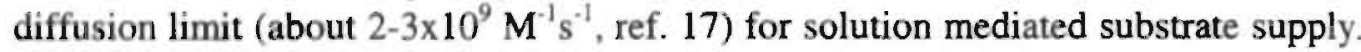
By comparison of the kinetics of prothrombin activation on small and large vesicles and on planar membranes in this earlier study we demonstrated that the value of $\mathrm{K}_{\mathrm{m}}$ decreases with increasing membrane area surrounding the prothrombinase. It was concluded that the fluxes of prothrombin from solution to the membrane and on the membrane towards the prothrombin converting complex, both regulated by the resulting prothrombin concentration in solution near the membrane, govern the kinetics of prothrombin conversion. The membrane acts as a funnel that facilitates the collection of prothrombin that once bound to the membrane is efficiently delivered to the prothrombinase by lateral transport (17). Secondly, processing of prothrombin by prothrombinase involves two successive proteolytic cleavages $(6,34)$. Despite the gross simplification associated with the application of the simple Michaelis-Menten model several studies have shown a good agreement between model and measured activation kinetics both on vesicles $(4,5,17)$ and on planar bilayers (17-19). The present study extends this observation: identical values for $K_{m}$ were obtained from kinetics of prothrombin conversion and from the prothrombin dependent kinetics of prothrombinase inhibition. This confirms the notion that the Michaelis constant reflects the binding of prothrombin to factor $\mathrm{Xa}$ in the prothrombinase complex.

Comparison of pentasaccharide and UFH revealed that the latter heparin on molecular basis is about 30 -fold more effective as an inhibitor of prothrombinase (20). This suggests a role of heparin-prothrombinase interaction in the enhanced inhibition in addition to the pentasaccharide. Despite this conjectured interaction our data show that inhibition of prothrombinase by heparin-antithrombin complexes is also fully competitive, with a similar value of the Michaelis constant, $K_{m}=2 n M$, estimated from the inhibition kinetics.

The observation that inhibition of prothrombinase by antithrombin is fully competitive with prothrombin conversion is probably physiological relevant. With a value of the Michaelis constant $K_{m}=3 \mathrm{nM}$ nearly 700 to 1000 -fold below the plasma 


\section{Chapter 5}

concentration, our observation indicates a complete protection of prothrombinase during the initial phase of activation of the coagulation cascade.

\section{References}

1. Jackson, C. M., and Nemerson, Y. (1980) Annu. Rev. Biochem. 49: 765-811.

2. Mann K.G., Nesheim M.E., Church W.R., Haley P., \& Krishnaswamy S. (1990) Blood 76: 1-16.

3. Hemker H.C., Esnouf M.P., Hemker P.W., Swart A.C.W., \& MacFarlane RG. (1967) Nature 215: 248-251.

4. Nesheim M.E., Taswell J.B., \& Mann K.G. (1979) J. Biol. Chem. 254: 10952-10962.

5. Rosing J., Tans G., Govers-Riemslag J.W.P., Zwaal R.F.A., \& Hemker H.C. (1980) J. Biol. Chem. 255: 274-283.

6. Rosing, J., Zwaal, R.F.A., \& Tans, G. (1986) J. Biol. Chem. 261: 4224-4228.

7. Zwaal, R.F.A., Comfurius, P.,\& Bevers, E.M. (1992) Biochim. Biophys. Ácta. 1180: 1-8.

8. Comfurius P., Smeets E.F., Willems G.M., Bevers E.M., \& Zwaal R.F.A. (1994) Biochemistry 33: 10319-10324.

9. Esmon C.T. (1989) J. Biol. Chem. 264: 4743-4746.

10. Rapaport S.I. (1989) Blood 73: 359-365.

11. Egeberg O. (1965) Thromb. Diath. Haemorrh. 13:516-530.

12. Abilgaard U. (1969) Scand. J. Clin. Lab. 24: 23-27.

13. Rosenberg R.D., \& Damus P.S. (1973) J. Biol. Chem. 248: 6490-6505.

14. Olson S.T. (1988) J. Biol. Chem. 263: 1698-1708.

15. Craig P.A., Olson S.T., \& Shore J.D. (1989) J. Biol. Chem. 264: 5452-5461.

16. Schoen P., Lindhout T., Willems G., \& Hemker H.C. (1990) Thromb. Haemostas. 64: 542-547.

17. Giesen, P.L.A., Willems, G.M., \& Hermens, W.Th. (1991) J. Biol. Chem. 266: 1379-1382.

18. Willems, G.M., Giesen, P.L.A., \& Hermens, W.Th. (1993) Blood 82: 497-504.

19. Billy D., Speijer H., Willems G., Hemker H.C., \& Lindhout T. (1995) J. Biol. Chem. 270: 1029-1034.

20. Speijer, H., Billy, D., Willems, G., Hemker, H.C., \& Lindhout, T. (1995), Thromb. Heamostas. 73: 648-653.

21. Schoen P., Wielders S., Petitou M., \& Lindhout T. (1990) Thromb. Res. 57: 415-423.

22. Lindhout T., Govers-Riemslag J.W.P. van de Waart P., Hemker H.C., \& Rosing J. ( 1982) Biochemistry 21: 5494.5502.

23. Schoen P., Lindhout T., Willems G.M., \& Hemker H.C. (1989) J. Biol. Chem. 264: I0002-10007.

24. Willems, G. M., Giesen, P. L. A., and Hermens, W. Th. (1993) Blood 82:497-504

25. Schoen P., \& Lindhout T. (1991) Blood 78, 118-124.

26. Marciniak E. (1973) Br. J. Haematol. 24, 391-400.

27. Teitel, J.M., \& Rosenberg R.D. (1983) J. Clin. Invest. 71, 1383-1391.

28. Ellis V., Scully M.F., \& Kakkar V.V. (1986) Biochem. J. 233, 161-165.

29. Barroweliffe T.W., Havercroft S.J.. Kemball-Cook G., \& Lindahl U. (1987) Biochem. J. 243. 31-37.

30. Lindhout T. Baruch D., Schoen P.. Franssen J.. \& Hemker H.C. (1986) Biochemistry 25, 5962-5969.

31. Béguin S., Lindhout T., \& Hemker H.C. (1988) Thromb. Haemost. 60, 457-462.

32. Olson S.T., Björk L., Sheffer R. Craig P.A., Shore J.D., \& Choay J. (1992) J. Bıol. Chem. 267. 12528-12538.

33. Schoen. P., Lindhout, T., \& Hemker. H.C. (1992) Brit. J. Haematol. 81, 255-262.

34. Krishnaswamy, S., Mann. K.G., \& Nesheim ME. (1986) J. Biol. Chem. 261, 8977-8985. 



\section{Chapter 6}

\section{Prothrombin Contributes to the Assembly of the Factor Va-Factor Xa Complex at Phosphatidylserine-containing Phospholipid Membranes.}

Didier Billy, George Willems, H. Coenraad Hemker, and Theo Lindhout, 1995. J. Biol. Chem. 270: 26883-26889.

\section{Summary.}

The activation of prothrombin is catalyzed by prothrombinase, a complex of factor $\mathrm{Xa}$ and factor $\mathrm{Va}$ assembled on a negatively charged phospholipid membrane. We used a tubular flow reactor to identify the relative contributions of factor $\mathrm{Va}$, prothrombin and the negatively charged phosphatidylserine to the assembly of prothrombinase. Perfusion of phospholipid-coated capillaries with a mixture of factor $\mathrm{Xa}$, factor $\mathrm{Va}$ and prothrombin resulted in a steady-state rate of thrombin production that increased with (i) the phosphatidylserine content of the phospholipid bilayer, (ii) the factor $\mathrm{Va}$ concentration and, most interestingly, (iii) the prothrombin concentration of the perfusion solution. Incorporation of $20 \mathrm{~mol} \%$ phosphatidylethanolamine, a phospholipid with poor ability to promote prothrombinase activity, into a $5 \mathrm{~mol} \%$ phosphatidylserine membrane also increased the steady-state rate of thrombin production. Direct measurements of the amount of prothrombinase in the flow reactor demonstrated that increased catalytic activities were the result of an increased steady-state amounts of membrane-associated prothrombinase. Thus, similar turnover numbers of prothrombin activation $\left(3100 \mathrm{~min}^{-1}\right)$ were calculated, irrespective of the phosphatidylserine content of the membrane. We established for membranes with low phosphatidylserine content $(<10 \mathrm{~mol} \%)$ a linear relationship between the prothrombinase activity and the arithmetical product of the factor $\mathrm{Va}$ concentration in the perfusion solution and the prothrombin concentration near the catalytic surface. Our results indicate that in addition to factor $\mathrm{Va}$ also prothrombin is essential to the assembly of prothrombinase at macroscopic surfaces with low phosphatidylserine content. The data further suggest that the prothrombin concentration near the surface, controlled by the prothrombinase activity and mass transfer, is an important regulator of the prothrombinase surface density.

\section{Introduction}

Prothrombinase, the enzyme complex that converts prothrombin into thrombin, is composed of the serine protease factor $\mathrm{Xa}$, the protein cofactor factor $\mathrm{Va}$, and phospholipids $(1,2)$. Kinetic studies have indicated that the reversible proteinphospholipid and protein-protein interactions in the prothrombinase complex all contribute to the $10^{5}$ fold increase in the catalytic efficiency of factor Xa (3-6). It is 
generaily accepted that the interaction of factor $\mathrm{Xa}$ with factor $\mathrm{Va}$ enhances the tumover number of factor $\mathrm{Xa}$ about 3000-fold (5) and that the interaction of prothrombin with the membrane is responsible for a dramatic decrease in the $\mathrm{K}_{\mathrm{m}}$ for prothrombin activation, namely from $\approx 90 \mu \mathrm{M}$ in the absence of phospholipid (5) to about $3 \mathrm{nM}$ in the presence of a planar membrane $(7,8)$.

Negatively charged phospholipids are essential constituents of membranes that support prothrombin activation $(9,10)$. Optimum prothrombinase activity has been reported for membranes that contain at least $10 \mathrm{~mol} \%$ phosphatidylserine (11-14). It is rationalized that this dependency is the result of the lower binding affinity of membranes with low phosphatidylserine content for the protein constituents of the enzyme complex (factor $\mathrm{Xa}$ and factor $\mathrm{Va}$ ) as well as for of its substrate prothrombin (15-17). Consequently, membranes with a low phosphatidylserine content require higher concentrations of fluid phase factor $\mathrm{Va}$ to incorporate the same amount of factor $\mathrm{Xa}$ into membrane-associated prothrombinase than membranes with a high phosphatidylserine content $(11,18,19)$. The reported $k_{\text {cat }}$ values therefore do not always reflect the true catalytic ability $(13,14)$.

Because factor Va also interacts with phospholipid-bound prothrombin $(20,21)$ one cannot a priori exclude the possibility that prothrombin contributes to the stability of the prothrombinase complex. The consequence of such an effect is that increasing amounts of factor $\mathrm{Xa}$ will be incorporated into the prothrombinase complex with increasing prothrombin concentrations (22). It has been shown, though, that prothrombin does not contribute to the assembly of prothrombinase at membranes with $25 \mathrm{~mol} \%$ phosphatidylserine, under conditions that were considered as physiologically relevant with respect to the factor $\mathrm{Va}$ and factor Xa concentrations (19). However, no information is available about the role of prothrombin under conditions that are less optimal for prothrombinase assembly, e.g. low phosphatidylserine content and non-saturating conditions with respect to reactant concentrations. Such a situation might prevail when coagulation takes place at the surface of activated platelets or other cells in flowing blood (23). Interestingly, a stabilizing effect of a substrate on its membrane-bound cofactor-enzyme complex has been reported, namely that of factor $\mathrm{X}$ on the tissue factor- factor VIIa complex (24).

In the present study, we used a tubular flow reactor to assess the contribution of prothrombin to the assembly of prothrombinase and the kinetics of prothrombin activation at low phosphatidylserine membranes. In earlier studies with prothrombinase in a tubular flow reactor we demonstrated that the kinetics of prothrombinase assembly and the kinetics of thrombin production can be adequately described using a simple model for mass transport for immobilized enzymes (8). Therefore, the tubular flow reactor may have some clear advantages over the 


\section{Chapter 6}

experimental settings using unilamellar phospholipid vesicles. Firstly, the prothrombin concentration near the catalytic surface can be easily calculated from the flow conditions, the concentration of prothrombin in the bulk solution and the thrombin production in the flow reactor. Secondly, the amount of prothrombinase in the flow reactor can be readily estimated from the amount of phospholipid-bound factor Xa. This paper reports in detail on the relative contributions of prothrombin, factor $\mathrm{Va}$ and the phosphatidylserine content to the assembly of prothrombinase and their implications for the kinetics of prothrombin activation.

\section{Experimental Procedures}

Materials. 1,2-Dioleoyl-sn-glycero-3-phosphatidylserine (DOPS), 1,2-Dioleoylsn-glycero-3-phosphatidylcholine (DOPC) and 1.2-Dioleoyl-sn-glycero-3phosphatidylethanolamine (DOPE) were purchased from Avanti Polar Lipids, Inc. (Alabaster, $\mathrm{AL}$ ). S2238, the chromogenic substrate for thrombin, was obtained from Chromogenix (Mölndal, Sweden). Bovine serum albumin (BSA) was from Sigma (St. Louis, MO). Bovine factor $\mathrm{V}$ and factor $\mathrm{Va}$ were prepared and quantitated as previously described (18). Human prothrombin was purified as described (25) and the molar concentration was determined after complete activation with Echis carinatus venom (Sigma, St. Louis, MO) by active site titration with p-nitrophenyl p'-guanidinobenzoate hydrochloride (pNPGB) (26). Human factor Xa was prepared by activation of purified factor $\mathrm{X}$ (27) with the factor $\mathrm{X}$ activating protein from Russell's Viper venom (Sigma, St. Louis, MO) and isolated as described for bovine factor Xa (28). The molar concentration was determined by active site titration with pNPGB (29). Small unilamellar vesicles of mixed phospholipids were prepared as described before (30). Throughout this paper, the mixed phospholipids are described with their mol\% of the negatively charged phospholipid; the remainder of the phospholipid is DOPC.

The flow reactor. The capillary flow reactor used in this study has been described (8). Briefly, microcapillary tubes (length of $127 \mathrm{~mm}$ and inner diameter of $0.65 \mathrm{~mm}$ ) obtained from Brand AG (Wertheim, Germany), were cleaned and coated with a bilayer of phospholipids. Thereafter, the phospholipid-coated capillaries were perfused with a reaction mixture containing factor $\mathrm{Xa}$, factor $\mathrm{Va}$ and prothrombin in Tris-buffer ( $50 \mathrm{mM}$ Tris- $\mathrm{HCl}, 175 \mathrm{mM} \mathrm{NaCl}, 3 \mathrm{mM} \mathrm{Cacl}_{2}$, pH 7.9, containing $0.5 \mathrm{mg}$ $\mathrm{BSA} / \mathrm{ml})$. Samples $(60 \mu \mathrm{l})$ were collected at the outlet of the flow reactor into cuvettes containing $500 \mu \mathrm{l}$ of $50 \mathrm{mM}$ Tris- $\mathrm{HCl}, 175 \mathrm{mM} \mathrm{NaCl}, 20 \mathrm{mM}$ EDTA, 0.5 $\mathrm{mg} \mathrm{BSA} / \mathrm{ml}, \mathrm{pH} 7.9$ and assayed for thrombin after addition of $60 \mu \mathrm{l}$ of S2238 (2.4 $\mathrm{mM}$ ) as described (8). The rate of thrombin production in the flow reactor, pmol thrombin/min, is calculated from the thrombin concentration at the outlet (P) and the 
volumetric flow rate $(Q)$ : $v=P Q$. All experiments were performed at $37^{\circ} \mathrm{C}$ and at a flow rate of $30 \mu \mathrm{l} / \mathrm{min}$ (wall shear rate of $20 \mathrm{~s}^{-1}$ ).

Determination of prothrombinase density in the flow reactor. At the end of a perfusion experiment, the capillaries containing $42 \mu \mathrm{l}$ perfusion solution were emptied in $42 \mu 1$ of $50 \mathrm{mM}$ Tris- $\mathrm{HCl}, 175 \mathrm{mM} \mathrm{NaCl}, 5 \mathrm{mM}$ EDT A, $0.5 \mathrm{mg} \mathrm{BSA} / \mathrm{ml}$, $\mathrm{pH} 7.9$ and thoroughly rinsed with the combined solutions. An additional rinse with $42 \mu \mathrm{l}$ of Tris/EDTA-buffer was performed to assure a quantitative recovery of phospholipid-bound factor Xa. After dilution of the eluant, $30 \mu \mathrm{l}$ was added to a cuvette with $420 \mu \mathrm{l}$ Tris-buffer that contained factor Va $(0.6 \mathrm{nM})$, phospholipid vesicles ( $25 \mathrm{~mol} \%$ DOPS/ $75 \mathrm{~mol} \%$ DOPC, $12 \mu \mathrm{M}$ ), and the chromogenic substrate $\mathrm{S} 2238(0.24 \mathrm{mM})$. After $4 \mathrm{~min}$ at $37^{\circ} \mathrm{C}, 50 \mu \mathrm{l}$ prothrombin $(5 \mu \mathrm{M})$ was added. The progress curve of optical density at $405 \mathrm{~nm}$ was analyzed according to a quadratic function to yield the amount of factor Xa present in the sample. Reference curves were prepared from known amounts of factor $\mathrm{Xa}$. The amount of phospholipidbound factor Xa was obtained by subtracting the known amount of factor $\mathrm{Xa}$ in the perfusion solution present in the capillary from the measured amount of factor $\mathrm{Xa}$ in the sample. Control experiments revealed that the amount of factor Xa-bound to the membrane but not complexed with factor $\mathrm{Va}$ was negligible. Capillaries with 10 mol\% DOPS $/ 90 \mathrm{~mol} \%$ DOPC were perfused with factor Xa (2 pM) and prothrombin $(200 \mathrm{nM})$ in the absence of factor Va. The total amount of factor Xa in the capiliary at the end of the perfusion did not differ significantly from the amount that was present in the fluid phase of the capillary.

Kinetics for the transport-limited prothrombin conversion. The rate of conversion of prothrombin to thrombin by membrane-bound prothrombinase equals the rate at which prothrombin can be supplied from the bulk solution to the catalytic surface (32):

$$
V=\Delta\left(C_{b}-C_{0}\right)
$$

where $\Delta$ is the mass transfer coefficient. $C_{b}$ is the prothrombin concentration in the bulk soltution, and $\mathrm{C}_{0}$ is the prothrombin concentration near the catalytic surface. The mass transfer coefficient is a function of the geometry of the capillary, the volumetric flow rate, the kinematic viscosity of the fluid and the diffusion coefficient of the protein. For a flow rate of $30 \mu \mathrm{l} / \mathrm{min}$ and the capillary (length $12.7 \mathrm{~cm}$ and inner diameter of $0.065 \mathrm{~cm}$ ) used in this study, the mass transfer coefficient, $\Delta$, for prothrombin equals $0.01 \mathrm{~cm}^{3} / \mathrm{min}$ (cf. Ref. 8).

The maximum rate of prothrombin activation,

$$
\mathrm{V}_{\max }=\Delta \mathrm{C}_{\mathrm{b}}
$$




\section{Chapter 6}

is thus obtained when the membrane-bound enzymatic activity causes a total depletion of the prothrombin concentration near the surface $\left(\mathrm{C}_{0}=0\right)$. For intermediate situations when the rate of prothrombin activation is smaller than the prothrombin mass transfer rate, the prothrombin concentration at the capillary wall can be calculated from Equation 1:

$$
\mathrm{C}_{0}=\mathrm{C}_{\mathrm{b}}-\mathrm{V} / \Delta
$$

\section{Results}

The assembly of prothrombinase from perfusion mixtures containing factor $\mathrm{Xa}_{\text {a }}$ factor $\mathrm{Va}$ and prothrombin. Phospholipid-coated capillaries were perfused (30 $\mathrm{ml} / \mathrm{min}$ ) with Tris-buffer containing $2 \mathrm{pM}$ factor Xa, $50 \mathrm{pM}$ factor $\mathrm{Va}$ and $100 \mathrm{nM}$ prothrombin. Fig.1 shows that the rate of thrombin production increased until a steady-state was reached of $0.2 \mathrm{pmol} / \mathrm{min}$ for the membrane containing $5 \mathrm{~mol} \%$ DOPS and a maximum of $1 \mathrm{pmol} / \mathrm{min}$ for the membrane containing $25 \mathrm{~mol} \%$ DOPS.

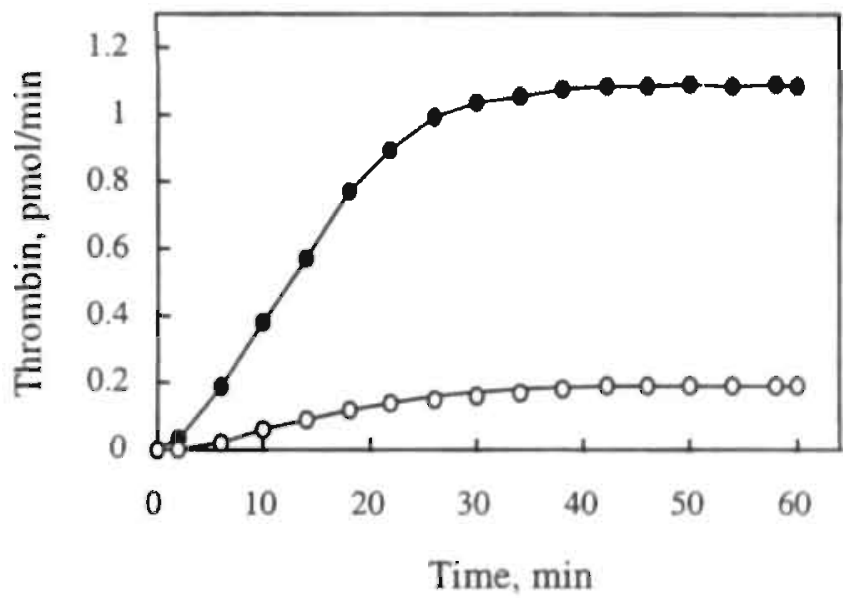

Figure 1. Thrombin generation in a tubular flow reactor. Capillanes coated with a phospholipid membrane containing 5 . mol\% DOPS-95 mol\% DOPC $(\mathrm{O})$ and 25 mol\% DOPS-75 mol\% DOPC (-) were perfused with Tris-buffer containing factor $\mathrm{Xa}(2 \mathrm{pM})$, factor $\mathrm{Va}(50 \mathrm{pM})$, and prothrombin $(100 \mathrm{nM})$. The perfusion was performed at a flow rate of 30 . $\mu \mathrm{l} / \mathrm{min}$ (wall shear rate of $20 \mathrm{~s}^{-1}$ ) at $37^{\circ} \mathrm{C}$. The rate of thrombin production is plotted versus the perfusion time.

Measurement of the amount of factor Xa bound to the phospholipid bilayer in the flow reactor at the end of the perfusion experiments showed that $0.06 \mathrm{fmol}$ and $0.66 \mathrm{fmol}$ prothrombinase were assembled at the $5 \mathrm{~mol} \%$ and $25 \mathrm{~mol} \%$ DOPS membranes, respectively. The turnover numbers of prothrombin activation are thus. $2970 \mathrm{~min}^{-1}$ and $1500 \mathrm{~min}^{-1}$, respectively. As pointed out under Experimental Procedures, the steady-state rate of thrombin production under the conditions of the 
experiment cannot exceed $1 \mathrm{pmol} / \mathrm{min}$ (Equation 2). Therefore, it is reasonable to assume that in the latter case the transport-limited supply of prothrombin causes the lower turnover number. Interestingly, the turnover number measured for the $5 \mathrm{~mol} \%$ DOPS membrane is close to the $\mathrm{k}_{\text {cat }}$ previously reported for $25 \mathrm{~mol} \%$ phosphatidylserine membranes (8).

An other interesting feature of the flow experiment with the $5 \mathrm{~mol} \%$ DOPS membrane is that in spite of a continuous perfusion with a mixture of $2 \mathrm{pM}$ factor $\mathrm{Xa}, 50 \mathrm{pM}$ factor $\mathrm{Va}$ and $100 \mathrm{nM}$ prothrombin not more than $0.06 \mathrm{fmol}$ of prothrombinase could be assembled. Based on reported binding parameters for the factor Va-factor Xa complex (cf. Ref.13), we estimated that the binding capacity of the $5 \mathrm{~mol} \%$ DOPS membrane is at least $10^{4}$ fold higher. It is apparent that an equilibrium was established between membrane-associated prothrombinase and the reactants in the perfusion solution.

The steady-state rate of thrombin production as a function of the DOPS content of the membrane. Capillaries with phospholipid bilayers that contained varying mol\% DOPS (2-10 mol\%) were perfused with factor Xa (2 pM), factor Va (50 pM) and prothrombin $(100 \mathrm{nM})$. The perfusion was continued until a steady-state rate of thrombin production was reached. At the end of the perfusion, we measured the amount of prothrombinase present in the capillary. Fig.2 shows the relationship between the rate of thrombin production and the amount of prothrombinase as a function of the DOPS content of the membrane. It is apparent that both the steadystate rate of thrombin production and the amount of prothrombinase increased equally with the DOPS content of the membrane. As a result, the tumover number $\left(3100\right.$ min $\left.^{-i}\right)$ did not change with the DOPS content of the membrane. We note that in all experiments the steady-state rate of thrombin production was below the transport-limited rate of $1 \mathrm{pmol} / \mathrm{min}$. The results obtained so far indicate that if the thrombin production reaches a steady-state, the amount of prothrombinase in the flow reactor is in equilibrium with the reactants in the perfusion solution. It is concluded that under these conditions the thrombin production is proportional to the amount of prothrombinase assembled at the phospholipid-coated capillary wall.

The steady-state rate of thrombin production as a function of the factor $\mathrm{Va}$ concentration. From earlier studies on the assembly of prothrombinase activity on vesicles it is known that membranes with a low DOPS content need higher factor $\mathrm{Va}$ concentrations to assembly the same amount of prothrombinase found with membranes of high DOPS content $(4,18)$.

To examine the contribution of factor $\mathrm{Va}$ to the assembly of an equilibrium concentration of prothrombinase in the flow reactor, phospholipid (5 mol\% DOPS)coated capillaries were perfused with Tris-buffer containing $2 \mathrm{pM}$ factor $\mathrm{Xa}, 100 \mathrm{nM}$ prothrombin and varying concentrations of factor $\mathrm{Va}(0.01-2 \mathrm{nM})$ until a steady-state 


\section{Chapter 6}

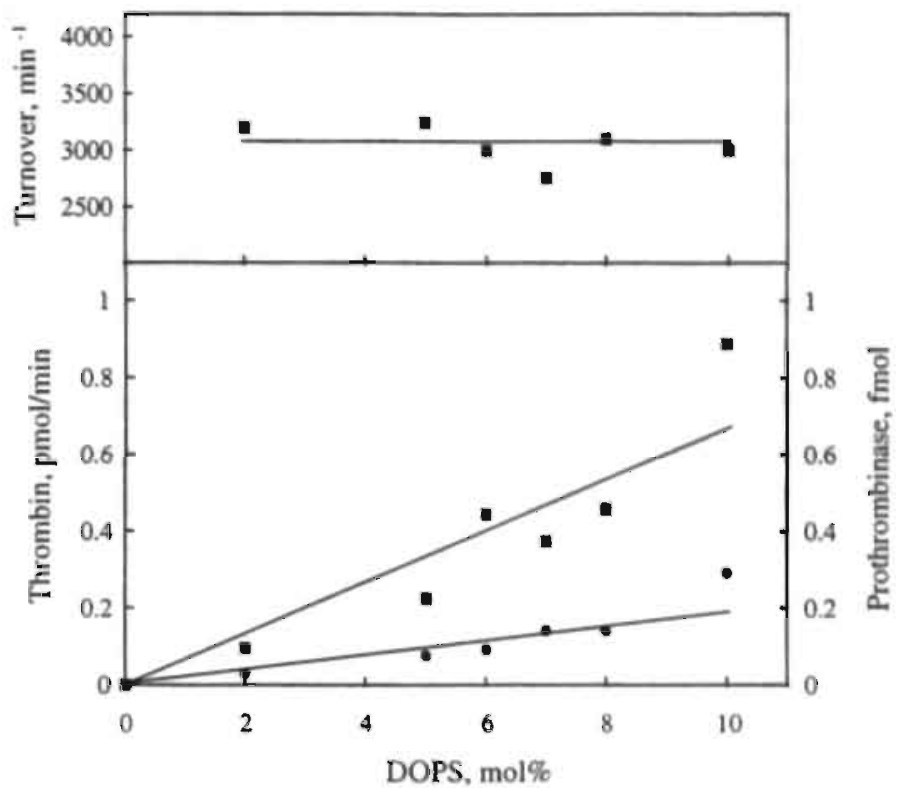

Figure 2. The steady-state rate of thrombin formation as function of the DOPS content of the membrane. Capillaries with membranes of varying DOPS content were perfused as described. for Fig. 1. Lower panel gives the steady-state rate of thrombin production (1) and the amount of prothrombinase in the capillary at the time the steady-state of thrombin production was obtained (-) as a function of the DOPS content of the membrane. The upper panel gives the turnover number of prothrombin activation calculated from rate of thrombin production and prothrombinase concentration.

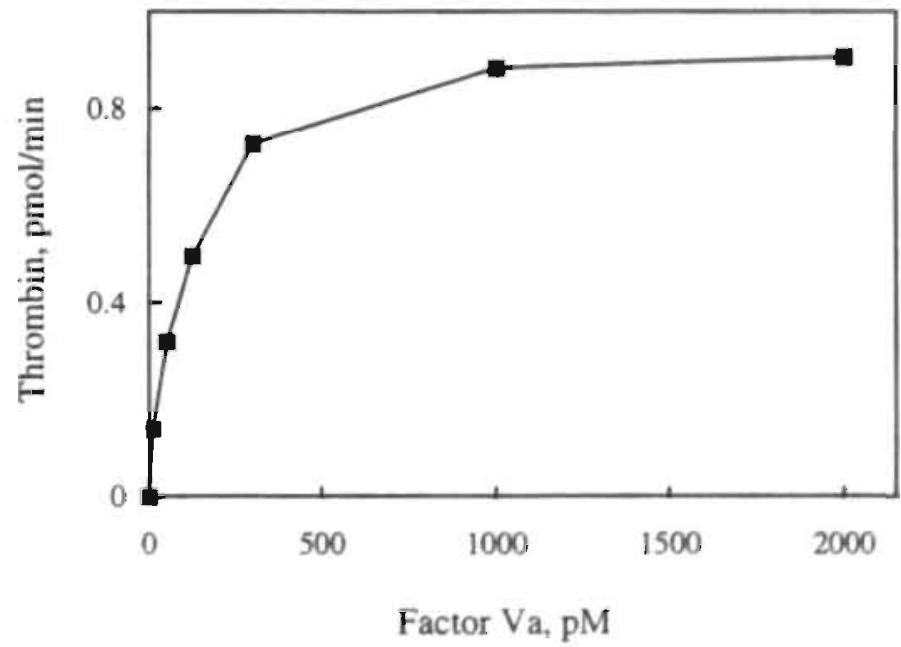

Figure 3. The steady-state rate of thrombin formation as function of the factor $\mathrm{V}_{\mathrm{a}}$ concentration in the perfusion solution. Phospholipid-coated (5 mol\% DOPS-95 mol\% DOPC) capillanes were perfused with Tris-buffer containing 2 $\mathrm{pM}$ factor $\mathrm{Xa}, 100 \mathrm{nM}$ prothrombin, and varying factor $\mathrm{V}_{\mathrm{a}}$ concentrations. 
rate of thrombin production was reached. The steady-state rate of thrombin production increased with the factor Va concentration in the perfusion solution until a maximum of $0.9 \mathrm{pmol} / \mathrm{min}$ (Fig.3). This value is close to the transport rate limit of $1 \mathrm{pmol}$ thrombin/min.

The steady-state rate of thrombin production as a function of the prothrombin concentration and the DOPS content of the membrane. To investigate the contribution of prothrombin to the assembly of prothrombinase at a macroscopic phospholipid surface, capillaries coated with membranes of varying DOPS content (5-10 mol\%) were perfused with mixtures that contained factor Xa (2 pM), factor $\mathrm{Va}$ $(50 \mathrm{pM})$ and varying prothrombin concentrations (50, 100 and $200 \mathrm{nM})$. The steadystate rate of thrombin production increased with increasing prothrombin concentration in the perfusion solution and with increasing DOPS content of the membrane (Table I).

Table I. Effect of Prothrombin and Lipid Composition on the Assembly and Catalytic Activity of Prothrombinase

\begin{tabular}{|c|c|c|c|c|}
\hline $\begin{array}{l}\text { Phospholipid } \\
\text { composition }\end{array}$ & $\begin{array}{l}\text { Prothrombin } \\
\text { concentration }\end{array}$ & $\begin{array}{c}\text { Rate of thrombin } \\
\text { production }\end{array}$ & $\begin{array}{c}\text { Membrane-associated } \\
\text { prothrombinase }\end{array}$ & $\begin{array}{c}\text { Tumover } \\
\text { rate } \\
\end{array}$ \\
\hline & $\mathrm{nM}$ & $\mathrm{pmol} / \mathrm{min}$ & fmol & $\min ^{-1}$ \\
\hline \multirow[t]{3}{*}{ PSPC 5:95 } & 50 & 0.09 & 0.024 & 3700 \\
\hline & 100 & 0.19 & 0.055 & 3400 \\
\hline & 200 & 0.31 & 0.11 & 2800 \\
\hline \multirow[t]{3}{*}{ PSPC 6:94 } & 50 & 0.10 & 0.026 & 3800 \\
\hline & 100 & 0.45 & 0.09 & 3000 \\
\hline & 200 & 0.59 & 0.21 & 2800 \\
\hline \multirow[t]{3}{*}{ PSPC 7:93 } & 50 & 0.13 & 0.033 & 3900 \\
\hline & 100 & 0.36 & 0.14 & 2600 \\
\hline & 200 & 0.85 & 0.28 & 3000 \\
\hline \multirow[t]{3}{*}{ PSPC 8:92 } & 50 & 0.25 & 0.1 & 2500 \\
\hline & 100 & 0.46 & 0.14 & 3200 \\
\hline & 200 & 0.90 & 0.31 & 2900 \\
\hline \multirow[t]{2}{*}{ PSPC 10:90 } & 100 & 0.87 & 0.29 & 3000 \\
\hline & 200 & 1.44 & 0.45 & 3200 \\
\hline
\end{tabular}


It is important to note that the observed rates of thrombin production were well below the transport limited rate of prothrombin conversion. The increase of the steady-state rates of thrombin production with increasing prothrombin concentration and increasing DOPS content was due to an increased assembly of prothrombinase (Table I). It appeared that the turnover numbers calculated from the rate of thrombin production and the prothrombinase content of the flow reactor did not vary significantly with the prothrombin concentration and the DOPS content of the membrane. As a matter of fact, the turnover numbers thus obtained were close to the values earlier reported (8) for membranes with $25 \mathrm{~mol} \%$ phosphatidylserine.

The steady-state rate of thrombin production as a function of the prothrombin and factor $\mathrm{Va}$ concentration. We already demonstrated that the amounts of prothrombinase assembled at the time that a steady-state rate of thrombin production was reached, increased with the DOPS content of the membrane as well as with the factor $\mathrm{Va}$ and prothrombin concentration in the perfusion solution. Next we designed experiments to unravel the relative contributions of factor $\mathrm{Va}$ and prothrombin to the assembly of membrane-associated prothrombinase. Fig.4 shows the thrombin production in capillaries containing $5 \mathrm{~mol} \%$ DOPS as function of the prothrombin concentration.

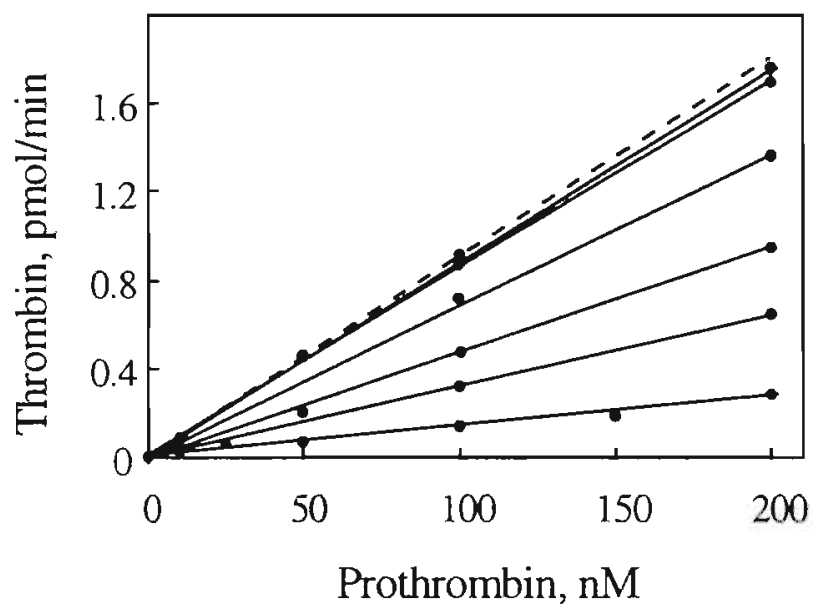

Figure 4. The steady-state rate of thrombin formation as function of the prothrombin concentration in the perfusion solution. Capillaries that contained a phospholipid bilayer composed of 5 mol\% DOPS-95 mol\% DOPC were perfused with Tris-buffer containing $2 \mathrm{pM}$ factor $\mathrm{Xa}$, prothrombin at the indicated concentrations and, from bottem to top. 10. 20, $100,300,1000$ and $2000 \mathrm{pM}$ factor $\mathrm{Va}$. The steady-state rates of thrombin production are plotted versus the prothrombin concentration in the perfusion solution. The dotted line represents the transport-limited rate of thrombin production under the conditions of the flow experiment. 


\section{Chapter 6}

It is apparent that at fixed factor $\mathrm{Xa}$ and factor Va concentrations the rate of prothrombin activation increased linearly with the prothrombin concentration in the perfusion solution. The slopes of these lines clearly increased with increasing factor Va concentrations in the perfusion solution. The interesting question that remains to be answered is whether the slopes of the lines depicted in Fig.4 increased linearly with the factor $\mathrm{Va}$ concentration. If so, then factor $\mathrm{Va}$ and prothrombin contribute equally to the assembly of the prothrombinase complex.

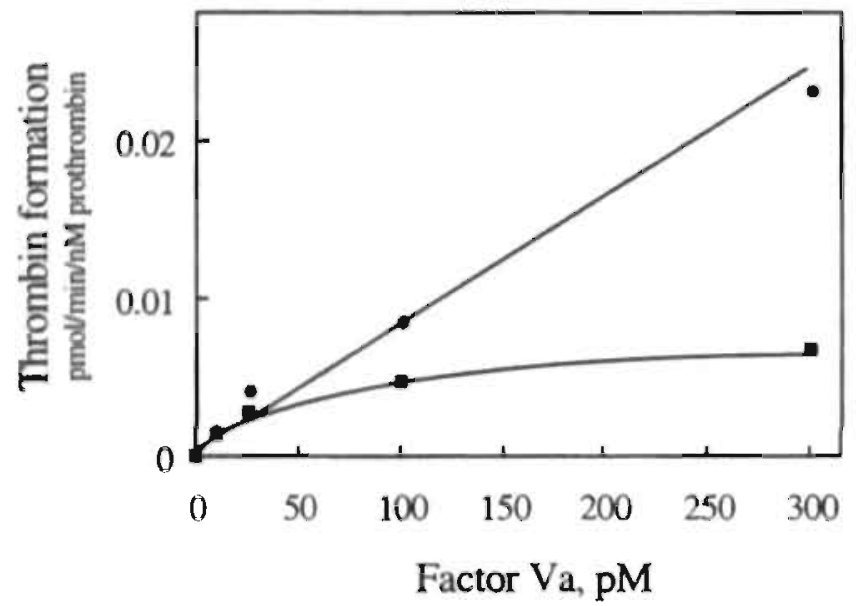

Figure 5. Effect of factor $\mathrm{V}_{\mathrm{a}}$ on the steady-state rate of thrombin production normalized for the prothrombin. concentration in the perfusion solution or near the surface. The slopes of the lines of Fig.4, with the exception of those obtained with 1 and $2 \mathrm{nM}$ factor $\mathrm{Va}$, are plotted versus the factor $\mathrm{Va}$ concentration in the perfusion solution (closed squares). The closed circles are the slopes of the same rates of thrombin production plotted versus the corresponding prothrombin concentration near the surface, calculated using Equation 3.

From Fig. 5 it is clearly seen that the slopes of the lines of Fig.4 do not increase linearly with the factor $\mathrm{Va}$ concentration in the range of 10 to $300 \mathrm{pM}$ (closed squares). However, as noted under Experimental Procedures (Equation 3), the presence of prothrombinase can easily cause a sever depletion of prothrombin near the catalytic surface. As a matter of fact, Equation 3 predicts that with a constant. prothrombin concentration in the perfusion solution $\left(\mathrm{C}_{b}\right)$, the prothrombin concentration near the surface $\left(\mathrm{C}_{0}\right)$ will decrease in parallel with the factor $\mathrm{Va}$ dependent increase of the rate of thrombin production. The slope of the lines shown in Fig.4, therefore, should be corrected for the true prothrombin concentration, i.e. $\mathrm{C}_{0}$. The closed circles in Fig.5 are the result of this correction. It is now clearly seen that the rate of thrombin production, normalized for the prothrombin concentration. near the catalytic surface, linearly increased with the factor Va concentration. The 
observed linear relationships indicate that for a constant amount of factor $\mathrm{Xa}$ in the perfusion solution, the equilibrium amount of membrane-associated prothrombinase is proportional to the arithmetical product of the factor Va concentration in the bulk solution and the prothrombin concentration near the surface.

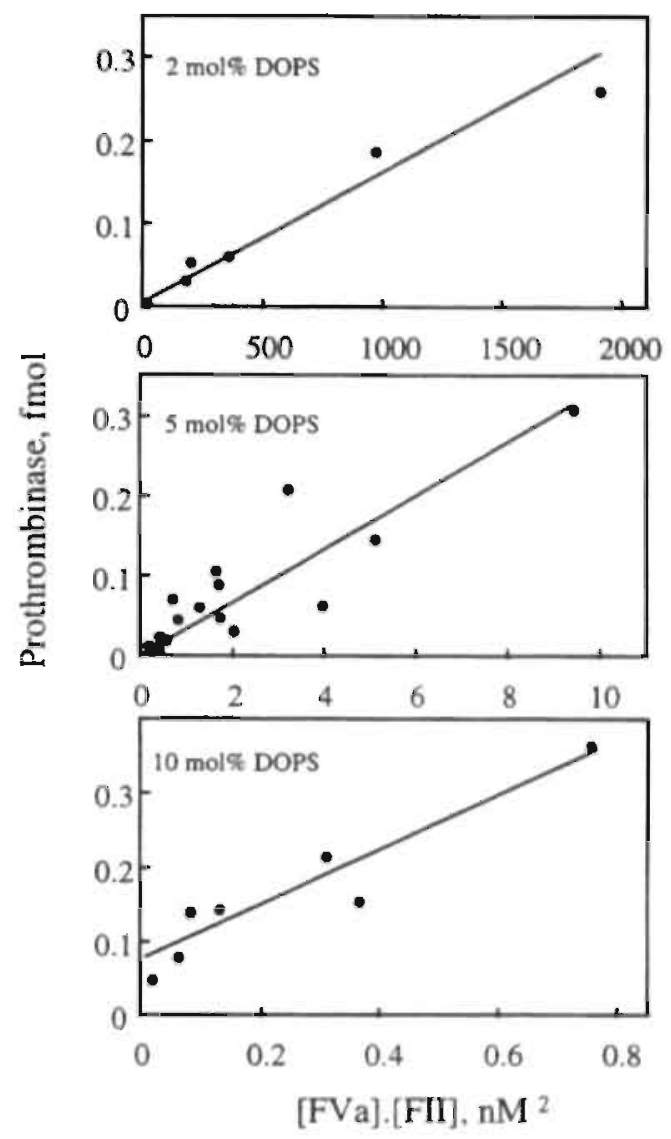

Figure 6. Dependency of prothrombinase density at membranes with varying DOPS on the arithmetical product of the factor $\mathrm{Va}$ concentration in the perfusion solution and the prothrombin concentration near the surface. Capillaries with 2. 5 and 10 mol\% DOPS membranes were perfused with 2 pM factor $\mathrm{Xa}_{3}$ 5-100 pM factor $\mathrm{Va}_{\mathrm{a}}$ and 50-200 nM prothrombin. The amounts of prothrombinase at the steady-state phase of thrombin production and the prothrombin concentration near the surface were calculated from the steady-state rates of thrombin production and prothrombin concentration in the perfusion solution, respectively. Further details are given in the text.

In order to substantiate our notion, we measured in similar experiments, as shown in Fig.4, the steady-state rates of thrombin production at membranes with 2, 5 and $10 \mathrm{~mol} \%$ DOPS membranes as a function of the factor $\mathrm{Va}$ and the prothrombin concentration. The amount of prothrombinase was obtained from the steady-state 
rates of thrombin production divided by the previously determined (Fig.2) tumover number of $3100 \mathrm{~min}^{-1}$. In an attempt to obtain accurate data we selected experimental conditions, i.e. factor $\mathrm{Va}$ and prothrombin concentrations in the perfusion solution, that gave less than $70 \%$ depletion of the prothrombin near the catalytic surface in the steady-state phase of the experiment. Fig.6 shows for the different membranes the relationship between the amount of prothrombinase associated with the membrane and the arithmetical product of the factor Va concentration in the bulk solution and the prothrombin concentration near the surface. The slopes of the lines $( \pm \mathrm{SE}$ ), obtained by linear regression analysis, are $(1.4 \pm 0.1) \times 10^{-4},(2.9 \pm 0.4) \times 10^{-2}$ and $(3.7 \pm 0.5) \times 10^{-1} \mathrm{fmol} / \mathrm{nM}^{2}$ for the membranes with 2,5 and $10 \mathrm{~mol} \%$ DOPS, respectively.

The effect of phosphatidylethanolamine on the assembly of prothrombinase. Natural membranes contain relatively large amounts of phosphatidyl-ethanolamine (DOPE), a phospholipid that by itself does not stimulate prothrombin activation, but that might modulate the procoagulant activity of phosphatidylserine (33). To investigate the contribution of DOPE to the kinetics of thrombin production, we incorporated $20 \mathrm{~mol} \%$ DOPE in the phospholipid bilayer of the flow reactor that contained $5 \mathrm{~mol} \%$ DOPS and perfused the capillary with $2 \mathrm{pM}$ factor $\mathrm{Xa}, 50 \mathrm{nM}$ factor $\mathrm{Va}$ and varying prothrombin concentrations $(50-100-200 \mathrm{nM})$

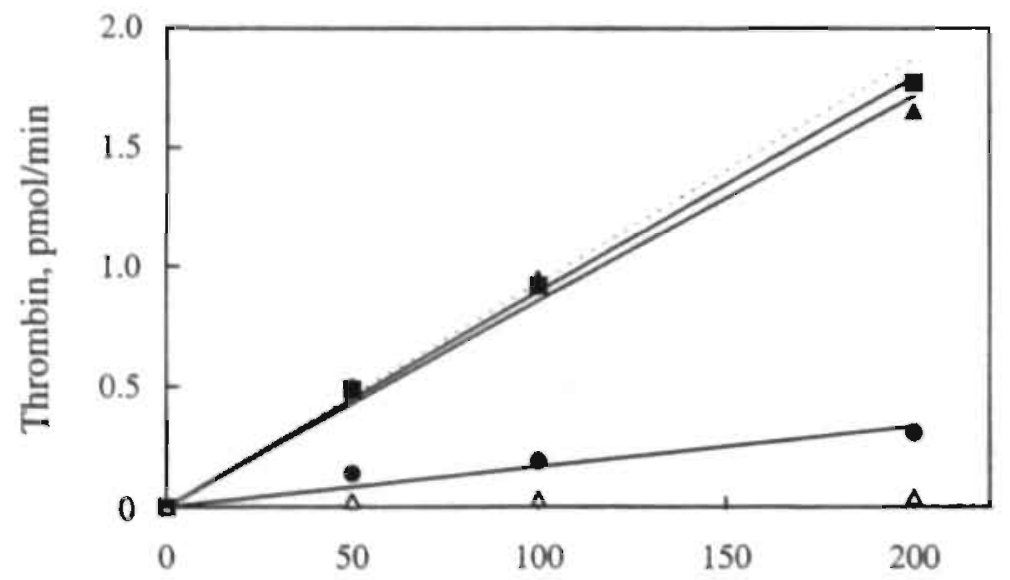

Prothrombin, nM

Figure 7. The dependency of the steady-state rate of thrombin production on the presence of phosphatidylethanolamine in 5 molf DOPS membranes. Capillaries were coated with phospholipid bilayers composed of 5 mol\% DOPS-95 mol\% DOPC ( ). 5 mol\% DOPS-20 mol\% DOPE-75 mol\% DOPC (A), 25 mol\% DOPS-75 mol\% DOPC (w) and 20 mol\% DOPE-80 mol\% DOPC ( $\Delta$ ). Perfusion was performed with Tris-buffer containing factor Xa (2 pM), factọ Va ( 50 pM). and prothrombin concentrations as indicated. The dotted. line represents the transport-limited rate of thrombin production under the conditions of the flow experiment. 
Fig.7 gives the steady-state thrombin production in capillaries coated with membranes of 5 mol\% DOPS-95 mol\% DOPC, 5 mol\% DOPS- $20 \mathrm{~mol} \%$ DOPE-75 mol\% DOPC, and $25 \mathrm{~mol} \%$ DOPS-75 mol\% DOPC as a function of the prothrombin concentration in the perfusion solution. As expected, the lowest steady-state rate of thrombin production was observed with $5 \mathrm{~mol} \%$ DOPS membranes. The thrombin production at membranes containing $25 \mathrm{~mol} \%$ DOPS was close to the transportlimited rate as predicted by mass transfer coefficient and prothrombin concentration. Incorporation of $20 \mathrm{~mol} \%$ of DOPE in the $5 \mathrm{~mol} \%$ DOPS membrane apparently resulted in an increase of the steady-state rate of thrombin production. The rate of prothrombin activation became indistinguishable from those seen with $25 \mathrm{~mol} \%$ DOPS. Membranes that contained only DOPE as the anionic phospholipid, e.g. 20 $\mathrm{mol} \% \mathrm{DOPE} / 80 \mathrm{~mol} \% \mathrm{DOPC}$, did not support prothrombin activation.

\section{Discussion}

The relative contributions of protein-phospholipid interactions and proteinprotein interactions to the overall stability of the prothrombinase complex and their consequences for the catalytic efficiency of the enzyme have been extensively studied $(14,34,35$ and references therein). The experimental design with a flow reactor, as presented here, enables however a straightforward study of prothrombinase assembly and kinetics of prothrombin activation. The clear advantage over a system with small unilamellar phospholipid vesicles is the readily controlled delivery of the individual components of the prothrombinase complex, factor $\mathrm{Xa}$ and factor $\mathrm{Va}$ and the substrate prothrombin, to the planar (macroscopic) phospholipid bilayer and, most importantly, the possibility of a direct determination of the amount of prothrombinase assembled on the macroscopic surface.

Initially, we wanted to determine the kinetics of prothrombin activation by known amounts of assembled prothrombinase as a function of the DOPS content of the membrane as previously described (8). However, pilot experiments revealed that perfusion of capillaries with mixtures of factor $\mathrm{Va}$ and factor $\mathrm{Xa}$ in case the membrane contained a low DOPS content, resulted in surprisingly low and unstable levels of membrane-associated prothrombinase. In contrast, when prothrombin was added to the factor Xa-factor Va mixtures, increasing amounts of thrombin appeared at the outlet of the capillary until a steady-state was reached. We hypothesized that with decreasing affinity of factor Xa and factor $\mathrm{Va}$ for DOPS membranes, prothrombin by virtue of its affinity for both factor $\mathrm{Va}$ and factor $\mathrm{Xa}$, significantly promotes the stability of the prothrombinase complex (cf. ref.15-17,36).

To verify our notion we examined the assembly of prothrombinase at membranes with varying DOPS content from perfusion solutions that contained , factor $\mathrm{Xa}(2 \mathrm{pM})$, factor $\mathrm{Va}(50 \mathrm{nM})$ and varying concentrations of prothrombin. We 
observed in all perfusion experiments that the thrombin production in the flow reactor reached a steady-state rate well below the transport-limit. From direct prothrombinase measurements we learned that the amount of mernbrane-associated prothrombinase in the flow reactor dramatically decreased with the DOPS content of the membrane. Increasing prothrombin concentrations in the perfusion solution, however, did increase the membrane-bound amount of prothrombinase. Although the turnover values, calculated from the steady-state rate of thrombin production and the corresponding amount of prothrombinase (Fig. 2 and Table I), varied between 2500 and $3900 \mathrm{~min}^{-1}$, it is reasonable to conclude that no gross differences were observed for the catalytic activities of the prothrombinase assembled at the membranes that varied in DOPS content from 2 to $10 \mathrm{~mol} \%$ and prothrombin concentrations that varied between 50 and $200 \mathrm{nM}$. The turnover numbers here obtained are close to the previously reported $\mathrm{k}_{\mathrm{cat}}$ value of $3600 \mathrm{~min}^{-1}$ for $25 \mathrm{~mol} \%$ phosphatidylserine membranes (8).

The observation that similar kinetics of thrombin production were found with a limited steady-state amount of membrane-associated prothrombinase indicates that the prothrombinase complex only remains assembled at the membrane of the fllow reactor when it is fully occupied with its substrate prothrombin. That is, prothrombinase that is not acting on its substrate will dissociate from the membrane. Consequently, under these conditions the kinetic parameter $K_{m}$, defined as the prothrombin concentration that is required to obtain half-saturation of the enzyme, looses its meaning.

Regarding the relative contributions of factor $\mathrm{Va}$ and prothrombin to the stability of the complex, we present evidence that with a constant amount of factor $\mathrm{Xa}$ in the perfusion solution, the amount of membrane-associated prothrombinase is proportional to the arithmetical product of the factor $\mathrm{Va}$ concentration in the perfusion solution and the prothrombin concentration close to the catalytic surface (Fig.5). The proportionality constant of this relationship, which probably reflects the protein-protein and protein-phospholipid affinities, decreases 2000 fold when the DOPS content of the membrane increases from 2 to $10 \mathrm{~mol} \%$. Only a 10 -fold difference was seen between $5 \mathrm{~mol} \%$ and $10 \mathrm{~mol} \%$ DOPS membranes.

Prothrombinase-catalyzed conversion of prothrombin into thrombin is a multistep reaction rather than a single product (thrombin) reaction. It has been reported (37) that the prothrombin concentration and the composition of the phospholipid membrane has an effect on the relative amounts of thrombin and meizothrombin formed. That is, higher prothrombin concentrations and higher DOPS content favor the formation of meizothrombin. The question has thus to be raised whether a change in the ratio of meizothrombin over thrombin also could affect the stability of the prothrombinase complex. However, it is rather difficult to see how meizothrombin is 
produced in the absence of a fully assembled prothrombinase. We also like to point at an other item of the present study that needs to be considered in the extrapolation of our results to the physiological situation. Throughout this and our previous study (8), we have used bovine factor Va. However, pilot experiments in which we used human factor Va (a kind gift of Dr. Jan Rosing) in stead of bovine factor Va, showed no marked differences in the amount of prothrombinase assembled on a $5 \mathrm{~mol} \%$ DOPS membrane.

It was recently reported that phosphatidylethanolamine (DOPE) incorporated into phospholipid vesicles containing DOPS and DOPC dramatically enhances activated protein $\mathrm{C}$ inactivation of factor $\mathrm{Va}$ (38). Smirnov and Esmon also stipulated that the incorporation of DOPE into DOPS-DOPC vesicles did not affect. the kinetics of prothrombin activation by prothrombinase. However, it should be stressed that their conditions of prothrombin activation were almost optimal with respect to the procoagulant surface (high DOPS content), factor $\mathrm{Va}$ and prothrombin concentration. Our observations regarding the role of prothrombin in the assembly of prothrombinase and the proposed modulating role of DOPE stimulated us to examine the effect of DOPE on prothrombinase assembly under the conditions of the present study. It is of interest to see that the incorporation of phosphatidylethanolamine (20 mol\%) into a membrane that contained 5 mol\% DOPS had a dramatic effect on the assembly of the prothrombinase complex (Fig.7). Prothrombinase densities were obtained that resulted in transport-limited catalysis for the prothrombin concentrations used (50-200 $\mathrm{nM}$ ) and became indistinguishable from membranes that contained $25 \mathrm{~mol} \%$ DOPS. When the same experiment was performed with membranes that contained 20\% DOPE but no DOPS, no detectable amounts of thrombin could be measured. Apparently, phosphatidylethanolamine is an important regulator of the procoagulant activity in membranes with low phosphatidylserine content. It is apparent that only for low DOPS membranes with limiting amounts of factor Va and prothrombin, DOPE contributes to the assembly of prothrombinase which in turn results in an increased catalytic efficiency of prothrombin activation.

In summary, studies on the prothrombinase assembly from a perfusion solution to planar phospholipid membranes that contained varying mol\% DOPS have provided evidence that the steady-state prothrombinase surface density is a function of the prothrombin concentration. Because the prothrombin concentration near the surface is controlled by convection and diffusion and the catalytic activity of that surface, prothrombinase seems to regulate its assembly via the prothrombin concentration near the surface. 


\section{Chapter 6}

\section{References}

1. Hemker, H.C., Esnouf, M.P., Hemker, P.W., Swart, A.C.W., and MacFarlane, R.G. 1967. Nature 215: 248-251.

2. Mann, K.G., Jenny, R.J. and Krishnaswamy, S. 1988. Annu. Rev. Biochem. 57: 915-956.

3. Esmon, C.T., Owen, W.G., and Jackson, C.M. 1974. J. Biol. Chem. 249: 7798-7807.

4. Nesheim, M.E., Taswell, J.B., and Mann, K.G. 1979. J. Biol. Chem. 254: 10952-10962.

5. Rosing, J., Tans, G., Govers-Riemslag, J.W.P., Zwaal, R.F.A., and Hemker. H.C. 1980. I. Biol. Chem. 255: 274-283.

6. Boskovic, D.S., Giles, A.R., and Nesheim, M.E. 1990. J. Biol. Chem. 265: 10497-10505.

7. Giesen, P.L.A., Willems, G.M., Hemker, H.C., and Hermens, W.T. 1991. J. Biol. Chem. 266: 18720-18725.

8. Billy, D., Speijer, H., Willems, G.M., Hemker, H.C., and Lindhout, T. 1995. J. Biol. Chem. 270: 1029-1034.

9. Papahadjopoulos, D., and Hanahan, D.J. 1964. Biochim. Biophys. Acta 90: 436-439.

10. Jackson, C.M., Owen, W.G., Gitil, S.N., and Esmon, C.T. 1974. Thromb. Diath. Haemorrh. 17: 273-293.

11. van Rijn, J.L.M.L., Govers-Riemslag, J.W.P., Zwaal, R.F.A., and Rosing. J. 1984. Biochemistry 23: 4557-4564.

12. Gerads, L, Govers-Riemslag, J.W.P., Tans, G., Zwaal, R.F.A., and Rosing, J. 1990. Biochemistry 29: 7967-7974.

13. Pei, G., Powers, D.D., and Lentz, B.R. 1993 J Biol Chem 268: 3226-3233.

14. Comfurius, P., Smeets, E.F., Willems, G.M., Bevers, E.M., and Zwaal, R.F.A. 1994. Biochemistry 33: 10319-10324.

15. Nelsestuen, GL., and Broderius, M. 1977 Biochemistry 16: $4172-4177$.

16. Bloom. J.W., Nesheim, M.E., and Mann, K.G. 1979. Biochemistry 18: 4419-4425.

17. van de Waart, P., Bruls, H., Hemker, H.C., and Lindhout, T. 1983. Biochemistry 22: 2427-2432.

18. Lindhout, T., Govers-Riemslag, J.W.P., van de Wart, P., Hemker, H.C., and Rosing, J. 1982 Biochemistry 21: 5495-5502.

19. Krishnaswamy, S. 1990 J. Biol Chem. 265: 3708-3718.

20. van de Waart, P., Hemker, H.C., and Lindhout, T. 1984 Biochemistry 23: 2838-2842.

21. Luckow, E.A., Lyons, D.A., Ridgeway, T.M., Esmon, C.T., andi Lave, T. 1989. Biochemistry 28: 2348-2352.

22. Jesty, J. 1988 Thromb. Res. 50: 745-746.

23. Mann, K.G., Krishnaswamy, S., and Lawson, J.H. 1992. Semin Hematol 29: 213-226.

24. Nemerson, Y., and Gentry, R. 1986. Biochemistry 25: 4020-4033.

25. Hendrix. H., Lindhout, T., Mertens, K. Engels, W., and Hemker, H.C. 1983. J. Biol. Chem. 258: 3637-3644.

26. Chase, T., and Shaw, E. 1969. Biochemistry 8: 2212-2224.

27. Mertens, K., and Bertina, R.M. 1980. Biochem. J. 185: 647-658.

28. Lindhout, T., Kop-Klaassen, B.H.M., and Hemker, H.C. 1978. Biochim. Biophys. Acta 533: 327-341.

29. Smith, R.L. 1973. J. Biol. Chem. 248: $2418-2423$.

30. Govers-Riemslag, J.W.P., Janssen, M.P., Zwaal, R.F.A., and Rosing, J. 1992. Biochemistry 31: 10000-10008.

31. Schoen, P., Lindhout, T.. Willems, G., and Hemker, H.C. 1990. Thromb. Haemostas. 64: 542-547.

32. Levich. V.G. 1962. Physicochemical Hydrodynamics, pp 112-116 Prentice-Hall, Englewood Cliffs, NJ.

33. Zwaal, R.F.A. 1978, Biochim. Biophys. Acta 515: 163-205.

34. Kung, C., Hayes, E., and Mann, K.G. 1994. J. Biol. Chem. 269: 25838-25848.

35. Walker, R.K., and Krishnaswamy. S. 1994. J. Biol. Chem. 269: 27441-27450.

36. Pusey, M.L., Mayer, L.D., Wei. G.J., Bloomfield, A., and Nelsestuen, G.L. 1982. Biochemistry 21: 5262-5269.

37. Tans, G., Janssen-Claessen, T. Hemker, H.C., Zwaal, R.F.A. and Rosing, J. 1991. J. Biol. Chemt. 266: 21864-21873.

38. Smimov, M.D., and Esmon, C.T. 1994. J Biol Chem 269: 816-819. 


\section{Chapter 7}

\section{Prothrombin Conversion under Flow Conditions by Prothrombinase Assembled on Adherent Platelets.}

Didier Billy, Johan W.M Heemskerk, H. Coenraad Hemker and Theo Lindhout.

\section{Summary}

Prothrombin activation by prothrombinase was investigated on platelets adhered onto a fibrinogen-coated coverslip mounted in a flow chamber. Once bound to the fibrinogen, platelets in the presence of plasma gradually changed their morphology: they developed pseudopods, spread over the surface and finally transformed into spherical structures. This last morphologic change required the presence of calcium and was accompagnied by the exposure of procoagulant phospholipid as detected by the capability of the platelets to bind FITC-labeled annexin V. Prothrombinase complexes were allowed to assemble on these adhered platelets by perfusion with factor Xa (2 pM) and varying prothrombin (100-200 nM) and factor Va (50-500 pM) concentrations. The obtained steady-state rate of thrombin formation increased with the prothrombin concentration but not with the factor $\mathrm{Va}$ concentration. Perfusion of the adherent platelets with factor Xat $(1 \mathrm{pM})$ in presence of an excess of factor $\mathrm{Va}(1 \mathrm{nM})$, followed by a perfusion with prothrombin $(100 \mathrm{nM})$ and factor $\mathrm{Va}$ $(1 \mathrm{nM})$, resulted also in a stable steady-state rate of thrombin formation, indicating that factor Xa-factor Va complexes could be assembled in the absence of prothrombin. Collectively, these results demonstrate the efficient ability of the procoagulant surface of adherent platelet to support the assembly of functional and stable prothrombinase complexes.

\section{Introduction}

At sites of vascular injury, adhesion of platelets to the damaged vessel wall is a first step in the haemostatic process. Under conditions of high shear stress, platelet adhesion to immobilized von Willebrand factor on exposed subendothelial matrix is mediated by the platelet membrane glycoprotein GPIb-IX complex (reviewed in ref. 1). At this initial stage, platelets may still retain their discoid shape or extend a few pseudopods. In a more advanced stage platelets spread on the surface and more platelets will be recruited on the initially adhered platelets leading to the formation of platelet aggregates (2). Spreading and aggregation are thought to be mediated by the activation of the fibrinogen receptor, the glycoprotein GPIIb/IIIa complex, at the plasma membrane of the platelet (3).

These morphological changes are accompagnied by a whole range of intracellular responses, finally resulting in the exposure of aminophospholipids at the 
platelet plasma membrane, which promotes assembly of the membrane-dependent enzymatic complexes of the blood coagulation system (4). The prothrombinase complex, consisting of the serine protease factor $\mathrm{Xa}$, the cofactor protein factor $\mathrm{Va}$, adsorbed via calcium ions to the membrane, is one of them. The assembly of this complex, on the mernbranes of activated platelets in suspension has been thoroughly studied (5).

At present, however, no information is available with respect to the assembly of prothrombinase and its enzymatic activity on adherent platelets under conditions that mimic the in vivo situation. To the best of our knowledge, there is only one report on the assembly of the prothrombinase, under static conditions, on human platelets adhering to glass surfaces coated with von Willebrand factor. It was demonstrated here, that both unstimulated and thrombin-stimulated adherent platelets could expose procoagulant surfaces supporting the assembly of the factor Xa-factor Va complex (6). In a accompanying paper, it was shown that release of microvesicles into the solution was induced by the addition of thrombin. However, in contrast to what was found with microvesicles shed from activated platelets in suspension, microvesicles from von Willebrand factor adherent platelets did not show increased procoagulant activity, compared to the unstimulated adherent platelets (7).

We previously reported on the assembly of prothrombinase on artificial phospholipid surfaces and on the efficiency of prothrombin activation at such catalytic surfaces under flow conditions $(8,9)$. We observed that the phospholipid composition of the membrane was critical to the assembly but not to the intrinsic catalytic activity of the enzymatic complex. To study this process on a more physiological membrane surface, we investigated prothrombin activation on adherent platelets on fibrinogen-coated coverslips mounted in a parallel plate chamber. Adhesion of platelets in platelet-rich plasma to the fibrinogen-coated glass and subsequent morphological changes were followed in time with phase-contrast microscopy. In addition, the appearance of procoagulant sites on the surface of adherent platelets, i.e. the exposure of anionic phospholipids at the plasma membrane, was monitored with a fluorescence-imaging system using fluoresceinlabelled annexin $V(10)$. To directly study the ability of adherent platelets to support prothrombinase assembly and prothrombin activation, the parallel plate chamber was also perfused with solutions of factor $\mathrm{Va}$, factor $\mathrm{Xa}$ and prothrombin in varying concentrations and thrombin formed was measured in the effluent.

\section{Experimental Procedures}

Materials. S2238, a chromogenic substrate for thrombin, was obtained from Chromogenix (Mölndal, Sweden). Bovine serum albumin (fatty acid-free) and bovine fibrinogen (fraction I, type IV) were from Sigma (St. Louis, USA). Bovine 
factor Va, human prothrombin and human factor $\mathrm{Xa}$ were purified and quantified as described $(11,12)$. Fluorescein-labelled annexin V (FITC-annexin V) was a product of Nexins Research BV (Rotterdam, the Netherlands).

Platelet rich plasma. Human platelets were obtained from blood, freshly drawn from healthy volunteers. The blood was collected on $0.13 \mathrm{M}$ trisodium citrate, nine parts of blood to one part of citrate solution. Then, platelet-rich plasma (PRP) was obtained after centrifugation of the blood (room temperature) at $200 \mathrm{~g}$ during $15 \mathrm{~min}$.

Flow chamber. The parallel plate chamber was a modification of the perfusion chamber described by Sakariassen et al (13). In a block of poly(methyl methacrylate) with dimensions of $75 \times 27 \times 7.5 \mathrm{~mm}$, a central hole was made with a depth of $0.2 \mathrm{~mm}$, a width of $5.0 \mathrm{~mm}$ and a length of $42.5 \mathrm{~mm}$. The two inlets of the flow chamber ( 1 $\mathrm{mm}$ internal diameter) gradually tapered off over a length of $7 \mathrm{~mm}$ to the rectangular cross section of the central hole at an angle of $20^{\circ}$. A coverslip made from glass microscope slide of $50 \times 24 \mathrm{~mm}$ served as the roof of the flow chamber. The coverslip surface in contact with the perfusion fluid was $2 \mathrm{~cm}^{2}$ and the flow cell volume was approximately $60 \mu \mathrm{l}$. Experiments were performed at a flow rate of $30 \mu \mathrm{l} / \mathrm{min}$, which corresponded to a calculated shear rate, $\gamma$, of $15 \mathrm{~s}^{-1}$, according to:

$$
\gamma=6 \mathrm{Q} / \mathrm{bd}^{2}
$$

where $Q$ is the volumetric flow rate $\left(\mathrm{cm}^{3} / \mathrm{s}\right), \mathrm{b}(\mathrm{cm})$ the width and $\mathrm{d}(\mathrm{cm})$ the depth of the slit.

The rate of transport of prothrombin to the catalytic surface, $\mathbf{J}\left(\mathrm{pmol}_{\mathrm{s}} \mathrm{s}^{-1}\right)$, can be calculated from the expression (14):

$$
\mathrm{J}=1.48 \mathrm{Q}^{1 / 3} \mathrm{~d}^{-2 / 3} \mathrm{~b}^{2 / 3} \mathrm{~L}^{2 / 3} \mathrm{D}^{2 / 3} \mathrm{C}_{\mathrm{b}}
$$

where, under the conditions of the experiment, $Q=0.5 \cdot 10^{-3} \mathrm{~cm}^{3} \cdot \mathrm{s}^{-1}, \mathrm{~d}=0.02 \mathrm{~cm}, \mathrm{~b}=$ $0.5 \mathrm{~cm}, \mathrm{~L}=4.25 \mathrm{~cm}, \mathrm{D}=6.210^{-7} \mathrm{~cm}^{2} . \mathrm{s}^{-1}$ and a varying fluid phase concentration of prothrombin, $\mathrm{C}_{\mathrm{b}}\left(\mathrm{pmol} . \mathrm{cm}^{-3}\right)$.

Imaging system. A combined fluorescence imaging and microphotometric system was constructed basically as described before (15), but equipped with excitation as well as emission filter-wheels, and with a bright-field video camera to record phase-contrast images (Applied Imaging, U.K.). This system, connected to an inverted fluorescence microscope, was used for the continuous detection of phospholipid-bound fluorescein-labelled annexin $\mathrm{V}$ on adherent platelets. The recorded fluorescent images were stored on a personal computer and the phasecontrast images on a video tape. The optical configuration of the system was in such a way that both types of images could directly be compared. 


\section{Chapter 7}

Platelet immobilization. Glass coverslips ( $5 \times 24 \mathrm{~mm}$; Menzel-Gläser, Germany) were cleaned with a solution containing equal volumes of ethanol $(96 \mathrm{v} / \mathrm{v} \%)$ and $\mathrm{HCl}(37 \mathrm{v} / \mathrm{v} \%)$ and rinsed with deionized water and $0.9 \mathrm{w} / \mathrm{v} \% \mathrm{NaCl}$ (saline solution). The cleaned coverslips were coated with $10 \mathrm{mg} / \mathrm{ml}$ fibrinogen in saline solution for $40 \mathrm{~min}$ at room temperature (15). The coverslips were then extensively rinsed with saline solution and mounted in the flow chamber. Citrated PRP was exposed to the fibrinogen-coated glass coverslip at room temperature for $40 \mathrm{~min}$. To remove the non-adherent platelets, the flow chamber was then perfused with Hepesbuffer ( $10 \mathrm{mM}$ Hepes, $136 \mathrm{mM} \mathrm{NaCl}, 2.7 \mathrm{mM} \mathrm{KCl}, 2 \mathrm{mM} \mathrm{MgCl} 2,3 \mathrm{mM} \mathrm{CaCl}, 0.5$ $\mathrm{mg} / \mathrm{ml} \mathrm{BSA}$ and $0.1 \mathrm{U} / \mathrm{ml}$ apyrase, $\mathrm{pH} 7.45$ ) at $300 \mu \mathrm{l} / \mathrm{min}$ during $10 \mathrm{~min}$. The adherent platelets were then incubated in the Hepes-buffer for additional $40 \mathrm{~min}$ to allow spreading and formation of procoagulant membrane surfaces.

Procoagulant adherent platelets. Procoagulant sites at the surface of adherent platelets were identified by their ability to bind FITC-annexin V (10). Platelets bound to fibrinogen-coated coverslips were incubated with $0.6 \mu \mathrm{M}$ FITC-annexin V in Hepes-buffer for approximatively $20 \mathrm{~min}$ at room temperature. Fluorescence was examined by the fluorescence imaging system (see above).

The flow system. The flow chamber containg adherent platelets on immobilized fibrinogen was attached to a Hamilton gas-tight syringe. The flow rate was controlled by a syringe pump (Harvard Apparatus Co., South Natich, MA). At the outlet of the flow chamber samples of $30 \mu \mathrm{l}$ were collected into cuvettes containing $20 \mathrm{mM}$ EDTA. Thrombin was measured in the cuvettes after the addition of the chromogenic substrate $\mathrm{S} 2238$, as described previously (16).

Assay for procoagulant membranes at the outlet of the flow chamber. Samples of $100 \mu \mathrm{l}$ were collected at the outlet each minute in cuvettes containing $340 \mu \mathrm{l}$ Trisbuffer $(50 \mathrm{mM}$ Tris- $\mathrm{HCl}, 175 \mathrm{mM} \mathrm{NaCl}, 3 \mathrm{mM} \mathrm{CaCl} 2$ and $0.5 \mathrm{mg} / \mathrm{ml}$ of BSA, pH 7.9). Then. $135 \mu \mathrm{l}$ of a mixture containing factor $\mathrm{Xa}$, factor $\mathrm{Va}$ and chromogenic substrate S2238 was added. After $5 \mathrm{~min}$ of incubation at $37^{\circ} \mathrm{C}$, generation of thrombin was started by the addition of $25 \mu \mathrm{l}$ prothrombin. The final concentrations of the reactants were $0.1 \mathrm{pM}$ factor $\mathrm{Xa}, 0.5 \mathrm{nM}$ factor $\mathrm{Va}, 0.2 \mathrm{mM} \mathrm{S} 2238$ and $0.5 \mu \mathrm{M}$ prothrombin. The progress curve of the product of the reaction between thrombin and the chromogenic substrate, pNA, was monitored in a photometer at $405 \mathrm{~nm}$ and analyzed by the quadratic function (17):

$$
\mathrm{OD}=b \mathrm{t}^{2}+\mathrm{ct}+\mathrm{a}
$$

where OD is the optical density at $405 \mathrm{~nm}$, $t$ is the time, $b$ is the arithmetical product of the rate constant of thrombin generation and the rate constant of pNA production, and $c$ is the rate constant of spontaneous pNA production. The parameter $b$ is 
proportional to the amount of procoagulant lipid in the assay. Reference curves were constructed utilizing mixed phospholipid vesicles composed of $25 \mathrm{~mol} \%$ phosphatidylserine and $75 \mathrm{~mol} \%$ phosphatidylcholine. The amount of phospholipid in the effluent of the flow chamber was expressed as the phospholipid molar concentration.

\section{Results and Discussion}

Platelet adhesion to immobilized fibrinogen. Fibrinogen-coated coverslips, mounted in a parallel plate chamber, were exposed to citrated PRP (about $4 \times 10^{8}$ platelets $/ \mathrm{ml}$ ) and the morphological changes of the platelets were followed by video recording of the phase-contrast images. Fig. 1 shows the time course of adherence and shape change as monitored by phase contrast. Initially, discoid platelets adhered to the surface and developed one or two pseudopods (Fig.1A). It is important to note that even at a rather low wall shear rate of about $20 \mathrm{~s}^{-1}$ no platelet adhesion was observed. Static conditions were required to obtain a platelet-covered surface. After $20 \mathrm{~min}$ of incubation most of the adherent platelets started to spread at the surface, resulting in the appearance resembling a fried egg (data from scanning electron microscopy analysis, not shown). Finally, a stage was reached in which all platelets were fully spread (Fig.1B). The flow chamber was then perfused at $300 \mu \mathrm{l} / \mathrm{min}$ with calcium-containing Hepes-buffer for $10 \mathrm{~min}$ to remove the non-adhered platelets. This perfusion step with calcium-containing solution and an additional incubation (40 $\mathrm{min}$ ) under static conditions resulted in a further morphological change. The adherent spread platelets transformed to a spherical appearance with small globular structures of higher contrast attached to the surface, as indicated by the arrow in Fig.1C.

Most of our observations are in agreement with current notions about the interactions of platelets with immobilized fibrinogen. Thus, whereas unactivated platelets do not bind to soluble RGD-containing adhesive proteins like fibrinogen they adhere to fibrinogen-coated surfaces (18). There is some evidence that the immobilization of fibrinogen results in a conformational change of the molecule which, in tum, leads to the exposure of a dodecapeptide site that is more easily accessible for GPIIb-IIIa on the surface of unstimulated platelets $(19,20)$. The binding of immobilized fibrinogen to GPIIb-IIIa in resting platelets then initiates a number of additional events such as the exposure of secondary high-affinity binding sites for fibrinogen and the activation of second messenger pathways (21). As a result of all these signal transduction processes, platelets develop pseudopods and spread over the surface. 


\section{Chapter 7}
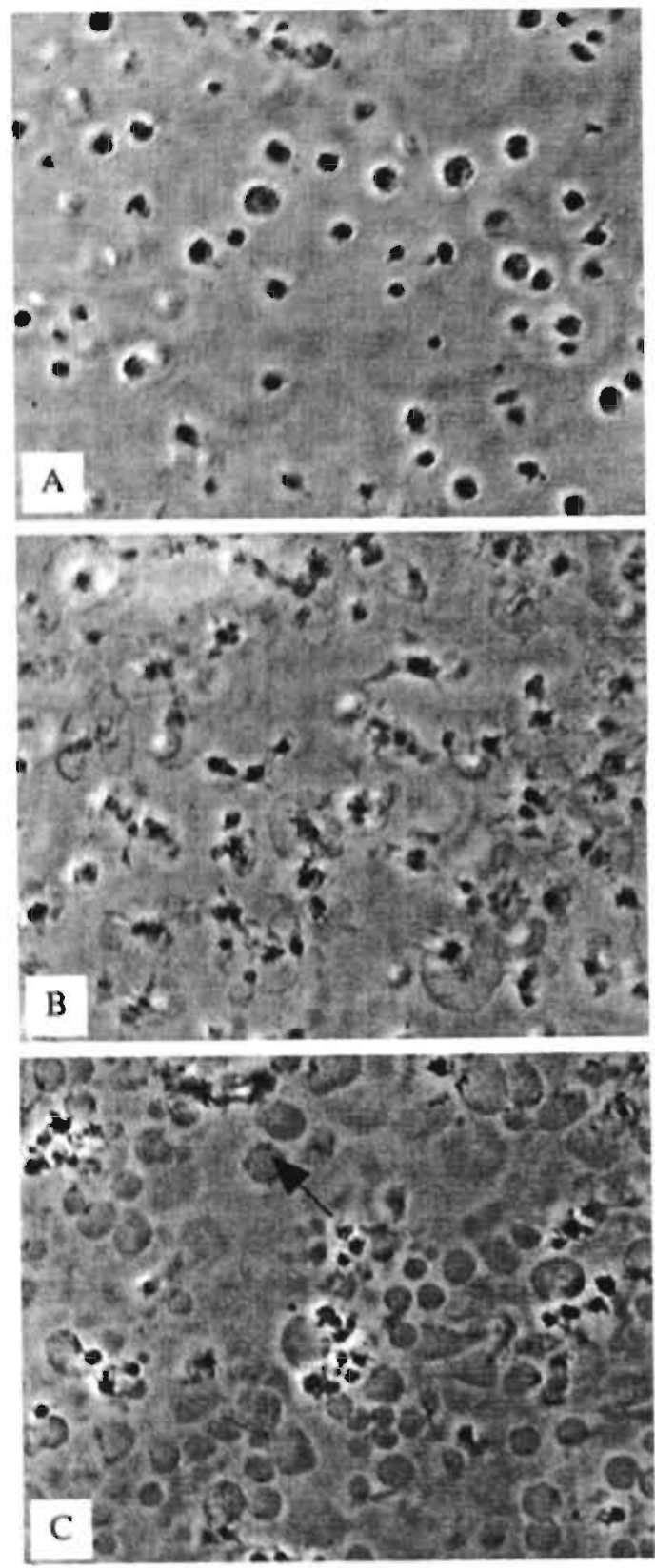

Figure 1. Changes in platelec morpholosy during adhesion A fibrinogen-coated gelass coverslip was exposed to citrated PRP $\left(=4 \times 10^{8}\right.$ platelets $\left./ \mathrm{m}\right)$. Platelet adhesion and morphological changes, were monitored by phase contrast light microscopy. A, $10 \mathrm{~min}$ incubation: B. $40 \mathrm{~min}$ incubation, and C, after wash of the non-adherent platelets for $10 \mathrm{~min}$, at 300 $\mu \mathrm{l} / \mathrm{min}$, with Hepes-buffer ( $3 \mathrm{mM} \mathrm{CaCl}$ ) and $20 \mathrm{~min}$ incubation. 
Annexin $\mathrm{V}$ binding to adherent platelets. To examine whether the adherent platelets also exhibited procoagulant sites, we exposed the coverslip to fluoresceinlabelled annexin V. Fig.2 (left panel) shows that spread platelets attached to the immobilized fibrinogen were unable to bind annexin $\mathrm{V}$ in presence of calciumbuffer. The right panel of Fig.2 indicates that once the spread became spherical, annexin $\mathrm{V}$ did bind to the platelet surface, indicating the translocation of phosphatidylserine from the inner leaflet to the outer leaflet of the plasma membrane. Earlier work has shown that the increase in cytosolic $\left[\mathrm{Ca}^{2+}\right]$ is crucial for the appearance of this procoagulant response (22).

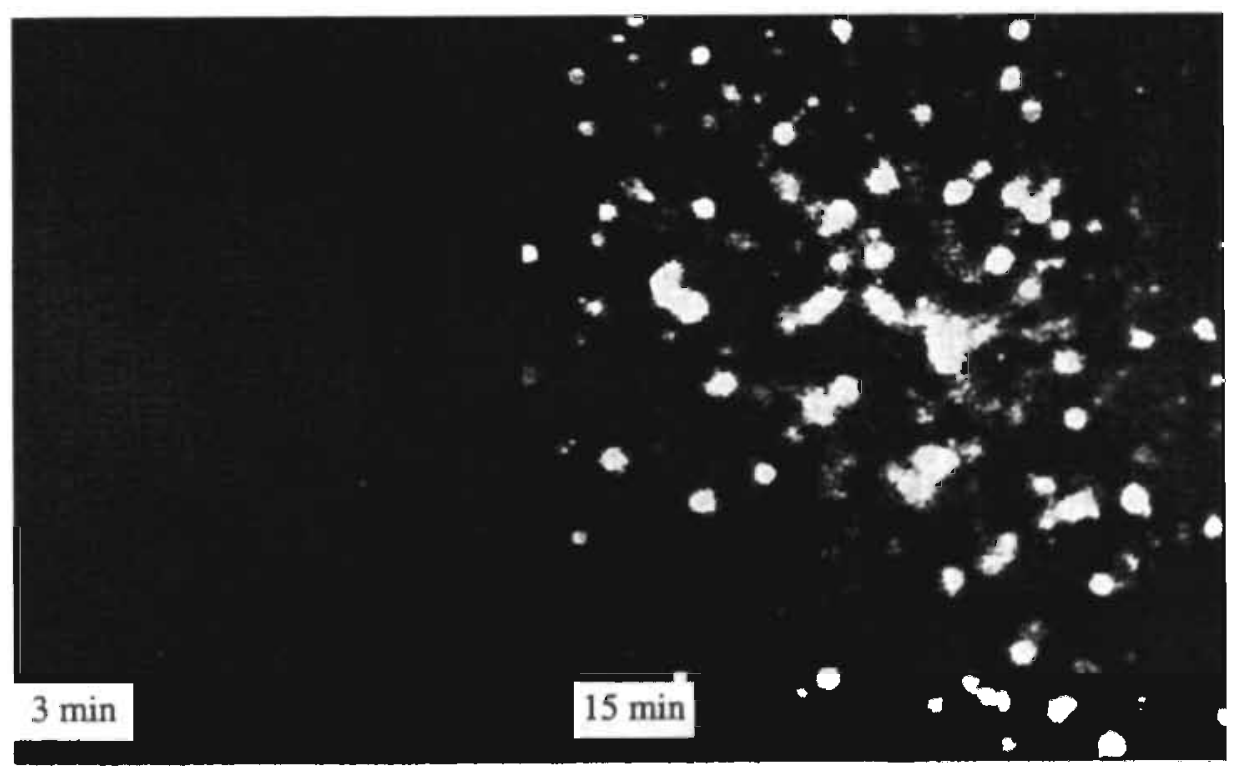

Figure 2. Appearance of procoagulant surfaces. After exposure of citrated PRP to immobilized fibrinogen, the plateletcontaining coverslip was rinsed with Hepes-buffer and then incubated with $0.6 \mu \mathrm{M}$ FTTC-annexin V in Hepes-buffer (3 $\mathrm{mM} \mathrm{CaCl}{ }_{2}$ ). Fluorescence micrographs were taken from the coverslip at the indicated time points of incubation. Platelet morphology at these time points was exactly as shown in Fig. IB and FigIC, respectively

Thrombin generation at the surface of adherent platelets. We next investigated the assembly of the factor $\mathrm{Xa}$-factor $\mathrm{Va}$ complex and thrombin generation at adherent platelets that showed the typical spherical structures (blebs). Prior to that, the coverslip with adherent platelets was extensively washed to remove detached platelets and/or released microvesicles. Hereto, the parallel plate chamber was perfused with calcium-containing Hepes-buffer at $300 \mu \mathrm{l} / \mathrm{min}$. Samples were collected at the outlet and assayed for the presence of procoagulant phospholipid. A 


\section{Chapter 7}

typical result is depicted in Fig.3. It is shown that the amount of procoagulant membranes (platelets and/or microvesicles) in the effluent of the flow chamber was relatively high at the start of the perfusion, but gradually decreased with perfusion time. After about $10 \mathrm{~min}$, significant amounts of procoagulant phospholipids were no longer detectable. We want to emphasize that the molar amount of procoagulant phospholipid indicated by the vertical axis in Fig.3, is calculated from a reference curve utilizing mixed phospholipid vesicles of a composition that has been shown to be optimal for prothrombinase activity (23). Since the composition of the membrane structures in the effluent is unknown, we can only conclude that after $10 \mathrm{~min}$ of perfusion the effluent is sufficiently devoid of procoagulant activity to assure that the only source of the procoagulant surface is the coverslip with adherent platelets.

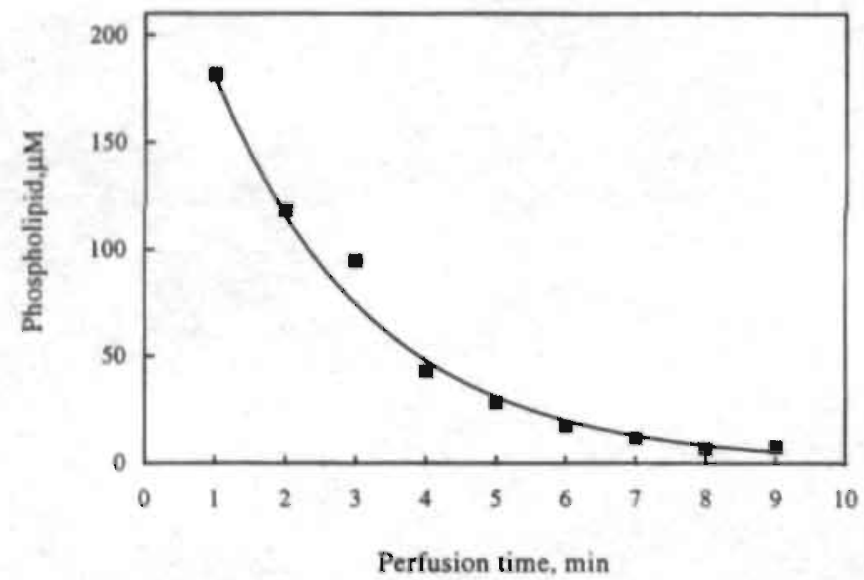

Figure 3. Wash-out of unbound procoagulant surfaces. After a $40 \mathrm{~min}$ incubation of adherent platelets on fibrinogencoated coverslip in presence of Hepes-buffer, the flow chamber was perfused at $100 \mu \mathrm{l} / \mathrm{min}$ with Hepes-buffer. Samples were collected at the outlet and assayed for procoagulant phospholipids. The phospholipid concentration was calculated from a reference curve using phospholipid vesicles with maximal procoagulant activity (25mol\% phosphatidylserine and $75 \mathrm{~mol} \%$ phosphatidylcholine).

The parallel plate chamber was then perfused at $30 \mu \mathrm{l} / \mathrm{min}$ with a solution containing factor $\mathrm{Xa}(2 \mathrm{pM})$, prothrombin $(50$ and $200 \mathrm{nM})$ and factor $\mathrm{Va}$ (50 and $500 \mathrm{pM}$ ). Fig.4 depicts the rates of thrombin production as a function of the perfusion time. Initially, the rate of thrombin production increased until an apparent steady-state rate was reached. It is seen that the apparent steady-state rate increased with the prothrombin concentration, but not when the factor Va concentration was increased from 50 to $500 \mathrm{pM}$. 


\section{Chapter 7}

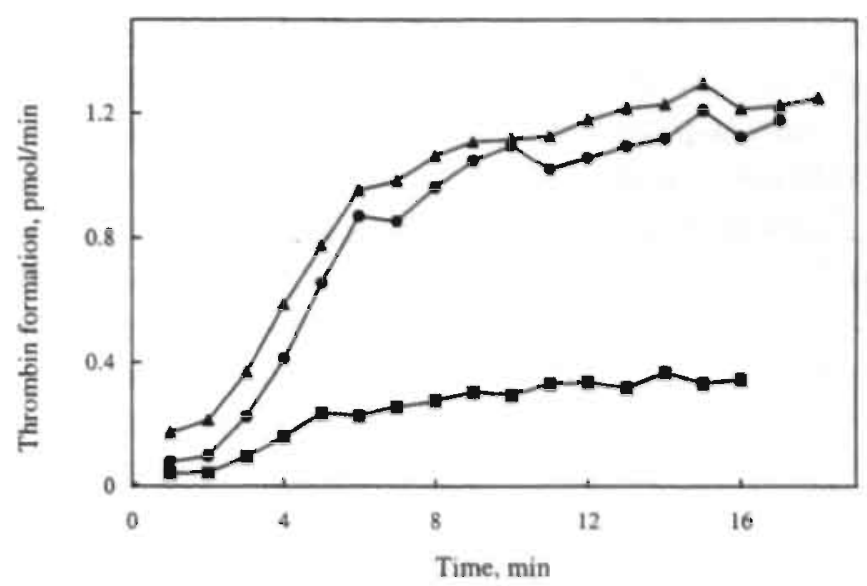

Figure 4. Rate of thrombin formation at the surface of adherent platelets. Flow chambers containing adherent platelets on a fibrinogen-coated coverslip were perfused at $30 \mu \mathrm{l} / \mathrm{min}$ (shear rate of $15 \mathrm{~s}^{-1}$ ) with Hepes-buffer $(3 \mathrm{mM} \mathrm{CaCh}$ ) containing $2 \mathrm{pM}$ factor $\mathrm{Xa}, 50 \mathrm{pM}$ factor $\mathrm{Va}$ and $50 \mathrm{nM}$ prothrombin $(\mathbf{m}), 2 \mathrm{pM}$ factor $\mathrm{Xa}, 50 \mathrm{pM}$ factor $\mathrm{Va}$ and $200 \mathrm{nM}$ prothrombin ( ) or with $2 \mathrm{pM}$ factor $\mathrm{Xa}, 500 \mathrm{pM}$ factor $\mathrm{Va}$ and $200 \mathrm{nM}$ prothrombin( $\mathbf{A}$ ).

In the presence of $2 \mathrm{pM}$ factor $\mathrm{Xa}$ and $50-500 \mathrm{nM}$ factor $\mathrm{Va}$, the apparent steady state rates of thrombin production were $0.35 \mathrm{pmol} / \mathrm{min}$ and $1.2 \mathrm{pmol} / \mathrm{min}$ for 100 and $200 \mathrm{nM}$ prothrombin, respectively. Our previous work with artificial phospholipid membranes ( $25 \mathrm{~mol} \%$ phosphatidylserine and $75 \mathrm{~mol} \%$ phosphatidylcholine), carried. out under identical conditions in a capillary flow reactor, has indicated that the apparent steady-state rate of thrombin production increased with the prothrombin concentration only when the transport of prothrombin towards the catalytic surface was rate-limiting. Under the flow conditions used and with 50 and $200 \mathrm{nM}$ prothrombin in the perfusion solution, the transport limited rate of thrombin production is expected to be 0.57 and $2.3 \mathrm{pmol} / \mathrm{min}$, respectively (see Experimental Procedures, Eq.2). Evidently, the experimental steady-state levels of thrombin production in the experiments with platelets are not in accordance with the predicted values. We could think of two explanations: a) prothrombin promotes the assembly of the factor Xa-factor $\mathrm{Va}$ complex at the adherent platelet surfaces and b), prothrombinase is present in patches of high local concentration. The first possibility is unlikely, because an increase in the factor $\mathrm{Va}$ concentration did not increase the apparent steady-state rate of thrombin production. This suggests either a saturation of all the procoagulant sites by prothrombinase complexes or a transport-limited situation. With respect to the second explanation (b), the calculation of the mass transfer rate of prothrombin assumes that the procoagulant sites are homogeneously distributed (100\% coverage) over the flow chamber surface. The staining of the coverslip with FITC-annexin V (Fig.2) already indicated a patch wise distribution of 
the procoagulant sites. In that case, we expect that the transport-limited steady state rate of thrombin production is a function of the surface coverage and thus below the theoretical values of 0.57 and $2.3 \mathrm{pmol} / \mathrm{min}$ for 50 and $200 \mathrm{nM}$ prothrombin, respectively. This also implies that it will be difficult to prepare these procoagulant surfaces with a high reproducibility with respect to the number of procoagulant sites.

Assembly of the prothrombinase complex in the absence of prothrombin. We have demonstrated previously (9) that the assembly of prothrombinase on phosphatidylserine-containing membranes is dependent upon the mol percentage of phosphatidylserine. That is, below $10 \mathrm{~mol} \%$ phosphatidylserine and suboptimal concentrations of factor $\mathrm{Va}$ ( 10 to $300 \mathrm{pM}$ ), the presence of prothrombin is required to allow the assembly of significant amounts of prothrombinase. To investigate if procoagulant platelets support the assembly of prothrombinase in the absence of prothrombin, we perfused activated platelets adhered to immobilized fibrinogen with factor $\mathrm{Xa}(1 \mathrm{pM})$ and factor $\mathrm{Va}(1 \mathrm{nM})$ during $10 \mathrm{~min}$ at a flow rate of $30 \mu \mathrm{l} / \mathrm{min}$. Subsequently, the flow chamber was perfused at the same flow rate with prothrombin $(100 \mathrm{nM})$ in the presence of factor $\mathrm{Va}(1 \mathrm{nM})$.

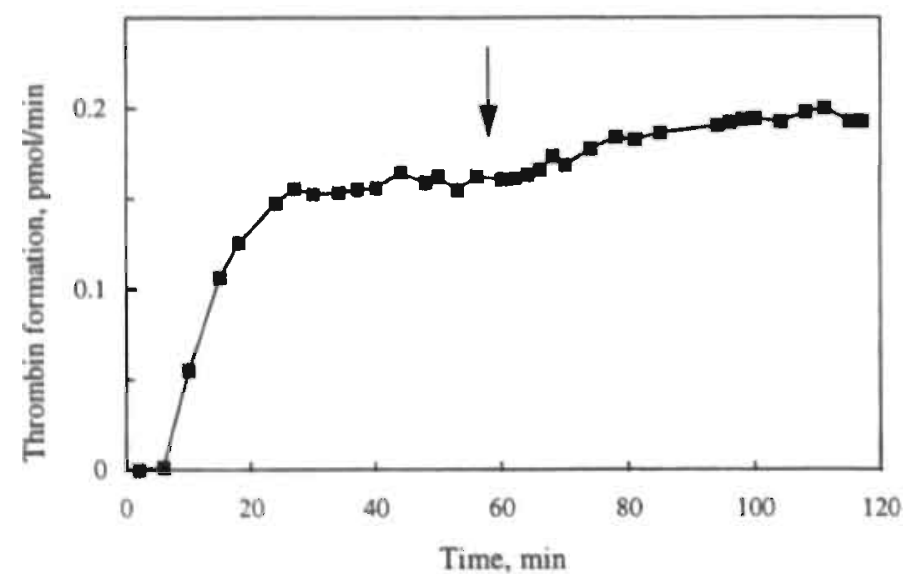

Figure 5. Rate of thrombin formation after pre-perfusion with factors $\mathrm{Xa}$ and $\mathrm{Va}$. Adherent plateiets on immobilized fibrinogen were first pre-perfused with factor $\mathrm{Xa}(1 \mathrm{pM})$ and factor $\mathrm{Va}(1 \mathrm{nM})$ at $30 \mu \mathrm{l} / \mathrm{min}$ (shear rate of $15 \mathrm{~s}^{-1}$ ) for 10 $\min$. Then, the flow chamber was perfused at the same flow rate with prothrombin $(100 \mathrm{nM})$ and factor $\mathrm{Va}(1 \mathrm{nM})$ for 60 min, followed by a 60 min perfusion with $\mathrm{Xa}(1 \mathrm{pM})$. factor $\mathrm{Va}(1 \mathrm{nM})$ and prothrombin $(100 \mathrm{nM})$.

Fig.5 shows that the rate of thrombin formation increased until a steady state rate of approximately $0.16 \mathrm{pmol} / \mathrm{min}$ was reached. Continuation with a perfusion mixture containing factor $\mathrm{Xa}(1 \mathrm{pM})$, factor $\mathrm{Va}(1 \mathrm{nM})$ and prothrombin $(100 \mathrm{nM})$ did not significantly increase the final level of thrombin formation. This latter result indicates that the exposed procoagulant sites were already saturated after the preperfusion with $1 \mathrm{pM}$ factor $\mathrm{Xa}$ and $1 \mathrm{nM}$ factor $\mathrm{Va}$. Moreover, we can conclude that 
prothrombinase can be fully assembled at the surface of procoagulant adherent platelets in the absence of prothrombin.

Stability of the prothrombinase complexes at the surface of adherent platelets. A flow chamber containing a fibrinogen-coated coverslip with adherent platelets was pre-perfused with $1 \mathrm{pM}$ factor Xa and $1 \mathrm{nM}$ factor $\mathrm{Va}$ for $10 \mathrm{~min}$ at $30 \mu \mathrm{l} / \mathrm{min}$. Then it was perfused with $100 \mathrm{nM}$ prothrombin in presence of $1 \mathrm{nM}$ factor Va for $60 \mathrm{~min}$. After $20 \mathrm{~min}$, the rate of thrombin formation reached a stable steady-state of about $0.45 \mathrm{pmol} / \mathrm{min}$ (Fig.6). This steady-state level was twice as high as in the previous experiment, which could be explained by the predicted variability in the number of procoagulant sites. To further investigate the stability of the assembled prothrombinase complex the chamber was then perfused with only factor $\mathrm{Va}(1 \mathrm{nM})$ for $20 \mathrm{~min}$, followed by a perfusion with $100 \mathrm{nM}$ prothrombin and $1 \mathrm{nM}$ factor Va. It is seen that a slightly lower $(\approx 10 \%)$ steady-state rate of thrombin production was obtained. This latter result indicates that the procoagulant surfaces exposed by adherent platelets are highly efficient in the assembly of stable prothrombinconverting complexes.

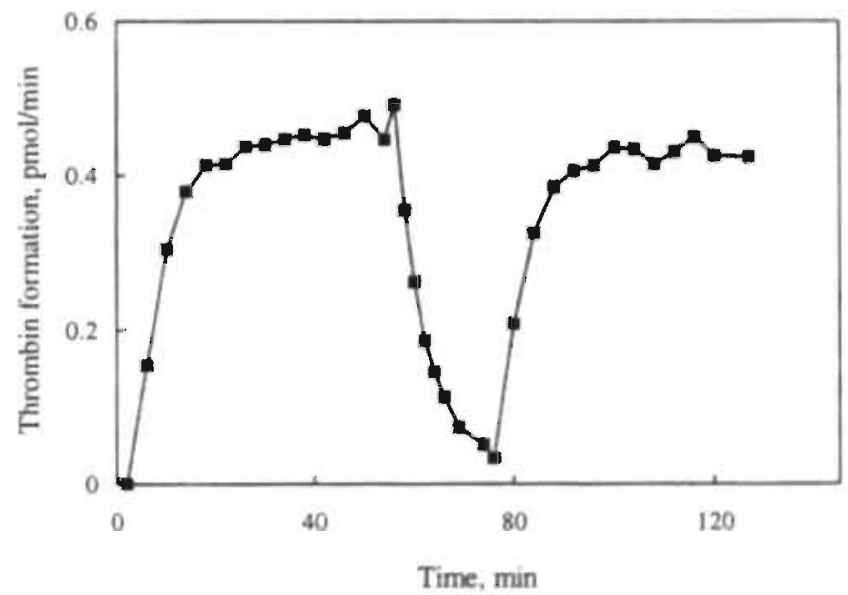

Figure 6. Stability of the prothrombinase complexes. After a pre-perfusion with factor $\mathrm{Xa}$ ( $1 \mathrm{pM})$ and factor $\mathrm{Va}(1 \mathrm{nM})$ during $10 \mathrm{~min}$ at $30 \mu \mathrm{l} / \mathrm{min}$, the flow chamber containing a fibrinogen-coated coverslip with adherent platelets was further perfused with prothrombin ( $100 \mathrm{nM}$ ) and factor $V_{a}(1 \mathrm{nM})$ during $60 \mathrm{~min}$. Then, the flow chamber was perfused for 20 min with $1 \mathrm{nM}$ factor $\mathrm{Va}$, followed by a second perfusion with prothrombin ( $100 \mathrm{nM}$ ) and factor $\mathrm{Va}(1 \mathrm{nM})$.

\section{Conclusions.}

The interaction of platelets in platelet-rich plasma with fibrinogen-coated glass surface led to adhesion of the platelets, morphological changes indicative of activation and exposure of procoagulant surfaces. Since it was possible to assemble factor Xa-factor $\mathrm{Va}$ complexes on the surfaces of these platelets in the absence of 
prothrombin, this study demonstrates that the exposed procoagulant surfaces had properties different from those of membranes with a low phosphatidylserine content ( $\leq 10 \mathrm{~mol} \%$ ), as studied in chapter 6 . Our present findings suggest that activated platelets on immobilized fibrinogen generate procoagulant sites containing a percentage of phosphatidylserine exceeding $10 \mathrm{~mol} \%$ and/or containing phosphatidylethanolamine which enhances the binding affinity of the membrane for the factors constituting the prothrombinase complex. In addition, the prothrombinase complexes on the surface of activated platelets, appear to be of a remarkable stability and capable to convert flowing prothrombin during a periode of at least two hours.

\section{References}

1. Roth G.J. 1991. Blood 77: 5-19.

2. Baumgartner H.R., Haudenschildt C. 1972. Ann New York Acad Sci 201:22-36.

3. Sixma J.J. 1994. Haemostasis and Thrombosis. Bloom AL. Thomas DP (eds.). 2nd ed. Churchill Livingstone, p. 259-284

4. Mann K.G., Nesheim M.E., Church W.R., Haley P., Krisnhaswamy S 1990. Blood 76: 1-16.

5. Bevers E. M., Comfurius P.. Zwaal R.F.A. 1991. Blood Reviews 5: 146-154.

6. Swords N.A., Mann K.G. 1993. Arterioscler. Thromb. 13: 1602-1612.

7. Swords N.A., Tracy P.B., Mann K.G. 1993, Arterioscler. Thromb. 13: 1613-1622.

8. Billy D. Speijer H, Willems G, Hemker HC, Lindhout T. 1995. J Biol Chem 270: 1029-1034

9. Billy D., Willems G.M., Hemker H.C., Lindhout T. 1995. J. Biol. Chem. 270: 26883-26889.

10. Thiagarajan P., Tait J.F. 1990. J. Biol. Chem. 265: 17420-17423.

11. Schoen P., Lindhout T., Willems G.M., Hemker H.C. 1989. J Biol. Chem. 264: 10002-10007.

12. Lindhout T., Govers-Riemslag J.W. P., van de Waart P., Hemker H.C., Rosing J. 1982. Biochemistry 21: 5494-5502.

13. Sakariassen K.S., Aarts P.A.M.M., de Groot P.G.. Houdijk W.P.M., Sixma J.J. 1983. J. Lab. Clin. Med. 102: 522-535.

14. Levich V.G. 1962; in Physiochemical Hydrodynamics. Prentice-Hali. Englewood Cliffs, NJ, p: 75.

15. Heemskerk J.W.M. Hoyland J., Mason W.T., Sage O.S. 1992. Biochem. J. 283: 379-383.

16 Schoen P., Lindhout T., Willems G., Hemker H.C. 1990. Thromb. Hemostas. 64: 542-547.

17. Kessel H., Béguin S., Wagenwoord R., Hemker H.C. 1990. Thromb. Hemostas. 66: 430-434.

18. Savage B. and Rugeri Z.M. 1991. J. Bio!. Chem. 266: 11227-11233.

19. Kieffer N., Matsueda G. 1991. Blood 78: 1113 (Abstr).

20. Zamarton C., Ginsberg M.H., Plow E.F. 1991. J. Biol. Chem. 266: 16193-16199.

21. Du X., Plow E.F., Frelinger A.L. et al, 1991. Cell 65:409-416.

22. Smeets E.F., Heemskerk J.W.M., Comfurius P., Bevers E.M., Zwaal R.F.A. 1993. Thromb. Haemostas, 70: 1024-1029.

23 Comfurius P., Smeets E.F., Willems G.M., Bevers E.M., and Zwaal R.F.A. 1994. Biochemistry 33: 10319-10324. 


\section{Chapter 8}

\section{Greneral Discussion}

We investigated the activation of prothrombin by the complex of factor Xa and factor Va assembled at a macroscopic phospholipid membrane coated on the interior of a glass capillary. In our first experiments the membrane was composed of 75 mol\% phosphatidylcholine and $25 \mathrm{~mol} \%$ phosphatidylserine. Our aim was to characterize the kinetics of prothrombin activation by membrane-bound prothrombinase under well-defined flow conditions and controlled prothrombinase surface densities. We demonstrated that, the observed steady-state rates of thrombin formation were either a function of the prothrombin concentration in the perfusion solution or of the prothrombinase density (chapter 3 ).

To investigate these two extreme situations, we used an important property of the flow reactor, namely the possibility to accurately control and assess the prothrombinase surface. When the shear rate was $20 \mathrm{~s}^{-1}$ and the prothrombin concentration in the perfusion solution was $500 \mathrm{nM}$, we observed that below 0.6 fmol prothrombinase $/ \mathrm{cm}^{2}$ the rate of thrombin formation was proportional with the surface density of prothrombinase. This observation is characteristic of a kineticallycontrolled situation where the rate of prothrombin conversion is lower than the mass transport rate of prothrombin to the surface-bound prothrombinase. At higher prothrombinase density thrombin production becomes transport-limited. This diffusion-controlled situation was already observed for a prothrombinase density that exceeded $1 \mathrm{fmol} / \mathrm{cm}^{2}$; an enzyme density that represents only $0.05 \%$ of the available prothrombinase binding sites at the phospholipid bilayer in the capillary.

In order to assess kinetic parameters, phospholipid-coated capillaries were prepared with prothrombinase densities sufficiently low to minimize transportlimited prothrombin conversion. Even at the lowest prothrombinase densities used in our experiments (around $0.02 \mathrm{fmol} / \mathrm{cm}^{2}$ ), depletion of prothrombin near the catalytic surface was expected. Using a mathematical model (chapter 3) we corrected our experimental data for the depletion of prothrombin near the catalytic surface. An important parameter in this theoretical treatment is the mass transfer coefficient. The validity of the model was confirmed by the excellent agreement between mass transfer coefficients determined from our experimental data and the predicted values (table II, chapter 3).

The capillary flow system is characterized by a non-uniformly accessible catalytic surface. Due to the conversion of prothrombin molecules by prothrombinase complexes bound to phospholipid bilayer, the concentration of the substrate depletes in the downstream direction. Since, in our model, the transport rate of the reactants to 
the macroscopic surface is dependent on the protein concentration (chapter 2; equation 2), the mass transfer rate of prothrombin to the macroscopic surface, between the capillary inlet and the end, is not a constant but decreases in the down stream direction. However, this depletion of prothrombin was shown to be a function of the prothrombinase activity and could therefore easily corrected for the determination of the true kinetic parameters (chapter 3 , equation 2 and 8 ). The $\mathrm{k}_{\mathrm{cat}}$ value of about $60 \mathrm{~s}^{-1}$ obtained is close to the reported $\mathrm{k}_{\text {cat }}$ for prothrombin activation in a phospholipid vesicles system $\left(60-65 \mathrm{~s}^{-1}\right.$, ref.1). However, the intrinsic $\mathrm{K}_{\mathrm{m}}$ (corrected for depletion of prothrombin near the catalytic surface) of $3 \mathrm{nM}$ is much lower than the calculated intrinsic $\mathrm{K}_{\mathrm{m}}$ values in vesicle suspensions (170 $\mathrm{nM}$, ref.2). Using an uniformly accessible macroscopic phospholipid Willems et al. (3) found a $\mathrm{K}_{\mathrm{m}}$ value of $6 \mathrm{nM}$. This makes us to believe that, in spite of some uncertainties with respect to the theoretical treatment, the tubular flow reactor is a valuable tool for deriving kinetic parameters from immobilized enzymes like the prothrombinase complex.

For the apparent discrepancy between the $K_{m}$ values reported for vesicles and macroscopic membranes the following explanation can be given. At a macroscopic surface with $0.02 \mathrm{fmol}$ prothrombinase per $\mathrm{cm}^{2}$ it can be calculated that one prothrombinase complex is surrounded by a relatively large enzyme-free area. Only $0.001 \%$ of the maximum binding capacity of the phospholipid bilayer was occupied by prothrombinase. This free surface is able to collect prothrombin molecules. Because the rate of transport by lateral diffusion is much faster than the rate of transport in the unstirred diffusion layer near the surface, saturation of prothrombinase with substrate is more readily achieved. Thus, less prothrombin molecules are needed for half saturation of the enzymatic complex, resulting in a lower $\mathrm{K}_{\mathrm{m}}$. In contrast, the half saturation of the prothrombinase complexes assembled on a phospholipid vesicle is limited by the diffusion rate of the prothrombin from the solution to those catalytic surfaces (2).

The intrinsic kinetic parameter as determined in the tubular flow reactor were not dependent on the shear rate. Thus, although the macroscopic surface influences the catalytic efficiency of bound prothrombinase complexes, dynamic effects resulting from an increase of shear rate do not affect its intrinsic enzymatic activity.

In vivo, blood coagulation also occurs on macroscopic procoagulant surface. Such membrane surfaces are provided by activated platelets, or by a damaged membrane derived either from damaged-cells of the endothelium or subendothelium. Therefore, the low value of the intrinsic $\mathrm{K}_{\mathrm{m}}$ observed for a macroscopic lipid bilayer (1000-fold lower than the plasma concentration of prothrombin), might have implications for prothrombin activation under physiological conditions. At earlier stages of the coagulation process, in presence of the first traces of factor $\mathrm{Va}$, 
the surface density of prothrombinase is probably very low. This may result in an initial thrombin generation kinetically controlled by the amount of prothrombinase present on the catalytic surface. Later, the bound prothrombinase concentration increases while the prothrombin concentration near the surface depletes. Such a condition may imply thrombin formation limited by the transport rate of the plasma prothrombin towards the catalytic surface, i.e. dependent on the shear rate. This can be interpreted as an autoregulation of the thrombin generation. Since the intrinsic characteristics of the prothrombinase $\left(\mathrm{k}_{\mathrm{cat}}\right.$ and $\left.\mathrm{K}_{\mathrm{m}}\right)$ on macroscopic surface appeared to be independent of the shear rate, these two situations could be true in all types of vessels that form the circulatory apparatus (microcapillaries, veins, arteries).

The low value of the intrinsic $\mathrm{K}_{\mathrm{m}}$ observed for a macroscopic lipid bilayer might have an additional implication for prothrombin activation under physiological conditions. That is, it is expected that inhibition of prothrombinase by the plasma protein antithrombin is influenced by the presence of prothrombin. We therefore investigated the anti-prothrombinase activity of antithrombin and antithrombinheparin under the conditions as described in chapter 3 . We found that under kineticcontrolled prothrombin activation, the inhibition of prothrombinase by antithrombin (plasma concentration of about $2 \mu \mathrm{M}$ ) was almost negligible. This was true even at a prothrombin concentration that was only one-tenth of the plasma concentration. A comparison between prothrombinase inhibition rate constants in the presence and absence of prothrombin revealed that prothrombin very efficiently protects prothrombinase from inhibition by antithrombin.

On a macroscopic surface, due to the high catalytic efficiency (low $K_{m}$ ) of prothrombin conversion, such protection of factor $\mathrm{Xa}$ is not surprising. In a kineticcontrolled situation, with prothrombin concentration greatly exceeding the intrinsic $\mathrm{K}_{\mathrm{m}}$ value, virtually all active sites of prothrombinase (factor $\mathrm{Xa}$ ) are continuously occupied with prothrombin. Indeed, we could demonstrate that prothrombin simply competes with antithrombin for the active site of factor Xa (chapter 5).

As expected, inhibition of prothrombinase was more effective when antithrombin was associated with heparin. We showed that the molar antiprothrombinase activity of antithrombin-heparin decreased with decreasing heparin chain length, in the order: unfractionated heparin (UFH) $>$ low molecular weight heparin (LMWH)> pentasaccharide. The UFH as well as the synthetic pentasaccharide that we used, contains the antithrombin binding sequence. This specific sequence of five monosaccharides is necessary for the interaction with antithrombin. However, we noticed, in presence and in absence of prothrombin, a significant difference between their anti-prothrombinase activities. UFH was about 30 -fold more efficient on a molar basis than the synthetic pentasaccharide. This suggests a specific interaction between UFH and surface-bound prothrombinase, in 


\section{Chapter 8}

addition to the antithrombin conformational change that can be induced either by the pentasaccharide or by the UFH. In presence of heparins, the inhibition of prothrombinase by antithrombin was fully competitive with prothrombin (chapter 4 and 5).

During diffusion controlled prothrombin activation immobilized prothrombinase is not saturated with prothrombin. In such a situation, antithrombinheparin complexes can easily inhibit non-occupied prothrombinase. However, all molecules of prothrombin that are transported to the catalytic surface are immediately converted to thrombin. Thus, in spite of a decreased prothrombinase density at the macroscopic surface, the rate of thrombin production at the outlet of the flow reactor did not change (chapter 4). This situation remains until the prothrombinase concentration on the surface has decreased to a value low enough to abolish significant depletion of prothrombin. When such a situation is reached, the rate of inactivation of prothrombinase will decrease drastically, because antithrombin has to compete again with prothrombin for the active site of factor Xa.

As already mentioned above, in vivo we can also expect the passage from control regime to another one, but in reversed order: at earlier stages of coagulation prothrombin activation is kinetic-controlled; at later stages, transport of prothrombin may become rate-limiting. Therefore, extrapolating our results to physiological conditions, we can assume that prothrombinase is completely protected from inhibition during prothrombin activation in the initial phase of coagulation. Moreover, even in a transport limited situation where part of prothrombinase is not protected by prothrombin and thus easily inactivated, the addition of heparinantithrombin complexes would have only minor effects on thrombin production because only the non-functioning prothrombinases are scavenged. Nevertheless, heparins are common drugs for treatment and prevention of thrombotic and thromboembolic diseases. In vue of our results, we hypothesize that non-membraneassociated factor $\mathrm{Xa}$ and thrombin may be the in vivo targets for the inhibitory activity of heparin-stimulated antithrombin. Such inhibition could, for example, act as a control mechanism of feedback reactions, especially those induced by thrombin, i.e promotion of exposure of procoagulant sites (activation of platelets) and activation of factors $\mathrm{V}$ and VIII. Thus, antithrombin and antithrombin-heparin may be involved in the regulation of the assembly of prothrombinase complex rather than in the inactivation of prothrombinase.

Another potential interesting regulator of prothrombinase assembly is its substrate, prothrombin. Prothrombin may be involved in the assembly of the prothrombinase complex, because it interacts with factor $\mathrm{Va}$ and factor $\mathrm{Xa}$ and the membrane, so that additional binding energies arise from these interactions could have a significant contribution to the stability of the prothrombinase complex, 


\section{Chapter 8}

especially at surfaces with relative low affinity for each of the prothrombinase components.

We noticed, that when factor Xa was perfused in the absence of factor $\mathrm{Va}$, no phospholipid-bound factor Xa could be detected. This means that, although factor Xa is transferred to the macroscopic surface and able to laterally diffuse on the membrane, it needs interaction with factor $\mathrm{Va}$ to be firmly bound to the phospholipid membrane. Factor Va plays the role that it may also play in vivo, on natural cell surfaces. That is, the cofactor provides an anchor for the membrane-bound serine protease factor Xa. However, in case of a membrane with a low phosphatidylserine content (PS $\leq 10 \mathrm{~mol} \%$ ), similar perfusions resulted in low and unstable levels of membrane-associated prothrombinase (chapter 6). Thus, a decrease of the phosphatidylserine amount in the bilayer, appeared to be accompanied by a decrease in affinity of factor $\mathrm{Xa}$ and factor Va for the phospholipid membrane.

In chapter 6 we show that, at low phosphatidylserine, a mixture of fixed factor $\mathrm{Xa}$ and factor $\mathrm{Va}$ concentrations and varying prothrombin concentration gives steady-state rates of thrombin production that were proportional with the prothrombin concentration in the perfusion solution. Direct measurements of membrane-bound prothrombinase demonstrated that these increased catalytic activities were the result of an increased amount of membrane-bound prothrombinase.

Increase of the amount of bound-prothrombinase was also observed with either an increase of the phosphatidylserine content of the membrane (2 to 10\%) or an increase of the factor $\mathrm{Va}$ concentration in the perfusion solution. Our results suggest a linear relationship between the amount of prothrombinase bound to the membrane, the factor $\mathrm{Va}$ concentration in the fluid phase (bulk) and the prothrombin concentration near the catalytic surface (wall), in presence of a constant amount of factor $\mathrm{Xa}$ :

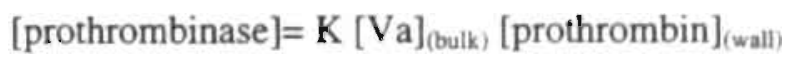

The proportionality constant $\mathrm{K}$ reflects both the affinity of the proteins for the membrane as well as the protein-protein affinities. We showed that $\mathrm{K}$ is a function of the phosphatidylserine composition of the membrane and increased with increasing phosphatidylserine content.

Under such particular situation (membranes with a low PS content), the substrate prothrombin appeared to be essential for the stability of the prothrombinase complex on the membrane. This suggests that prothrombinase not occupied by prothrombin will immediately dissociate. Thus under conditions where supply of substrate becomes limited because of high prothrombinase density, prothrombinase 
will dissociate until an equilibrium is established between membrane-associated prothrombinase and the reactants present on the catalytic surface. A situation which can be illustrated as follows:

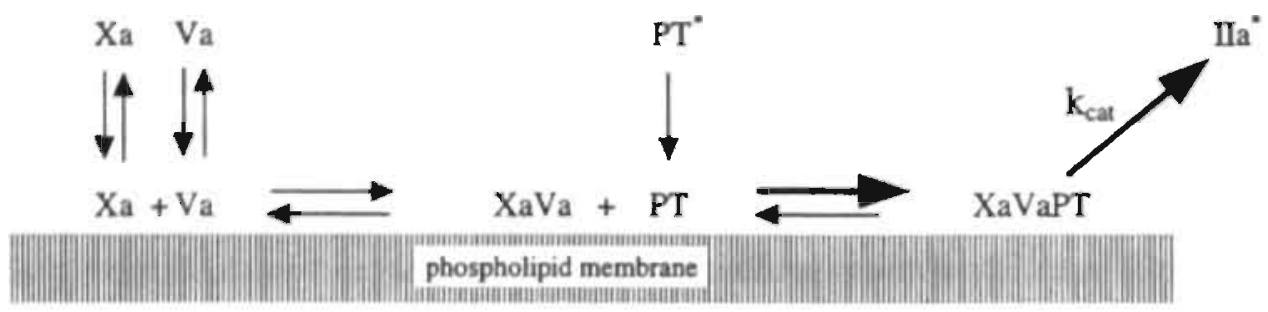

- PT: prothrombin and Ila: thrombin.

The platelet membrane contains a relatively large amount of phosphatidylethanolamine (4). Although this neutral phospholipid by itself does not stimulate prothrombin activation, it has been suggested that it might modulate the procoagulant activity of phosphatidylserine (5). Therefore, we also investigated prothrombinase assembly on membranes containing phosphatidylethanolamine (PE). Membranes that contained only phosphatidylethanolamine and phosphatidylcholine did not promote the assembly of prothrombinase. Interestingly, membranes composed of $5 \mathrm{~mol} \% \mathrm{PS}, 20 \mathrm{~mol} \% \mathrm{PE}$ and $75 \mathrm{~mol} \% \mathrm{PC}$ were indistinguishable from membranes containing $25 \mathrm{~mol} \%$ PS and $75 \mathrm{~mol} \%$ PC with respect to assembly of prothrombinase and prothrombin activation, indicating that incorporation of $\mathrm{PE}$ into a membrane with low phosphatidylserine content increases the affinity of factor $\mathrm{Xa}$ and factor $\mathrm{Va}$ for the surface. Thus, although, phosphatidylethanolamine does not directly participate in the binding of the prothrombinase complex it apparently promotes the assembly of the complex on membranes with a low PS content.

To verify the physiological relevance of our finding we investigated the prothrombinase activity on native platelets. Chapter 7 describes experimental results on prothrombin activation by prothrombinase complexes on immobilized platelets. We demonstrated that activated platelets, after their adhesion to immobilized fibrinogen, exposed procoagulant surfaces with higher affinity for prothrombinase that synthetic membranes with low phosphatidylserine content. It is tempting to speculate that phosphatidylethanolamine contributes to the procoagulant properties of activated platelets. Since during haemostasis, catalytic macroscopic surfaces are provided by activated platelets, it is likely that, in vivo, platelets represent an efficient support for the assembly of prothrombinase. 


\section{References.}

1. van Rijn J.L.M.N., Govers-Riemslag J.W.P., Zwaal R.F.A., Rosing J. 1984. Biochemistry 23: 4557-4564.

2 Giesen P.L.A., Willems G.M., Hermens W.Th. 1991. J. biol. Chem. 266: 1379-1382.

3. Willems G.M., Giesen P.L.A., Hermens W. Th. 1993. Blood 82: 497-504.

4. Schroit A.J., Zwaal R.F.A. 1991. Biochim. Biophys. Acta. 1071: 313-329.

5. Zwaal R.F.A. 1978. Biochim. Biophys. Acta 515: 163-205. 



\section{Résumé}

Le sang joue un rôle essentiel dans le maintien de l'équilibre physiologique. Continuellement en mouvement au sein de son système vasculaire, il irrigue les tissus de l'organisme en leur apportant tous les éléments indispensables à leur métabolisme et en assurant l'évacuation de leurs déchets vers les organes qui les éliminent. Il est donc important que le sang demeure confiné dans son appareil circulatoire. C'est ainsi qu'à tout accident vasculaire, l'organisme répond immédiatement par un mécanisme de défense qui lutte contre l'écoulement du sang hors d'un vaisseaux sanguin. L'hémostase est l'ensemble des phénomènes physiologiques qui participent à la prévention et à l'arrêt des hémorragies.

Processus rapide et efficace, l'hémostase doit être localisée et non extensive. Sa localisation est assurée par l'afflux immédiat des plaquettes circulantes, suivi de leur adhésion, sur le site d'une brèche vasculaire. Ce mécanisme appelé hémostase primaire conduit à l'agrégation de plaquettes, focalisant ainsi les réactions enzymatiques de la coagularion sur les membranes de ces mêmes plaquettes activées. Mécanisme amplifié par de nombreuses réactions enzymatiques séquentielles, la coagulation aboutit à la formation de la thrombine, qui transforme le fibrinogène plasmatique soluble en fibrine insoluble. Cette fibrine en polymérisant constitue l'armature finale du caillot hémostatique. Enfin, devant être non extensive et exclusivement localisée au site de la paroi vasculaire lésée, l'hémostase est efficacement limitée par les inhibiteurs plasmatiques de protéases.

Nos recherches présentées dans ce mémoire ont eu pour objet l'étude de la prothrombinase, complexe enzymatique responsable de la conversion de la prothrombine en thrombine. La prothrombinase est constituée par l'association du facteur Xa, l'enzyme, et du cofacteur-facteur Va sur une surface phospholipidique en présence de l'ion calcium.

Le sang étant continuellement en mouvement, le mécanisme de la coagulation, et par conséquent celui des réactions enzymatiques, est influencé par des phénomènes dynamiques induits par le flux sanguin. Pour cette raison nous avons développé un système expérimental afin de permettre une investigation des capacités enzymatiques de la prothrombinase dans des conditions de flux contrôlé. Brièvement exposé, notre système appelé "tubular flow reactor" est constitué d'une micro-pipette en verre dont la paroi interne a été recouverte d'une double couche phospholipidique. Sur cette surface procoagulante, composée de phosphatidylsérines et de phosphatidyl-cholines, est assemblé le complexe prothrombinase. Son activité enzymatique est mesuré par la thrombine générée, à l'aide d'un substrat chromogénique spécifique. Le flux au travers du réacteur est assuré par la perfusion 


\section{Chapter 8}

des éléments protéiques à l'aide d'une seringue reliée à une pompe qui permet un contrôle précis du débit.

Notre première investigation fut d'établir précisément les limites de notre système. Nous avons ainsi démontré qu'à l'intérieur du réacteur, dans des conditions déterminées, c'est à dire pour un flux de $30 \mu \mathrm{l} / \mathrm{min}$ et à $37^{\circ} \mathrm{C}$, la production de thrombine pouvait aisément être limitée par la vitesse du transport de la prothrombine présente dans la phase fluide vers la surface catalytique. Cette situation est caractérisée par le fait que la quantité de molécules de prothrombinase adsorbée sur la membrane phospholipidique est capable de convertir plus de prothrombine qu'elle n'en reçoit, et ceci, dans les conditions de notre investigation, bien qu'un seul site sur vingt soit occupé par un complexe prothrombinase. Donc, de façon à pouvoir analyser le réel potentiel enzymatique de la prothrombinase, le réacteur fut préparé avec un nombre de molécules de prothrombinase suffisamment bas pour exclure toute situation limitée par la concentration de prothrombine perfusée. Dans de telles conditions, nous avons pu déterminé le $\mathrm{K}_{\mathrm{m}}$ et la constante catalytique, $\mathrm{k}_{\text {cat }}$ (turnover), de la prothrombinase en faisant varier la concentration en substrat. Nous avons ainsi déterminé une constante $\mathrm{K}_{\mathrm{m}}$ de $3 \mathrm{nM}$ et un $\mathrm{k}_{\text {cat }}$ de $60 \mathrm{~s}^{-1}$. Des expériences réalisées à différents flux ont démontré que le "turnover" de la prothrombinase était insensible aux variations de débit dans le réacteur.

Dans un système clos utilisant des vésicules phospholipidiques en suspension comme supports procoagulants, le $\mathrm{K}_{\mathrm{m}}$ de la prothrombinase est approximativement de $0.2 \mu \mathrm{M}$. Il apparâ̂t donc que notre système expérimental d'étude de la prothrombinase, permet à l'enzyme d'atteindre une meilleure perfection cinétique.

L'efficacité de la prothrombinase dans le réacteur étant connue, nous avons ensuite étudié dans des conditions identiques de flux et de composition de la membrane phospholipidique, l'action inhibitrice de l'antithrombine (inhibiteur plasmatique de la thrombine et du facteur $\mathrm{Xa}$ ), associée ou non à de l'héparine, sur son comportement enzymatique. Maîtrisant parfaitement les limites de notre système, nous avons pu analyser la cinétique de cette inhibition dans des conditions expérimentales où la production de thrombine était proportionnelle à la densité de prothrombinase adsorbée sur la membrane phospholipidique. Nous avons démontré qu'en l'absence de prothrombine, l'antithrombine se révélait être un inhibiteur efficace du factor $\mathrm{Xa}$, associé au factor Va sur la membrane phospholipidique. Nous avons également pu montrer, que dans des conditions identiques, l'addition d'héparine accélérait, comme prévu, et d'une façon significative, la vitesse d'inhibition de la prothrombinase. L'utilisation d'héparines de différents poids moléculaires pour catalyser l'action inhibitrice de l'antithrombine, fut également étudiée. Il ressort de ces expériences que dans notre modèle d'investigation, une étroite corrélation existe entre la longueur de la chaîne saccharidique des héparines et 


\section{Chapter 8}

la constante d'inhibition. Ainsi, l'efficacité "anti-prothrombinase" du complexe antithrombine-héparine augmente avec le poids moléculaire de l'héparine.

Etudiée également en présence de prothrombine, la prothrombinase s'est révélée être beaucoup moins accessible à l'action inhibitrice de l'antithrombine. A des concentrations d'antithrombine supérieures à sa concentration plasmatique, ou bien stimulée par l'addition d'héparine, l'antithrombine, durant la conversion de la prothrombine - c'est à dire lorsque le substrat occupe le site enzymatique de l'enzyme - n'était plus qu'un faible inhibiteur de la prothrombinase. Une étude plus détaillée nous à permis de démontrer que la prothrombine protégeait le facteur $\mathrm{Xa}$, par sa présence sur le site même d'intervention de l'antithrombine. Ce résultat, traduit dans le langage cinétique comme étant une compétition entre l'antithrombine et la prothrombine, est indiscutablement lié au faible $\mathrm{K}_{\mathrm{m}}$ de $3 \mathrm{nM}$ décrit précédemment.

La présence de la prothrombine s'est aussi révélée essentielle pour l'association et la stabilité de la prothrombinase. Phénomène vérifié sur une membrane phospholipidique constituée de la phosphatidyl-choline, et d'une faible proportion (inférieure à $10 \mathrm{~mol} \%$ ) de phosphatidyl-sérine. La phosphatidyl-sérine étant le principal élément phospholipidique déterminant la capacité procoagulante de la membrane, une baisse de sa concentration entraine directement une baisse de l'affinité du facteur Xa et du facteur Va pour la membrane. Cependant, nous avons démontré que la prothrombine, pendant le processus de sa conversion, pouvait activement participer au renversement de cette tendance en stabilisant le complexe prothrombinase. Ce phénomène apparemment caractéristique d'une membrane avec un faible contenu en phosphatidyl-sérine est apparu aboli par l'incorporation de phosphatidyl-éthanolamine dans la membrane. Bien que la phosphatidyléthanolamine soit un lipide neutre incapable de promouvoir l'activité de la prothrombinase, il semble qu'elle participe néanmoins activement à promouvoir l'assemblage de ce complexe enzymatique. Cet effet étant mesurable uniquement sur une membrane avec un faible contenu en phosphatidyl-sérine, il est probable que la phosphatidyl-éthanolamine joue un rôle de catalyseur dans l'affinité des éléments protéiques de la prothrombinase avec la phosphatidyl-sérine.

Enfin pour étendre notre étude à des conditions se rapprochant du modèle physiologique, nous avons étudié l'activité du complexe prothrombinase à la surface des plaquettes sanguines. Brièvement, ce nouveau système est composé d'une fine lame de verre recouverte par un film de fibrinogène. Cette lame est ensuite déposée à l'intérieur d'une chambre à flux ("flow chamber"). Après incubation, les plaquettes se fixent sur le fibrinogène immobilisé et, à la suite d'une succession de changements morphologiques, exposent un ensemble non-uniforme de surfaces procoagulantes. Nous avons observé que seules les plaquettes adhérées présentant une forme 
circulaire, exposaient des sites procoagulants et que l'apparition de ces formes caractéristiques était dépendant du calcium. Pour mesurer l'activité de la prothrombinase à la surface de ces plaquettes activées, nous avons perfusé la chambre à flux avec du facteur $\mathrm{Xa}$, du facteur Va et de la prothrombine, en présence de l'ion calcium. Ce système à révélé que les plaquettes adhérées sur le fibrinogène exposaient des surfaces procoagulantes de grande affinité avec la prothrombinase. Sachant qu'une plaquette activée, en plus de la phosphatidyl-sérine, expose entre autres de la phosphatidyl-éthanolamine, il est tentant de comparer ce résultat avec cellui trouvé dans le système précédent. Il est en effet probable que comme dans le cas d'une "membrane synthétique", la phosphatidyl-éthanolamine contribue activement aux propriétés procoagulantes de la plaquette activée.

En conclusion, cette étude a permis une mesure quantitative de l'activité de la prothrombinase, sur une surface macroscopique, soumise à la dynamique d'un flux. Elle a également démontré, que dans certaines conditions le substrat prothrombine pouvait jouer un rôle protecteur ou stabilisateur du complexe prothrombinase. Enfin, elle a confirmé que les plaquettes activées pouvaient exposer de performantes surfaces procoagulantes, supports physiologiques pour la formation de thrombine. 
Bloed voorziet, onafgebroken in beweging binnen zijn vaatstelsel, alle weefsels van het organisme van de onmisbare elementen voor hun stofwisseling en voert de afbraakprodukten af naar de organen die het vervolgens verwijderen. Het is dus belangrijk dat het bloed binnen het vaatstelsel blijft. Daarom wordt iedere aanval op de integriteit van de bloedvaten onmiddellijk door het organisme beantwoord met een verdedigingssysteen dat bloedverlies probeert tegen te gaan. Het geheel van de fysiologische verschijnselen dat deelneemt in het voorkomen en stoppen van bloedingen wordt haemostase genoemd.

Omdat bloedstelping een snel en efficient proces is, moet de haemostase gelocaliseerd blijven tot die plaatsen waar dit nodig is en zich niet uitbreiden naar plaatsen waar bloedstelping een verstopping van het vaatstelsel veroorzaakt. Localisatie van het proces van haemostase wordt in eerste instantie bewerkstelligd door de in de bloedcirculatie aanwezige cellen en wel de trombocyten (bloedplaatjes). Trombocyten hechten zich aan de wand van het beschadigde bloedvat. Dit mechanisme, primaire haemostase geheten, leidt tot een lokale samenklontering van trombocyten en doet de bloeding stoppen. Vervolgens treedt een tweede verdedigingssysteem in werking: de bloedstolling. Aan het oppervlak van de verkleefde bloedplaatjes wordt door een serie opeenvolgende enzymatische reacties trombine gevormd. Trombine zet het oplosbare plasma eiwit fibrinogeen om in het onoplosbare fibrine. Een netwerk van fibrinedraden zorgt voor een stevige verankering van de bloedplaatjesprop aan de beschadigde vaatwand. Onder normale omstandigheden beperkt de fibrinevorming zich tot de plaats van de beschadiging, omdat in het plasma verschillende remstoffen van de fibrinevorming aanwezig zijn.

Onze onderzoekingen, gepresenteerd in dit proefschrift, hadden het prothrombinase, een enzymatisch complex dat verantwoordelijk is voor de omzetting van protrombine in trombine, als onderwerp. Het protrombinase wordt gevormd door de complexvorming van serineprotease geactiveerd factor $\mathrm{X}$ (factor $\mathrm{Xa}$ ) en de cofactor-factor Va op een fosfolipide-oppervlak. Om de situatie in stromend bloed zo goed mogelijk na te boctsen hebben we een experimenteel systeem ontwikkeld waarmee we de vorming en het funktioneren van het protrombinase onder goed gectefinieerde stromingscondities konden bestuderen. Kort uiteengezet bestaat ons systeem uit een glas-capillair waarvan de binnenwand is bedekt door een dubbele fosfolipidenbilaag. Door dit capillair met de fosfolipide-membraan kunnen we oplossingen van verschillende samenstellingen laten stromen om de vorming en enzymatische aktiviteit van het prothrombinase complex te bestuderen.

Ons eerste onderzoek betrof het nauwkeurig vaststellen van de grenzen van ons systeem. We hebben aangetoond dat aan de fosfolipide-laag (in het glascapillair) de 
productie van trombine zeer snel beperkt wordt door de snelheid waarmee het substraat van het prothrombinase complex, protrombine, van de vloeistof fase naar het catalytisch oppervlak kan worden getransporteerd. Deze situatie wordt gekenmerkt door het feit dat de hoeveelheid fosfolipid-gebonden protrombinase sneller protrombine omzet dan er aangevoerd kan worden. Om de werkelijke enzymatische capaciteit van het protrombinase te kunnen analyseren, werd de fosfolipide laag in het glascapillair bezet met zeer weinig protrombinase $(0.1$ $\mathrm{fmol} / \mathrm{cm}^{2}$ ) zodat de snelheid waarmee protrombine wordt omgezet evenredig is met de hoeveelheid protrombinase en niet beperkt wordt door het transport van protrombine naar het catalytisch oppervlak.

Onder deze omstandigheden hebben we voor prothrombinase bepaald hoeveel protrombine nodig is om een half-maximale snelheid van trombinevorming te krijgen $\left(\mathrm{K}_{\mathrm{m}}\right)$ en wat de de catalytische constante $\left(\mathrm{k}_{\mathrm{cat}}\right)$ is. We vonden een 100 -keer lagere $\mathrm{K}_{\mathrm{m}}$ ( $3 \mathrm{nM}$ ) dan werd gerapporteerd voor microscopische fosfolipide-oppervlakken (vesicles). De $\mathrm{k}_{\text {cat }}\left(60 \mathrm{~s}^{-1}\right)$ was in beide systemen vergelijkbaar. We vonden dat de stromingscondities geen effect hadden op de catalytische efficientie van het protrombinase aan macroscopische oppervlakken, zoals in het glascapillair.

De bijzonder efficiente omzetting van protrombine door het protrombinase aan macroscopische fosfolipide-oppervlakken, bracht ons er toe om het effect van protrombine op de remmende werking van antitrombine op het protrombinase complex te bestuderen. Omdat we eerder de beperkingen van ons stromingsmodel in een glascapillair hadden bestudeerd, konden we deze remming bestuderen onder omstandigheden waarin de productie van trombine evenredig was met de protrombinase dichtheid op het fosfolipiden-oppervlak. We hebben aangetoond dat, in afwezigheid van protrombine, antitrombine zich ontpopte als een effectieve remmer van het factor $\mathrm{Xa}$ in complex met factor Va op het fosfolipide-membraan. We hebben ook kunnen aantonen dat, onder identieke omstandigheden, de toevoeging van heparine de snelheid van inactivering van protrombinase, door antitrombine, zeer sterk verhoogt. Hierbij kwam tevens naar voren dat er een nauwe correlatie bestaat tussen de lengte van de heparine keten en de catalytische werking van heparine op de inactivering van het protrombinase door antitrombine: de antiprotrombinase-activiteit van het antitrombine-heparine complex neemt toe met het molecuulgewicht van heparine. Evenzo interessant was de vinding dat protrombine het protrombinase beschermt tegen de inactivering door antitrombineheparine. Bij de plasmaconcentratie van prothrombine werd protrombinase niet geinactiveerd door een plasma concentratie aan antitrombine.

Een meer gedetailleerde studie toonde aan dat de bescherming door protrombine berust op een competitie tussen protrombine en antitrombine voor het actieve centrum van protrombinase. Omdat zeer geringe hoeveelheden protrombine ( $c a 3 n M$ ) reeds een half-maximale bezetting van het protrombinase bewerkstelligen, is het 
voor antitrombine zeer moeilijk om ook aan het actieve centrum van protrombinase te binden.

De aanwezigheid van protrombine is ook essentieel gebleken voor de vorming van het protrombinase complex op een fosfolipide-membraan met een laag fosfatidylserinegehalte $(\leq 10 \mathrm{~mol} \%)$. De affiniteit van zowel factor $\mathrm{Va}$ als factor $\mathrm{Xa}$ voor een fosfolipide-membraan neemt sterk af met het fosfatidylserine gehalte. Bij een beperkende hoeveelheid factor Xa en factor Va vonden we dat de aanwezigheid van protrombine in sterke mate bijdroeg tot de vorming van het protrombinase. Als verklaring hiervoor nemen we aan dat door de affiniteit die protrombine heeft voor factor $\mathrm{Va}$, factor $\mathrm{Xa}$ en fosfolipiden, protrombine kan optreden als een extra verankering van het factor $\mathrm{Xa}$-factor Va complex aan een fosfolipide-membraan met lage affiniteit voor factor Xa. Deze rol van protrombine heeft tevens tot gevolg dat de hoeveelheid protrombinase mede bepaald wordt door de hoeveelheid protrombine in de nabijheid van protrombinase. Omdat protrombinase het protrombine omzet in trombine, zal een toename in protrombinase een afname in de hoeveelheid protrombine betekenen en dus resulteren in een afname van de hoeveelheid protrombinase.

We vroegen ons af of dit zelfregulerend vermogen van protrombinase ook op fosfolipidelagen, met een fysiologisch relevante samenstelling, aanwezig zou kunnen zijn. Toevoegen van het in natuurlijke membranen voorkomende fosfatidylethanolamine aan membranen met een gering gehalte aan fosfatidylserine, zorgden voor fosfolipide-membranen met een hoge affiniteit voor protrombinase. Het gevolg is dat protrombine van weinig belang meer is voor protrombinase complexvorming aan dergelijke fosfatidylethanolamine bevattende membranen. We hebben deze bevinding getoetst in een experimentele opzet met geactiveerde bloedplaatjes die we hebben laten hechten aan een met fibrinogeen bekleed glasplaatje waarover een oplossing van factor $\mathrm{Va}$, factor $\mathrm{Xa}$ en/of protrombine stroomt. Met deze opzet hebben we aangetoond dat het oppervlak van de gehechte bloedplaatjes op het geimmobiliseerde fibrogeen een grote affiniteit heeft voor het protrombinase. Met geringe hoeveelheden factor $\mathrm{Va}$ en factor $\mathrm{Xa}$ kan er voldoende protrombinase gevormd worden voor een significante trombinevorming aan dergelijke fysiologisch relevante macroscopische oppervlakken. 

De auteur van dit proefschrift werd geboren te Parijs op 13 maart 1965. Hij behaalde het Baccalaurréat (scheikunde, biologie) an het "lycée $S^{t}$.Sauveur" te Redon (Frankrijk) in 1984. In 1987 werd het diplome d'Etudes Universitaires Générales (D.E.U.G. Science de la narure et de la Vie) behaald aan de "Faculté des Sciences" te Rennes (Frankrijk). In 1989 werd de "licence" en "maîtrise" in biochemie afgelegd aan de "Université des Sciences et Technique" te Lille (Frankrijk). In het kader van het Erasmusproject werd examen D.E.A. (Diplôme d'Etudes Approfondie en Sciences de la Vie et de la Santé) en doctoraal examen. scheikunde aan de Rijksuniversiteit Utrecht afgelegd in 1992. Van april 1992 tot april 1996 is hij als onderzoeker in opleiding in dienst van het NWO (Nederlands Wetenschappelijk Onderzoek) en werkzaam bij de afdeling biochemie van de Rijksuniversiteit Limburg te Maastricht. Gedurende deze periode werd onder leiding van Professor Dr. H.C. Hemker en Dr. T Lindhout het onderzoek verricht dat heeft geleid tot deze dissertatie. 
